\title{
Evaluation of Sedimentary Structure Near the Advanced Test Reactor Complex at the Idaho National Laboratory
}

October 2017

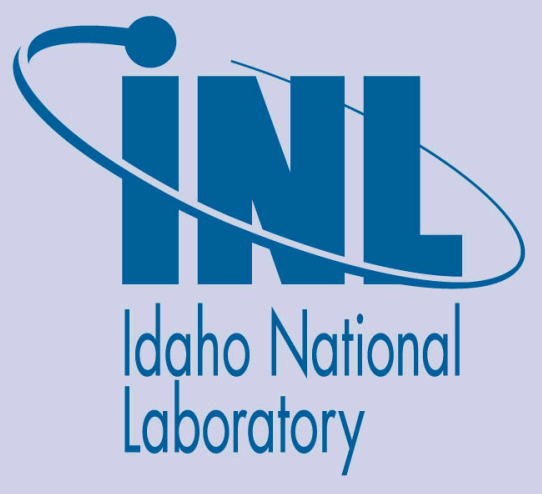

The INL is a U.S. Department of Energy National Laboratory operated by Battelle Energy Alliance 


\section{DISCLAIMER}

This information was prepared as an account of work sponsored by an agency of the U.S. Government. Neither the U.S. Government nor any agency thereof, nor any of their employees, makes any warranty, expressed or implied, or assumes any legal liability or responsibility for the accuracy, completeness, or usefulness, of any information, apparatus, product, or process disclosed, or represents that its use would not infringe privately owned rights. References herein to any specific commercial product, process, or service by trade name, trade mark, manufacturer, or otherwise, does not necessarily constitute or imply its endorsement, recommendation, or favoring by the U.S. Government or any agency thereof. The views and opinions of authors expressed herein do not necessarily state or reflect those of the U.S. Government or any agency thereof. 


\section{Evaluation of Sedimentary Structure Near the Advanced Test Reactor Complex at the Idaho National Laboratory}

October 2017

Idaho National Laboratory Idaho Falls, Idaho 83415

http://www.inl.gov

Prepared for the

U.S. Department of Energy

Office of Nuclear Energy

Under DOE Idaho Operations Office

Contract DE-AC07-05ID14517 



\begin{abstract}
An analysis of relevant sediment stratigraphy near Idaho National Laboratory's Advanced Test Reactor Complex in support of the Remote-Handled Low-Level Waste Disposal Facility is presented. The scope of analysis includes a geostatistical evaluation of sedimentary interbed top elevations and thicknesses compiled for wells near the Advanced Test Reactor Complex from land surface to the elevation of the water table. It also includes an evaluation of expected sediment texture and composition based on information contained in existing reports. Finally, based on this analysis, recommendations for characterization well spacing and appropriate transport model dimensionality are made.
\end{abstract}




\section{CONTENTS}

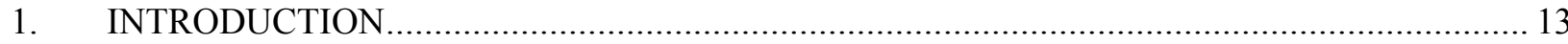

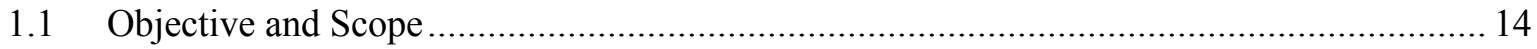

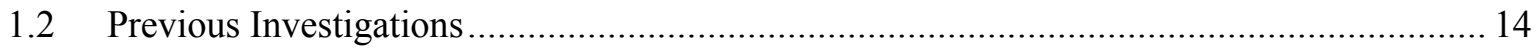

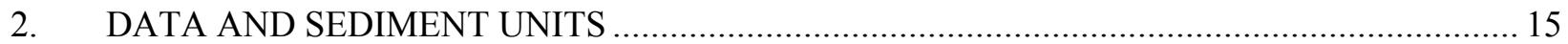

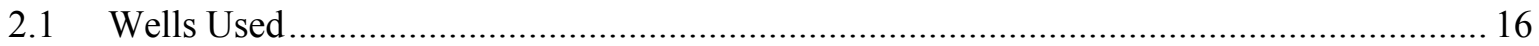

2.2 Identified Vadose Zone Sediment Units .................................................................... 19

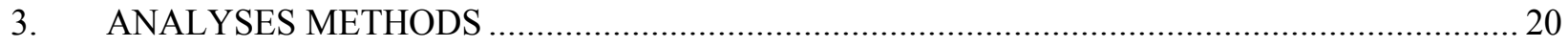

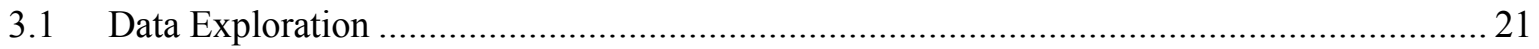

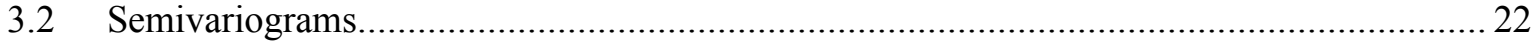

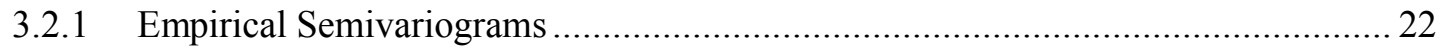

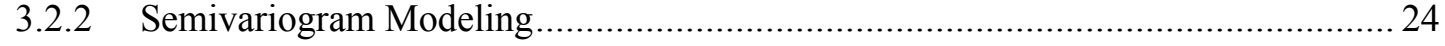

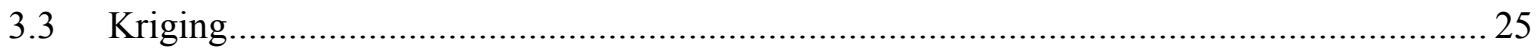

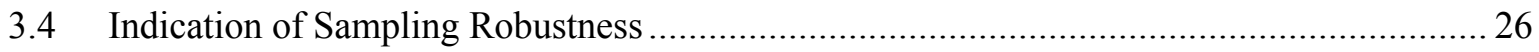

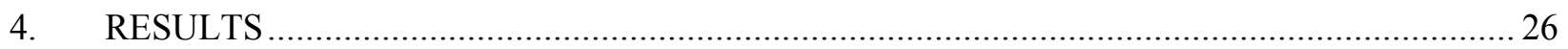

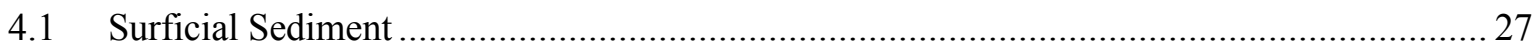

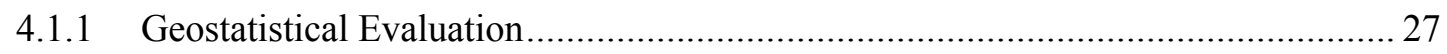

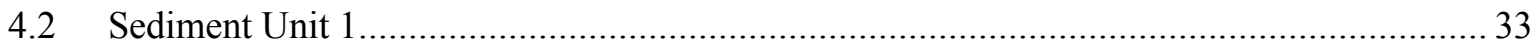

4.2.1 Geostatistical Evaluation................................................................................ 34

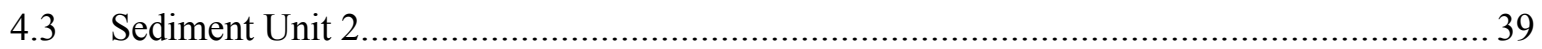

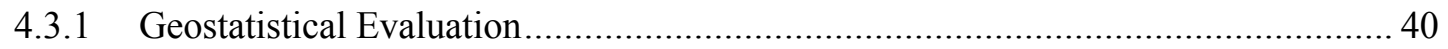

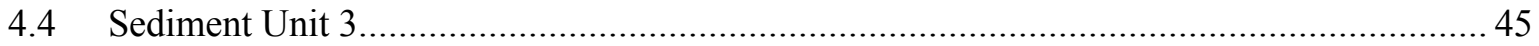

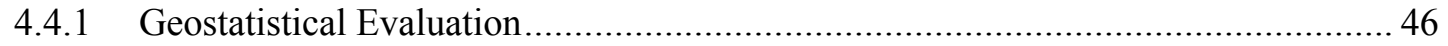

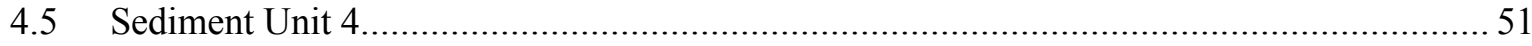

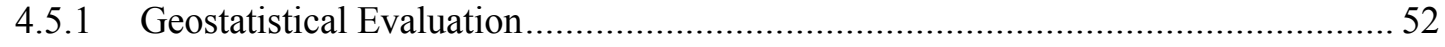

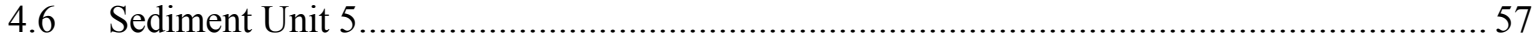

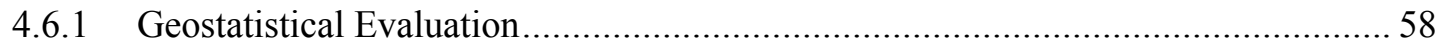


4.7 Sediment Unit 6

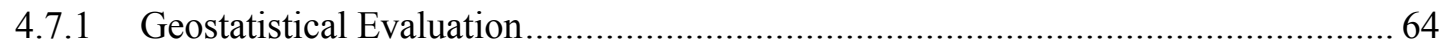

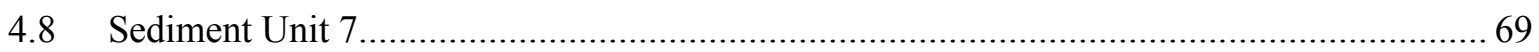

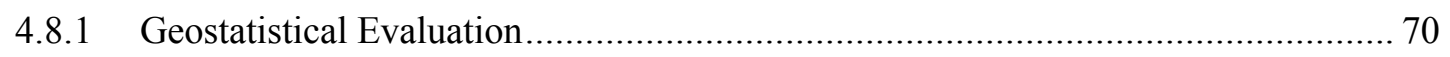

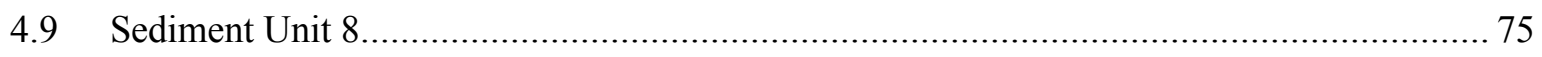

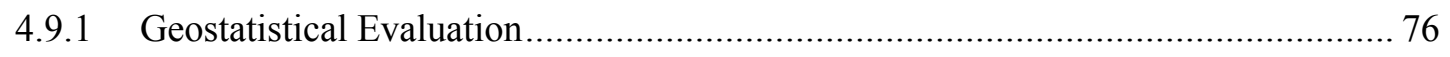

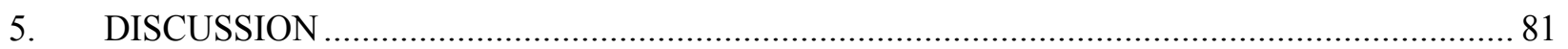

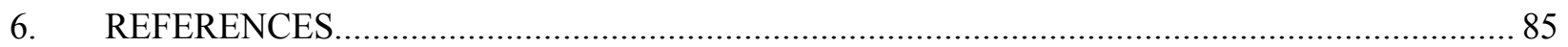

Appendix A, Lithology Log for Well USGS-136 and Fence Diagrams Near the ATR Complex ............. 86

\section{FIGURES}

Figure 1. RH-LLW Disposal Facility location near the ATR Complex. Sediment properties were evaluated in the region contained in the green outlined area spanning 2,000 meters eastto-west, and 4,000 meters north-to-south.

Figure 2. All wells used to define the surficial and deeper sediment unit distributions.

Figure 3. Surficial geology of the INTEC-ATR Complex area showing selected well locations (A) and larger domain (B) (from Helm-Clark et al. 2005).

Figure 4. Fence diagram across the ATR-INTEC area showing the vertical discontinuities between basalt of similar ages (from Helm-Clark et al. 2005).

Figure 5. Example empirical semivariogram with model parameters labeled. ......................................25

Figure 6. Wells used to define surficial sediment distributions.

Figure 7. Histogram of surficial sediment elevation (top) and thickness (bottom). Summary statistics for both distributions are shown to the right of each plot. .28

Figure 8. Anisotropic empirical (colored lines and symbols) and modelled (black lines) semivariograms for the surficial sediment top elevation.

Figure 9. Anisotropic empirical (colored lines and symbols) and modelled (black lines) semivariograms for the surficial sediment thicknesses.

Figure 10. Kriging predictions (left) and kriging variance (right) for surficial sediment top elevation $(\mathrm{m})$. Points represent sample locations

Figure 11. Kriging predictions (left) and kriging variance (right) for surficial sediment thickness

(m). Points represent sample locations ........ .33 


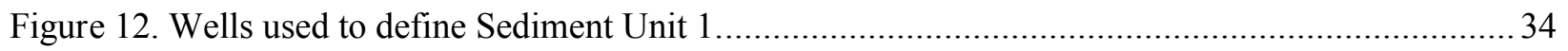

Figure 13. Histogram of Sediment Unit 1 elevation (top) and thickness (bottom) ............................... 35

Figure 14. Anisotropic empirical (colored lines and symbols) and modelled (black lines) semivariograms for Sediment Unit 1 top elevations......................................................... 36

Figure 15. Anisotropic empirical (colored lines and symbols) and modelled (black lines) semivariograms for Sediment Unit 1 thicknesses (bottom).

Figure 16. Kriging predictions (left) and kriging variance (right) for Sediment Unit 1 top elevation (m) 38

Figure 17. Kriging predictions (left) and kriging variance (right) for Sediment Unit 1 thickness (m) 39

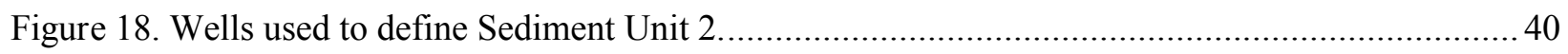

Figure 19. Histogram of Sediment Unit 2 elevation (top) and thickness (bottom) 41

Figure 20. Anisotropic empirical (colored lines and symbols) and modelled (black lines) semivariograms for Sediment Unit 2 top elevation. 42

Figure 21. Anisotropic empirical (colored lines and symbols) and modelled (black lines) semivariograms for Sediment Unit 2 thicknesses.

Figure 22. Kriging predictions (left) and kriging variance (right) for Sediment Unit 2 top elevation $(\mathrm{m})$.....

Figure 23. Kriging predictions (left) and kriging variance (right) for Sediment Unit 2 thickness (m) 45

Figure 24. Wells used to define Sediment Unit 3. 46

Figure 25. Histogram of Sediment Unit 3 elevation (top) and thickness (bottom) 47

Figure 26. Anisotropic empirical (colored lines and symbols) and modelled (black lines) semivariograms for Sediment Unit 3 top elevation.

Figure 27. Anisotropic empirical (colored lines and symbols) and modelled (black lines) semivariograms for Sediment Unit 3 thicknesses.

Figure 28. Kriging predictions (left) and kriging variance (right) for Sediment Unit 3 top elevation $(\mathrm{m})$

Figure 29. Kriging predictions (left) and kriging variance (right) for Sediment Unit 3 thickness (m). .51

Figure 30. Wells used to define Sediment Unit 4. 52

Figure 31. Histogram of Sediment Unit 4 elevation (top) and thickness (bottom) .53 
Figure 32. Anisotropic empirical (colored lines and symbols) and modelled (black lines)

semivariograms for Sediment Unit 4 top elevation.

Figure 33. Anisotropic empirical (colored lines and symbols) and modelled (black lines)

semivariograms for Sediment Unit 4 thickness.

Figure 34. Kriging predictions (left) and kriging variance (right) for Sediment Unit 4 top elevation $(\mathrm{m})$

Figure 35. Kriging predictions (left) and kriging variance (right) for Sediment Unit 4 thickness

(m)

Figure 36. Wells used to define Sediment Unit 5. .58

Figure 37. Histogram of Sediment Unit 5 elevation (top) and thickness (bottom)

Figure 38. Anisotropic empirical (colored lines and symbols) and modelled (black lines)

semivariograms for Sediment Unit 5 top elevation.

Figure 39. Anisotropic empirical (colored lines and symbols) and modelled (black lines) semivariograms for Sediment Unit 5 thickness.

Figure 40. Kriging predictions (left) and kriging variance (right) for Sediment Unit 5 top elevation $(\mathrm{m})$

Figure 41. Kriging predictions (left) and kriging variance (right) for Sediment Unit 5 thickness

(m)

Figure 42. Wells used to define Sediment Unit 6.

Figure 43. Histogram of Sediment Unit 6 elevation (top) and thickness (bottom)

Figure 44. Anisotropic empirical (colored lines and symbols) and modelled (black lines) semivariograms for Sediment Unit 6 top elevation.

Figure 45. Anisotropic empirical (colored lines and symbols) and modelled (black lines) semivariograms for Sediment Unit 6 thickness.

Figure 46. Kriging predictions (left) and kriging variance (right) for Sediment Unit 6 top elevation $(\mathrm{m})$.

Figure 47. Kriging predictions (left) and kriging variance (right) for Sediment Unit 6 thickness

(m)

Figure 48. Wells used to define Sediment Unit 7. .70

Figure 49. Histogram of Sediment Unit 7 elevation (top) and thickness (bottom) .71

Figure 50. Anisotropic empirical (colored lines and symbols) and modelled (black lines) semivariograms for Sediment Unit 7 top elevation. 
Figure 51. Anisotropic empirical (colored lines and symbols) and modelled (black lines)

semivariograms for Sediment Unit 7 thickness.

Figure 52. Kriging predictions (left) and kriging variance (right) for Sediment Unit 7 top elevation $(\mathrm{m})$....

Figure 53. Kriging predictions (left) and kriging variance (right) for Sediment Unit 7 thickness

(m) .75

Figure 54. Wells used to define Sediment Unit 8. 76

Figure 55. Histogram of Sediment Unit 8 elevation (top) and thickness (bottom) .77

Figure 56. Anisotropic empirical (colored lines and symbols) and modelled (black lines)

semivariograms for Sediment Unit 8 top elevation. 78

Figure 57. Anisotropic empirical (colored lines and symbols) and modelled (black lines) semivariograms for Sediment Unit 8 thickness.

Figure 58. Kriging predictions (left) and kriging variance (right) for Sediment Unit 8 top elevation $(\mathrm{m})$

Figure 59. Kriging predictions (left) and kriging variance (right) for Sediment Unit 8 thickness

(m)

Figure 60. Fence diagram for wells appearing in Table 6. This fence diagram is also reproduced in Appendix A in larger format.

\section{TABLES}

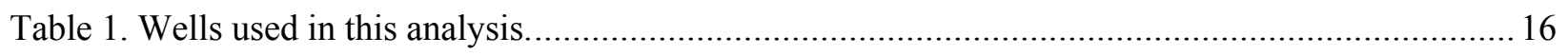

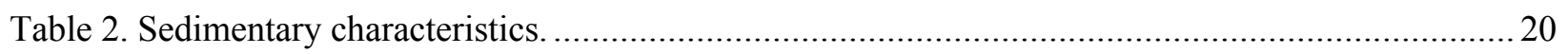

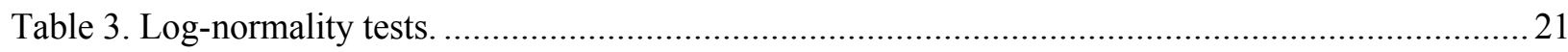

Table 4. Characteristics of the omnidirectional empirical semivariograms....................................... 24

Table 5. Semivariogram model parameters for vadose zone lithologic units. .....................................25

Table 6. Sedimentary materials near the RH-LLW Disposal Facility ............................................. 82

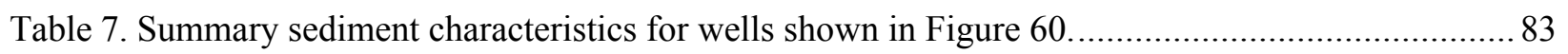




\section{ACRONYMS}

ATR Advanced Test Reactor

CERCLA Comprehensive Environmental Response, Compensation, and Liability Act

INL Idaho National Laboratory

INTEC Idaho Nuclear Technology and Engineering Center

LLW low-level waste

RH remote-handled

RWMC Radioactive Waste Management Complex

SRPA Snake River Plain Aquifer 


\section{Evaluation of Sedimentary Structure Near the Advanced Test Reactor Complex at the Idaho National Laboratory}

\section{INTRODUCTION}

Since 1952, all remote-handled low-level waste (RH-LLW) generated at the Idaho National Laboratory (INL) has been disposed of at the Subsurface Disposal Area of the Radioactive Waste Management Complex (RWMC). In anticipation of the closure of RWMC, INL is establishing a new RH-LLW Disposal Facility. The location for the new disposal facility will be southwest of the Advanced Test Reactor (ATR) Complex (see Figure 1). This site is located near the ephemeral Big Lost River and is roughly $450 \mathrm{ft}$ above the underlying Snake River Plain Aquifer (SRPA). Contaminants released from the facility could be transported downward through the stratigraphic layers comprising the vadose zone and into the aquifer. Once in the aquifer, there is the potential for mingling with existing contaminants and with future predicted contaminants. To assess potential aquifer impacts, a subsurface fate and transport evaluation will be conducted. The subsurface fate and transport evaluation will predict aquifer concentrations that will be used to determine the time-varying dose to potential receptors located downstream from the RH-LLW Disposal Facility as a result of potential releases from the RH-LLW Disposal Facility and in combination with other dose sources.

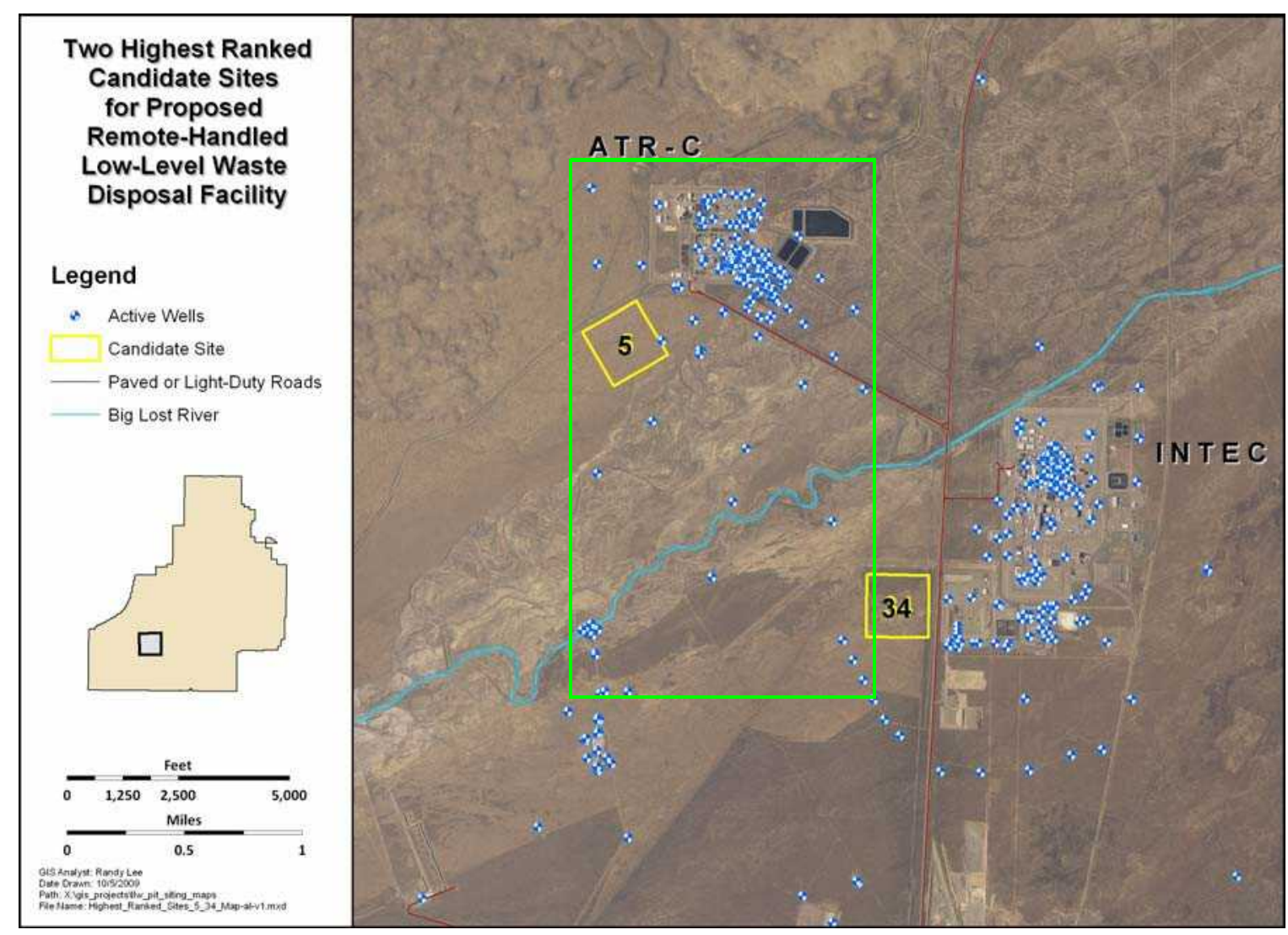

Figure 1. RH-LLW Disposal Facility location near the ATR Complex. Sediment properties were evaluated in the region contained in the green outlined area spanning 2,000 meters east-to-west, and 4,000 meters north-to-south.

Assessing groundwater impacts relies on numerical models of contaminant transport. These models consider infiltration, radioactive decay, advective-dispersive transport, and geochemical transformation processes as contaminants migrate from the disposal facility. Predicting advective-dispersive transport 
and geochemical transformation requires a framework for vadose zone and upper aquifer stratigraphy. At INL, the stratigraphy was emplaced during periodic eruptions of basalt lava flows followed by volcanic quiescence during which alluvial, lacustrine, and aeolian sediment were deposited. These alternating periods of volcanic eruption and quiescence have resulted in stratigraphy characterized by extensively interfingered basalt units and sedimentary interbeds. Basalt is relatively non-sorptive to contaminants, allowing contaminants to move through them with the rate of either aquifer water or surface-originating infiltration water. The basalt and interbed layers largely determine moisture content, porosity, hydraulic conductivity, and geochemical sorptive properties along transport pathways through the vadose zone, extending from near land surface to the underlying aquifer. The sedimentary interbed structure controls the downward migration of contaminants through the vadose zone, serving to retard contaminant migration. In the aquifer, the interbeds serve as semi-confining layers, but serve to add little adsorptive capacity because of their parallel-to-flow structure. However, shallow sedimentary interbeds in the aquifer determine an effective mixing thickness for contaminants arriving from the vadose zone due to their generally lower hydraulic conductivity relative to basalt.

Thickness and continuity of subsurface sediment and basalt layers are required at a facility scale to support predictions of flow and transport through the vadose zone. These sediment characteristics are available only in boreholes that are often not located within the area of interest for contaminant migration. In order to support flow and transport models where direct observations are unavailable, the sediment characteristics must be interpolated based on available data.

\subsection{Objective and Scope}

The objective of the following analysis is to evaluate sediment stratigraphy near the ATR Complex in support of the RH-LLW Disposal Facility. This evaluation includes an assessment of sediment spatial variability in the vadose zone near the location of the RH-LLW Disposal Facility. Sediment considered in the analysis are those sequences that can be positively correlated over distances spanning at least 5 acres. Sediment characteristics of importance include thickness and top elevation. These characteristics are defined using a geostatistical analysis approach, which provides a mathematical framework for estimating character variability.

The scope of analysis includes identification of laterally continuous sedimentary units described by top elevation and thickness and the analysis of their spatial correlation based on existing data taken from wells near the ATR Complex. The depth range of interest is from land surface to the elevation of the water table near the ATR Complex. For identified sedimentary units, a qualitative evaluation of expected sediment texture and composition is included. Finally, based on the identified sedimentary units and their analysis, recommendations for characterization well spacing and appropriate transport model dimensionality are made. The quantitative results and dimensionality recommendations will be used to support the vadose-zone transport model beneath the disposal facility.

\subsection{Previous Investigations}

Previous transport models constructed for the ATR Complex (formerly, Test Reactor Area and Reactor Technology Complex) Comprehensive Environmental Response, Compensation, and Liability Act (CERCLA) evaluations (Lewis et al. 1992) were based on a relatively simplistic model of vadose zone lithology. This approach treated the vadose zone above the aquifer as a surficial sediment layer and three interbeds separated by basalt. Thickness of the surficial sediment was set at a uniform $60 \mathrm{ft}$, and thicknesses of 10,20, and 20 to $40 \mathrm{ft}$ were assigned to the interbeds located at approximate depths of 80,150 , and $220 \mathrm{ft}$. The structure was based on 12 wells penetrating the surficial sediment and uppermost interbed, six wells penetrating the interbed at $150 \mathrm{ft}$, and four wells extending to the depth of the aquifer at roughly $480 \mathrm{ft}$. The well separation was on the order of 2,000 $\mathrm{ft}$ because of the sparseness of deep wells; spatial continuity was assumed to exist between these largely separated wells.

Since the 1992 model development, several additional wells have been drilled in the vicinity of the 
ATR Complex. The lithology encountered in most of these boreholes has been characterized using geophysical logging techniques. Additionally, the relationship between basalt flows existing between the sedimentary interbeds has been analyzed using age and geochemical signature data (Helm-Clark et al. 2005). Although the primary focus of the Helm-Clark et al. (2005) study was to determine basalt origins, there is sufficient detail in the stratigraphic fence diagrams to correlate sediment distributions between boreholes near the ATR Complex. This ability to correlate sediment between boreholes provides the fundamental information needed for a geostatistical analysis of sediment occurrence and distribution.

Previous geostatistical evaluations at INL have demonstrated that subsurface lithologic properties in the vadose zone and eastern SRPA are characterized by moderate to strong spatial autocorrelation, with greater statistical similarity over short distances that diminishes with longer distance. This has been exploited through various geostatistical modeling techniques (e.g., kriging) to make unbiased estimates of subsurface properties at unsampled locations. These previous geostatistical analyses have been conducted with one of two general aims: (1) characterizing the nature of subsurface hydrologic variability (Welhan and Reed 1997); and (2) modeling spatial variability to predict subsurface lithologic or hydrologic properties (Welhan et al. 2002, 2006; Leecaster 2002, 2004, 2006).

These studies have adopted different approaches to achieve their goals. For example, Welhan et al. (2002) used a stochastic indicator simulator to model aquifer hydraulic conductivity beneath the Test Area North; Leecaster $(2002,2004)$ applied ordinary kriging to predict sedimentary thicknesses and subsurface hydraulic properties of the vadose zone and aquifer beneath RWMC; the sedimentary interbed structure was evaluated at the Idaho Nuclear Technology and Engineering Center (INTEC) by Leecaster (2006) and Wang et al. (2010) using ordinary and indicator kriging, respectively; and the sedimentary abundance was evaluated across INL by Welhan et al. (2006). The purposes of each study required use and interpretation of different data, ranging from near-facility hydraulic properties to INL-wide sedimentary abundance.

Results of these studies indicate that spatial variability is largely dependent on the analysis objectives and specific site evaluated. For example, spatial correlation of sediment abundance across INL was determined for composite sedimentary units, resulting in correlation lengths on the order of $6,000 \mathrm{~m}$ (Welhan et al. 2006), while the spatial correlation of sedimentary interbeds at INTEC were on the order of hundreds of meters (Leecaster 2006). However different the resultant autocorrelation measures are, the overall observation is that geostatistical modeling can be used to provide a sound technical basis for flow and transport simulations (DOE-ID 1997, DOE-ID 2006a, DOE-ID 2006b).

\section{DATA AND SEDIMENT UNITS}

The data used in this evaluation will be specific to the ATR Complex as discussed in the following sections, and the methodology applied by Leecaster (2006) at INTEC was followed. The primary sources of data for this report are the Helm-Clark et al. (2005) analysis, corehole data collected across the RH-LLW Disposal Facility site (American Geotechnics 2011), and the data collected in wells USGS-136, USGS-140, and USGS-141 (Appendix A). The focus of the Helm-Clark et al. (2005) evaluation was identification of basalt origin, flow continuity, and general structure of the SRPA. Delineating the basalt structure also allows determination of sedimentary structures that exist between the age-identified basalt flows. Although the focus of the Helm-Clark et al. (2005) report is on deeper basalt structure, the report provides sufficient interpretation to delineate primary sediment above the aquifer that are contained or noted in more than a single well, indicating that the sedimentary structure is laterally extensive. Specific fence diagrams used from Helm-Clark et al. 2005 are reproduced in Appendix A of this report. Well head elevation and northing/easting locations were extracted from the INL Environmental Data Warehouse, where necessary. Corehole data were obtained for the 12 soil borings drilled from land surface to the top of the basalt in the spring of 2011 at the RH-LLW Disposal Facility location (American Geotechnics 2011). Wells USGS-136, USGS-140, and USGS-141 were 
drilled and cored in the 2010 to 2014 timeframe to support site characterization activities south of the ATR Complex.

\subsection{Wells Used}

Wells used in this analysis are listed in Table 1 and shown in Figure 2. These wells span the area just north of the ATR Complex to just south of the Big Lost River.

Table 1. Wells used in this analysis.

\begin{tabular}{lllllll}
\hline SITE-19 & USGS-079 & Middle-1823 & USGS-074 & TRA-08 & TRA-07 & PW-11 \\
PW-9 & USGS-073 & TRA-05A & TRA-02 & PZ-1 & PW-12 & USGS-060 \\
TRA-06 & TRA-06A & USGS-065 & PW-7 & USGS-072 & TRA-04 & ICPP-SCI-V-213 \\
PW-13 & TRA-A37 & USGS-063 & TRA-A30 & USGS-068 & TRA-A27 & TRA-A54 \\
SB-02 & TRA-A77 & TRA-A33 & TRA-01 & TRA-A28 & TRA-A76 & USGS-064 \\
SB-01 & SB-04 & TRA-A31 & TRA-A51 & SB-08 & SB-03 & ICPP-SCI-V-214 \\
TRA-A29 & SB-07 & TRA DISPOSAL & PW-10 & SB-05 & USGS-078 & TRA-A84 \\
TRA-A25 & TRA-A49 & TRA-A45 & USGS-056 & USGS-053 & TRA-A32 & USGS-071 \\
TRA-A11 & TRA-A15 & TRA-A75 & TRA-A17 & TRA-A59 & PW-14 & USGS-136 \\
SB-06 & TRA-A16 & TRA-A05 & TRA-A50 & TRA-A38 & TRA-A04 & TRA-A67 \\
TRA-A73 & TRA-A01 & TRA-A24 & TRA-A80 & TRA-A06 & TRA-A81 & USGS-061 \\
TRA-A36 & TRA-06-1 & CWP-06 & TRA-A60 & CWP-07 & USGS-076 & PW-8 \\
TRA-A03 & TRA-A78 & TRA-A71 & TRA-A43 & TRA-A79 & TRA-A47 & USGS-070 \\
TRA-A44 & TRA-A02 & TRA-A48 & TRA-A87 & SB-09 & TRA-A88 & TRA-A52 \\
TRA-A46 & TRA-A14 & CWP-08 & USGS-069 & TRA-A62 & TRA-A08 & USGS-062 \\
CWP-09 & USGS-055 & TRA-A42 & TRA-A07 & CWP-05 & MTRTEST & USGS-140 \\
TRA-A64 & TRA-A09 & TRA-A66 & TRA-A12 & TRA-A39 & TRA-A23 & USGS-141 \\
USGS-054 & TRA-A70 & TRA-A13 & TRA-A22 & TRA-A56 & TRA-A20 & \\
TRA-A57 & CWP-04 & TRA-A85 & TRA-A86 & CWP-01 & TRA-A58 & \\
TRA-A18 & TRA-A55 & USGS-058 & CWP-03 & TRA-A61 & TRA-A19 & \\
TRA-A26 & TRA-A82 & TRA-A83 & TRA-A68 & CWP-02 & TRA-A53 & \\
\hline \hline The 12 coreholes through the surficial alluvium shown in Figure 2 are not in this list. & & \\
& & & & & & \\
\hline
\end{tabular}




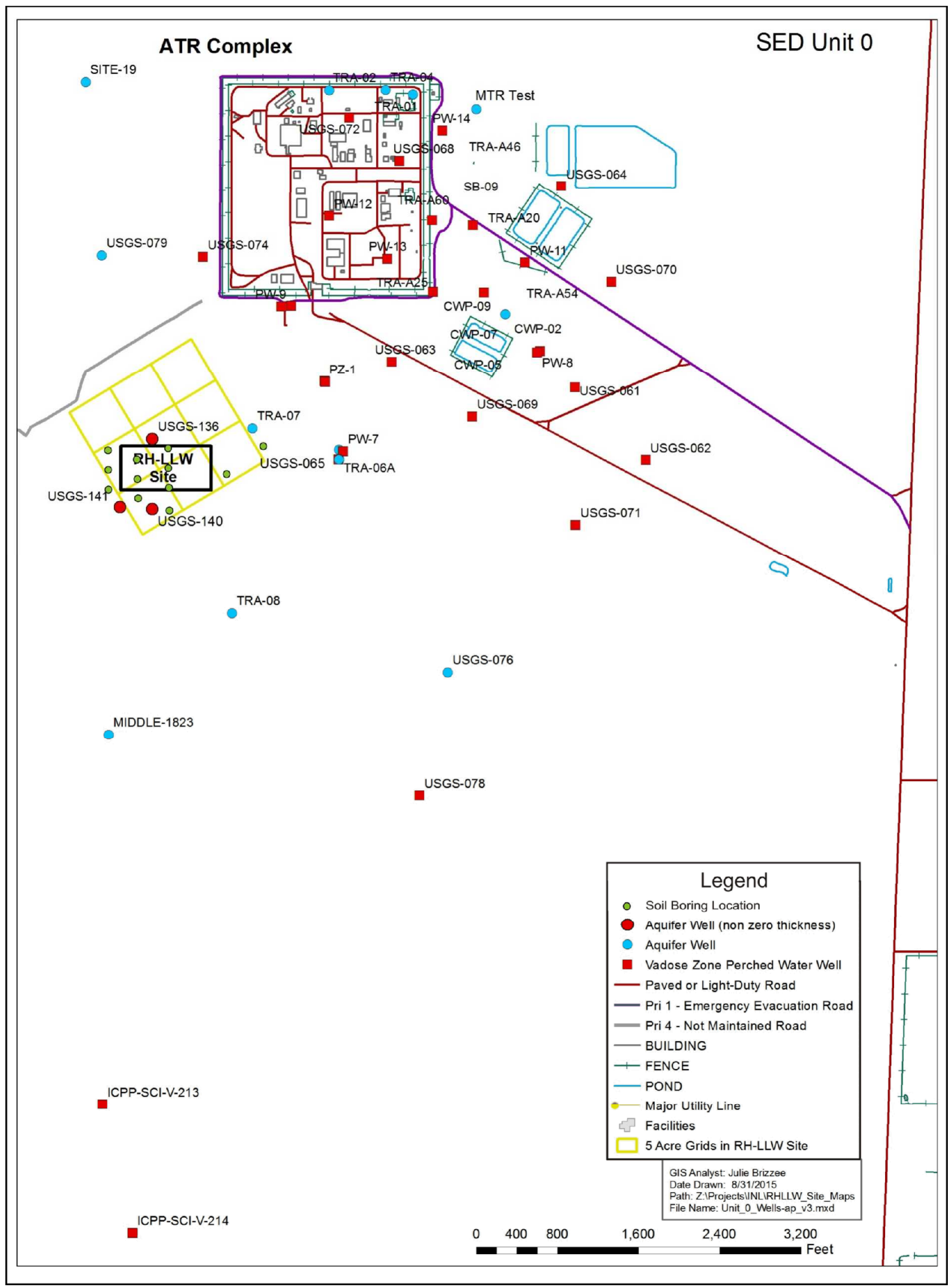

Figure 2. All wells used to define the surficial and deeper sediment unit distributions. 
Wells identified for use and shown in Figure 2 do not span the apparent discontinuity in stratigraphic elevation between INTEC and the ATR Complex identified by Helm-Clark et al. (2005) and noted by Wood et al. (2007). The discontinuity passes through a region bounded by USGS-39, USGS-43, USGS-66, and USGS-84 and was positively located using age dating and geochemical signatures in well Middle 2050A (Figure 3). The extent of the discontinuity is illustrated by the fence diagram shown in Figure 4, with wells USGS-66 and USGS-84 displaying stratigraphy that is correlated to the subsurface near the ATR Complex (Helm-Clark et al. 2005) and wells USGS-39 and USGS-43 displaying stratigraphy correlated to the subsurface under the southern two-thirds of INTEC.

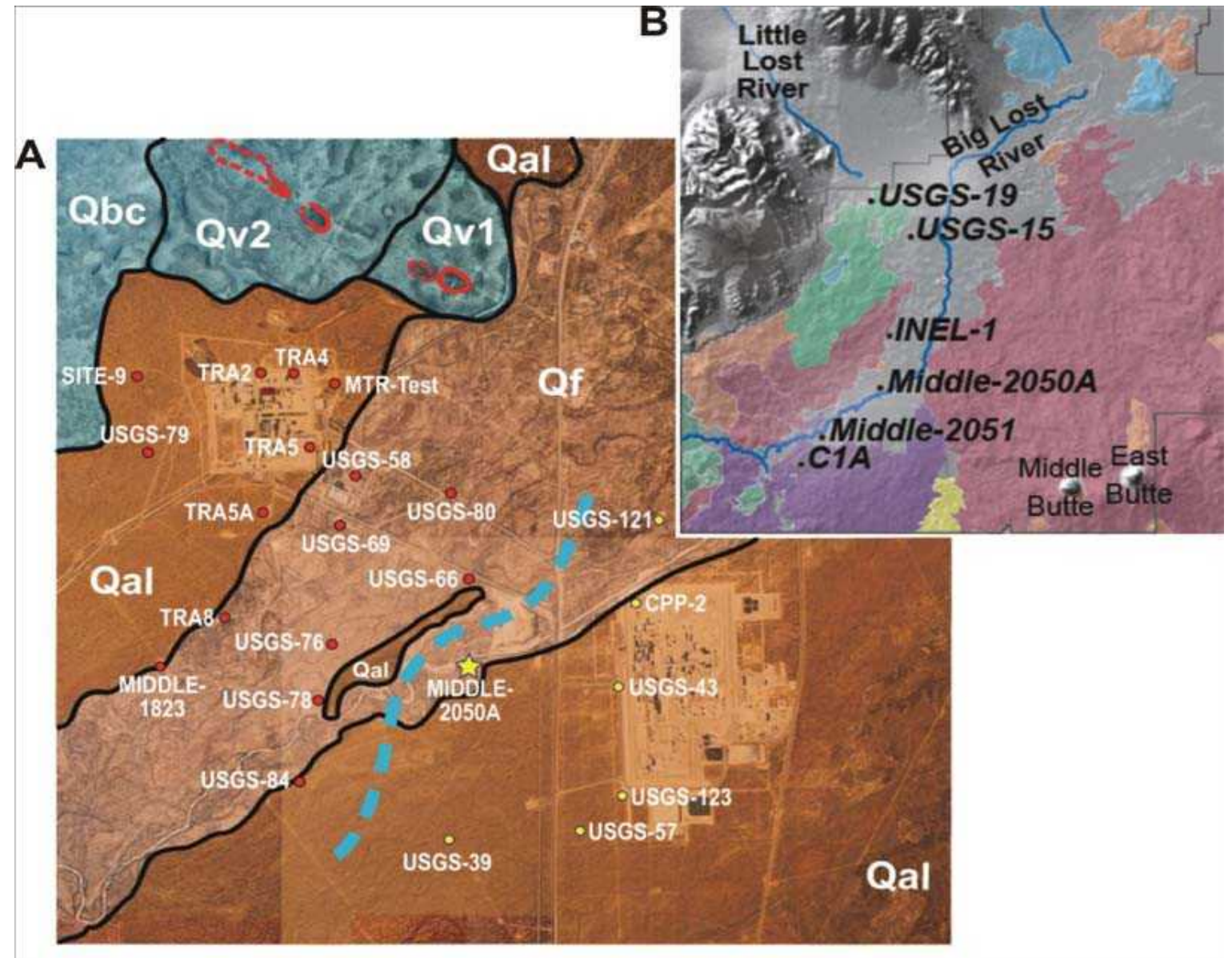

Figure 3. Surficial geology of the INTEC-ATR Complex area showing selected well locations (A) and larger domain (B) (from Helm-Clark et al. 2005).

Including wells spanning the discontinuity would give rise to artificially short horizontal correlation lengths in the region of the RH-LLW Disposal Facility location. Additionally, it would greatly increase the variance in top sediment elevation for units correlated across the discontinuity. Not spanning this feature is reasonable because wells north and west of the hypothesized path shown by the blue dotted line in Figure 3 show no evidence of the discontinuity. Adopting the analysis approach taken by Leecaster (2006) for INTEC is valid because, although the structure is vertically offset, it is statistically similar. From the perspective of aquifer flow, the feature does not have an obvious impact on either flow direction or velocity based on simulated transport of tritium from the ATR Complex (DOE-ID 1997, DOE-ID 2005, DOE-ID 2006a). 


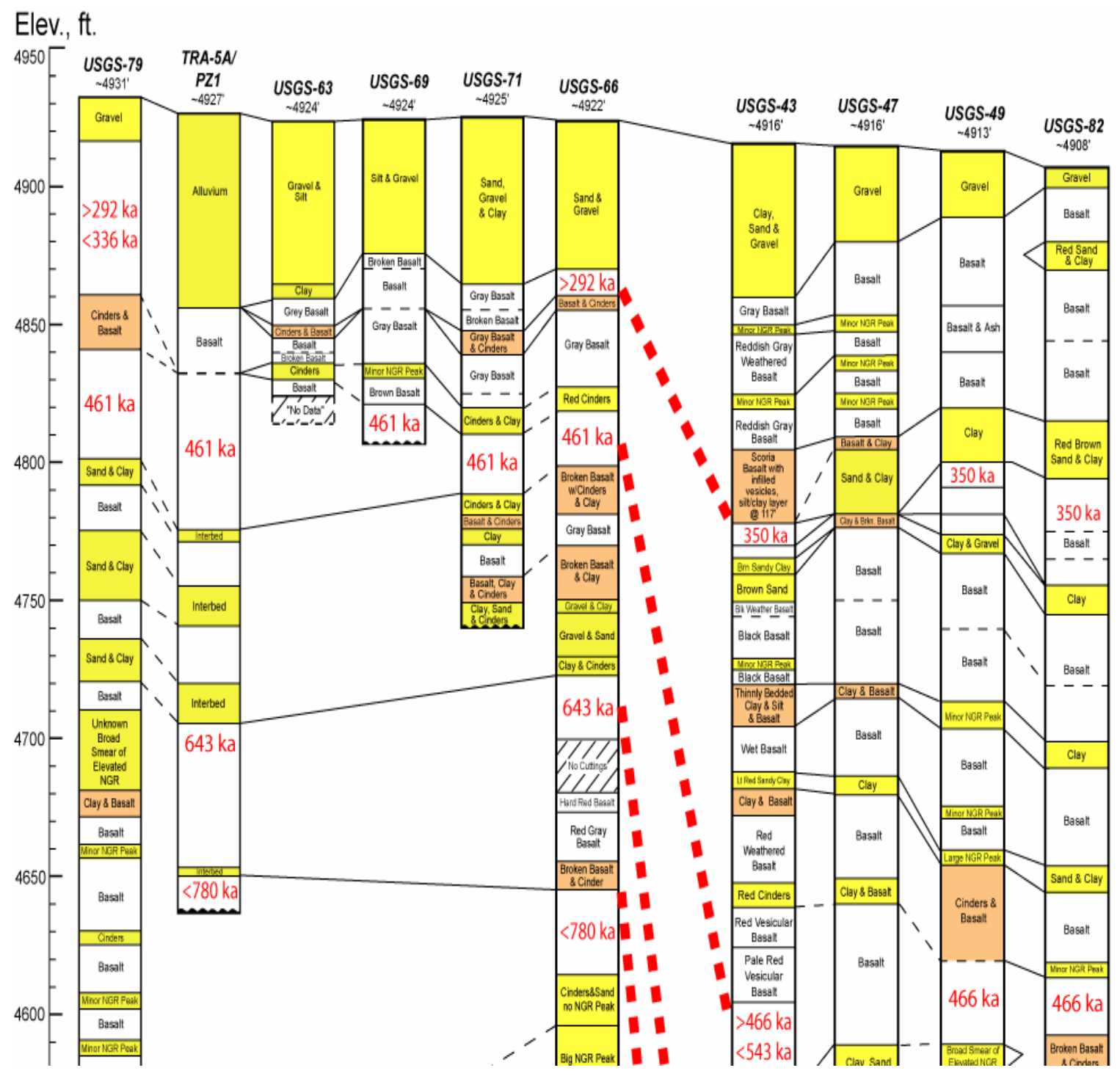

Figure 4. Fence diagram across the ATR-INTEC area showing the vertical discontinuities between basalt of similar ages (from Helm-Clark et al. 2005).

\subsection{Identified Vadose Zone Sediment Units}

Vadose zone lithology data for wells shown in Figure 2 were interpreted from land surface to the upper most sediment unit in the aquifer. Based on the fence diagrams, eight correlatable sediment occurrences were identified and categorized in addition to the surficial sediment. These are referred to as surficial sediment and Sedimentary Units 1 through 8. To provide the necessary information for flow and transport models, the geostatistical analyses presented for each of these units includes histograms of top elevation and thickness in addition to semivariograms, modeled semivariograms, and kriging models.

Table 2 presents an overview of the general property character for the surficial sediment and eight sedimentary units. The sedimentary units are designated by an arbitrary unit number shown in the first column. The second column contains the number of wells completed deep enough to have penetrated the entire thickness. The third and fourth columns contain the range of top elevation and thickness, respectively. Well spacing statistics are contained in the final three columns. The top elevation was obtained by taking the maximum elevation record for each of the interbeds listed in the table within 
each well. If a well did not encounter the interbed, the well was not used to determine the top at that location. If the well did not fully penetrate the sediment unit, it was not included in the analysis. If a sediment unit was clearly missing from one of the wells, a zero thickness was assigned. However, if the sediment unit could not be discounted, a zero thickness was not assigned and the well was not used in the analysis. As indicated by the well count, spatial coverage decreases with depth. As indicated by the elevation interval, the sedimentary units lie within the upper $400 \mathrm{ft}$, and correspond roughly to the three composite sediment layers identified by Welhan et al. (2006). Sedimentary Unit 1 corresponds roughly to the 80-ft depth interval sediment identified in the CERCLA model (Lewis et al. 1992), with the 150 and 220-ft interbeds identified in the CERCLA model explicitly represented by Sediment units 2 through 8. Also, as indicated by overlapping elevation ranges, these interbeds merge within their elevation ranges, with adjacent interbeds often not separated by basalt units, but with the adjacent interbeds defined by soil composition or textural class as noted in the fence diagrams reproduced in Appendix A.

Table 2. Sedimentary characteristics.

\begin{tabular}{|c|c|c|c|c|c|c|}
\hline \multirow{2}{*}{$\begin{array}{c}\text { Sedimentary } \\
\text { Unit }\end{array}$} & \multirow{2}{*}{$\begin{array}{c}\text { Number of Wells } \\
\text { with Data } \\
\end{array}$} & \multirow{2}{*}{$\begin{array}{c}\text { Elevation } \\
\text { Interval } \\
\text { meters (ft) }\end{array}$} & \multirow{2}{*}{$\begin{array}{c}\text { Thickness } \\
\text { Range } \\
\text { meters (ft) }\end{array}$} & \multicolumn{3}{|c|}{$\begin{array}{c}\text { Well Spacing } \\
\text { meters (ft) }\end{array}$} \\
\hline & & & & Average & Minimum & Maximum \\
\hline $\begin{array}{c}\text { Surficial } \\
\text { Sediment }\end{array}$ & 155 & $\begin{array}{c}1,498 \text { to } 1,508 \\
(4,913 \text { to } 4,948)\end{array}$ & $\begin{array}{l}4.6 \text { to } 23.5 \\
\text { (15 to } 77)\end{array}$ & $\begin{array}{c}627.0 \\
(2,057.0)\end{array}$ & $\begin{array}{c}0.5 \\
(1.6) \\
\end{array}$ & $\begin{array}{c}3,524.9 \\
(11,564.6)\end{array}$ \\
\hline Unit 1 & 38 & $\begin{array}{c}1,458 \text { to } 1,481 \\
(4,780 \text { to } 4,858)\end{array}$ & $\begin{array}{c}0.6 \text { to } 2.1 \\
\text { (2 to } 7 \text { ) }\end{array}$ & $\begin{array}{c}1,070.9 \\
(3,513.3)\end{array}$ & $\begin{array}{c}9.4 \\
(30.9) \\
\end{array}$ & $\begin{array}{c}3,524.9 \\
(11,564.6)\end{array}$ \\
\hline Unit 2 & 39 & $\begin{array}{c}1,457 \text { to } 1,481 \\
(4,779 \text { to } 4,860)\end{array}$ & $\begin{array}{c}0.5 \text { to } 9.1 \\
(1.8 \text { to } 30)\end{array}$ & $\begin{array}{c}1,077.8 \\
(3,536.1)\end{array}$ & $\begin{array}{c}1.7 \\
(5.5)\end{array}$ & $\begin{array}{c}3,524.9 \\
(11,564.6)\end{array}$ \\
\hline Unit 3 & 31 & $\begin{array}{c}1,449 \text { to } 1,464 \\
(4,754 \text { to } 4,830)\end{array}$ & $\begin{array}{l}1.2 \text { to } 10.4 \\
\text { (4.0 to } 34 \text { ) }\end{array}$ & $\begin{array}{c}1,140.3 \\
(3,741.1) \\
\end{array}$ & $\begin{array}{c}1.7 \\
(5.5) \\
\end{array}$ & $\begin{array}{c}3,524.9 \\
(11,564.6) \\
\end{array}$ \\
\hline Unit 4 & 23 & $\begin{array}{c}1,435 \text { to } 1,455 \\
(4,708 \text { to } 4,774)\end{array}$ & $\begin{array}{c}1.0 \text { to } 9.1 \\
(3.2 \text { to } 30)\end{array}$ & $\begin{array}{c}1,018.9 \\
(3,343.0) \\
\end{array}$ & $\begin{array}{c}1.7 \\
(5.5) \\
\end{array}$ & $\begin{array}{c}3,188.8 \\
(10,461.9) \\
\end{array}$ \\
\hline Unit 5 & 22 & $\begin{array}{c}1,421 \text { to } 1,455 \\
(4,662 \text { to } 4,774)\end{array}$ & $\begin{array}{l}0.6 \text { to } 8.5 \\
(2.0 \text { to } 28)\end{array}$ & $\begin{array}{c}1,136.7 \\
(3,729.4) \\
\end{array}$ & $\begin{array}{c}1.7 \\
(5.5)\end{array}$ & $\begin{array}{c}3,524.9 \\
(11,564.6) \\
\end{array}$ \\
\hline Unit 6 & 18 & $\begin{array}{c}1,425 \text { to } 1,431 \\
(4,676 \text { to } 4,695)\end{array}$ & $\begin{array}{c}0.2 \text { to } 4.6 \\
(0.8 \text { to } 15) \\
\end{array}$ & $\begin{array}{c}1,182.6 \\
(3,879.9) \\
\end{array}$ & $\begin{array}{c}1.8 \\
(5.8) \\
\end{array}$ & $\begin{array}{c}3,524.9 \\
(11,564.6) \\
\end{array}$ \\
\hline Unit 7 & 21 & $\begin{array}{c}1,397 \text { to } 1,421 \\
(4,583 \text { to } 4,663) \\
\end{array}$ & $\begin{array}{l}0.0 \text { to } 9.1 \\
(0 \text { to } 30)\end{array}$ & $\begin{array}{c}1,180.4 \\
(3,872.7) \\
\end{array}$ & $\begin{array}{c}1.7 \\
(5.5) \\
\end{array}$ & $\begin{array}{r}3,524.9 \\
(11,564.6) \\
\end{array}$ \\
\hline Unit 8 & 19 & $\begin{array}{c}1,392 \text { to } 1,421 \\
(4,570 \text { to } 4,663)\end{array}$ & $\begin{array}{l}1.8 \text { to } 6.1 \\
\text { (6 to } 20)\end{array}$ & $\left|\begin{array}{c}1,257.2 \\
(4,124.8)\end{array}\right|$ & $\begin{array}{c}1.8 \\
(5.8)\end{array}$ & $\begin{array}{c}3,524.9 \\
(11,564.6)\end{array}$ \\
\hline
\end{tabular}

\section{ANALYSES METHODS}

The goal of predicting subsurface characteristics over this volume of interest was achieved through data exploration, assessing and modeling spatial correlation, predicting values between measurement locations using kriging, and assessing kriging variability to allow assessment of data coverage. Kriging methods were developed to predict spatial distribution of spatially variable data, which in this case are sedimentary interbed top elevations and thicknesses. Kriging uses the spatial relationship among sample locations to improve prediction over a grid. The predictions presented here are based on twodimensional ordinary kriging. This approach was taken based on previous experience with the highly variable lithologic distributions observed across INL. It has been proven to provide the most 
geologically reliable estimates of lithological distribution, allowing adequate prediction of observed perched water and contaminant distributions at INTEC and RWMC. Although indicator kriging, for example, could be used in theory, it has not been shown to provide similarly robust estimates of lithology and corresponding predictions of transport processes. Software used in the following analyses included SGEMS: Stanford Geostatistical Modeling Software (Boucher et al. 2009) and GSLIB: Geostatistical Software Library (Deutsch and Journel 2000).

\subsection{Data Exploration}

In total, there were 18 independent data sets evaluated in this study that corresponded to the top elevations and thicknesses of the surficial sediment and eight sedimentary units shown in Table 3. These data sets were assessed separately, beginning with an evaluation for normality because kriging relies on data being symmetric, and, ideally, normally distributed (Goovaerts 1997). To assess normality, a Shapiro-Wilks test was conducted with the Shapiro-Wilks p-values for top elevation and thickness shown in Table 3. The relatively high P-values suggest that the distributions cannot be rejected as non-normal. Values for the log-normal transforms of the data were quite small, indicating the data are generally not log-normal. Therefore, approximate normality was assumed and the data were not normal-score transformed.

Table 3. Log-normality tests.

\begin{tabular}{ccc}
\hline & \multicolumn{2}{c}{ Shapiro-Wilks p-values } \\
Sedimentary Unit & Top Elevation & Thickness \\
\hline Surficial Sediment & 0.55 & 0.99 \\
Unit 1 & 0.72 & 0.69 \\
Unit 2 & 0.93 & 0.79 \\
Unit 3 & 0.96 & 0.94 \\
Unit 4 & 0.82 & 0.84 \\
Unit 5 & 0.90 & 0.98 \\
Unit 6 & 0.99 & 0.73 \\
Unit 7 & 0.80 & 0.81 \\
Unit 8 & 0.90 & 0.88 \\
\hline
\end{tabular}

Data collected in support of INL environmental evaluations tend to be clustered with respect to location, with the sample locations quite dense near facilities, and with wells extending primarily northeast to southwest, following the groundwater flow path. At the ATR Complex, there also are wells extending from the facilities toward the Big Lost River that have been used to delineate shallow perched water.

Historically, placement of these wells was chosen to represent areas of hydrologic and contaminant sampling interest, not preferentially chosen to provide specific data values (like hot spot sampling). Thus, although the data locations are clustered, the clustering should not bias measured values. In general, the geostatistical evaluations performed at INL (Welhan et al. 2006; Leecaster 2002, 2004, 2006) have shown that the influence of clustered location is minimal.

Data locations are not systematic (i.e., gridded) and they do not cover the entire prediction range. In general, clustering of data locations could bias the variogram, mean, and overall variance. However, because ordinary kriging was used, the effective mean value and variance are local. It was assumed the spatial correlation length determined via the semivariogram would not be influenced by data clustering, which implies that ordinary kriging results also would not be affected. This is consistent with the observations made in the geostatistical analysis of the INTEC sedimentary structures, where cell declustering analyses were performed (Leecaster 2006). In the INTEC analyses, declustered data were 
weighted by the sample location's degree of isolation; values located far from others had greater weight than values closely surrounded by others. The cell declustering method used in the INTEC analysis specified fixed cell size overlaid on the sample locations. The weights for values from locations within a cell were assigned a weight of one over the number of locations within the cell. These weights were then normalized so they summed to the number of sample locations. The cell sizes were chosen to achieve a minimum or maximum declustered data mean, allowing for the maximum utility of declustering. This was accomplished by plotting cell size versus declustered mean. The empirical cumulative distribution of data was compared to that of declustered data. Where the empirical cumulative distribution of weighted values was similar to that for unweighted values, it was assumed that clustering of sample locations was not related to clustered data values. A Kolmogorov-Smirnov two-sample test was used to determine if the distributions were significantly different. Effective cumulative distributions of data also were compared to those of the predictions. The INTEC assessment indicated that the predicted distributions of parameters were quite similar to the original data, primarily because of the ordinary kriging method used. Given this previous INTEC assessment and much sparser data near the ATR Complex, clustering effects were not evaluated in this study.

In the INTEC analyses, trend in sample values was assessed through regression analysis on the easting and northing coordinates, their interaction, and using quadratic forms (Leecaster 2006) for the primary interbeds at INTEC. Leecaster's analysis indicated that the overall variability was not conducive to fitting linear or quadratic trends across typical model domains. In the INTEC analysis, a backward selection algorithm was used to determine a best model; first, the full model was fit and successively insignificant $(t$-test $p>0.05)$ terms were removed until a significant $(F$-test $p<0.05)$ model with all significant ( $\mathrm{t}$-test $\mathrm{p}<0.05)$ terms remained. The residuals from the final regression model were spatially modeled, and the kriging predictions of the residuals were added to the regression predictions to create the final predictions. These were compared to the kriging predictions on the data values to assess the impact of modeling a trend.

In general, the INTEC trend plus kriging predictions exceeded the range of observed data in the sparsely sampled areas. While accounting for trend reduced the kriging variance, when the regression prediction variance was added to the kriging variance, the total variance was larger. Because of a primarily northeast to southwest well alignment at INTEC, the sample locations tended to form a trend of their own. This alignment with groundwater flow direction makes accurate determination of bidirectional trends difficult because of fewer data in the northwest to southeast direction, resulting in a bias in the estimated coefficients of the regression. Additionally, it was found that areas without sample locations were predicted to be influenced by the trend with little or no supporting information. Thirdly, ordinary kriging predictions account for locally variable mean values without extending moderate trends to areas without sample data. For these reasons, in the INTEC analysis, trends were not included in geostatistical results and they are not assessed here because the distribution of wells near the ATR Complex is similar to that at INTEC (i.e., primarily aligned in the direction of aquifer flow).

\subsection{Semivariograms}

The empirical semivariogram for a set of data is the corresponding values of lag distance and variance between pairs of values at that approximate lag distance. The empirical semivariogram was fit with a model whose estimated parameters were used to calculate kriging predictions. Although the terms semivariogram and variogram are often used interchangeably, the correct use for the values and plots used in this report is semivariogram.

\subsubsection{Empirical Semivariograms}

The empirical semivariogram is equal to one-half the variance of paired sample differences taken at lag distance, $\mathbf{h}$, plus or minus a tolerance: 


$$
\gamma(\mathbf{h})=\frac{1}{2} E\left\{[Z(\mathbf{u}+\mathbf{h})-Z(\mathbf{u})]^{2}\right\}=[c(\mathbf{h})-c(0)]
$$

where $E\{f\}$ is the expected value of $f, \mathbf{u}$ is the vector location of a sample, $Z(\mathbf{u})$ is the sample value at location $\mathbf{u}$, and $\mathrm{Z}(\mathbf{u}+\mathbf{h})$ is the sample value at a point separated from $\mathbf{u}$ by a lag vector distance $\mathbf{h}$. The empirical semivariogram depends on the lag distances, the lag tolerance, the minimum number of pairs required to estimate the semivariogram at a lag, and the maximum distance at which to calculate the semivariogram. Additionally, semivariograms can be directional, reflecting natural anisotropy.

- The distance lags (distance between two data locations used for calculating the semivariogram) are generally specified to provide an empirical semivariogram that has obvious structure but is not oversmoothed or undersmoothed. The lags are set small enough to discern the structure but large enough to avoid having sporadic imprecise estimates of variance that form "jumpy" semivariograms. Another approach to selection of lags is to coordinate them to a prediction grid. This was the approach used for the INTEC analysis, where the prediction grid corresponded to the vadose zone and aquifer discretization intervals. In this analysis, the lag separation was determined based on visual appearance of the variogram.

- The lag tolerance is the spacing interval around a lag distance for which pairs are included in the calculation for that lag distance. The lag tolerance is generally set to half the lag distance.

- The minimum number of pairs required to estimate the semivariogram at a lag was set to provide reliable estimates at all lags. This minimum is an issue at long and sort lag distances, where often few pairs exist. This parameter was specified in coordination with the lag distance in order to achieve a reliable semivariogram.

- The maximum distance for semivariograms is generally specified as half the range of locations or prediction grid because the number of pairs at greater distance decreases rapidly. The maximum distance also can be specified as smaller than half the range to account for limited data or to reduce the scope of the semivariogram. The vital part of the semivariogram is at short lag distances, where strong spatial correlation exists. These relatively few, close data locations are used in the actual kriging equations, as explained below.

- In directional semivariograms, empirical semivariograms are calculated using only pairs that fall in specific directions (azimuths). As with the variogram in general, the directional semivariogram is computed considering a tolerance, but in this case, it is an angular tolerance. Azimuths of every 45 degrees (with 22.5-degree tolerance) were used to investigate anisotropy. The four directional semivariograms were north-south ( 0 degrees), northeast-southwest (45 degrees), east-west (90 degrees), and northwest-southeast (135 degrees). The directional semivariogram was calculated using only pairs that were in the specified direction, plus or minus a tolerance angle of 22.5 degrees, half the difference between azimuths. The omnidirectional semivariogram represents the northsouth direction and was computed using a tolerance of 90 degrees.

The lag distance, lag tolerance, minimum number of pairs, and maximum distance characteristics are investigated simultaneously for their influence on the semivariogram. The effect of changing the values is assessed by looking at the semivariogram plots using the SGEMS software. Best-fit values were chosen that provided the semivariogram that was felt to be most representative and that could be modeled. The values used in the final semivariograms are given in Table 4. 
Table 4. Characteristics of the omnidirectional empirical semivariograms.

\begin{tabular}{ccccc}
\hline Sedimentary Unit & \# of Lags & $\begin{array}{c}\text { Top Elevation } \\
\text { Lag Separation }(\mathrm{m})\end{array}$ & \# of Lags & $\begin{array}{c}\text { Thickness } \\
\text { Lag Separation }(\mathrm{m})\end{array}$ \\
\hline Surficial Sediment & 20 & 91.4 & 20 & 152.4 \\
Unit 1 & 12 & 221.0 & 20 & 457.2 \\
Unit 2 & 20 & 304.8 & 20 & 243.8 \\
Unit 3 & 8 & 304.8 & 20 & 243.8 \\
Unit 4 & 10 & 228.6 & 20 & 228.6 \\
Unit 5 & 8 & 457.2 & 30 & 457.2 \\
Unit 6 & 20 & 304.8 & 20 & 228.6 \\
Unit 7 & 20 & 304.8 & 20 & 304.8 \\
Unit 8 & 20 & 365.8 & 20 & 304.8 \\
\hline
\end{tabular}

\subsubsection{Semivariogram Modeling}

The empirical semivariograms are fit with specific functional forms and associated parameters for use in the kriging equations to predict values at unsampled locations. The common semivariogram models are the spherical, Gaussian, and exponential. The difference between these is the shape at small lag (close data spacing): the Gaussian is concave, the exponential is convex, and the spherical is almost linear. These models relay different behaviors in the spatial correlation of values. The Gaussian model implies that spatial correlation remains strong at increasing lag distances, the exponential implies that the spatial correlation drops off quickly at increasing lag distances, and the spherical model implies that spatial correlation reduces almost linearly with increasing lag distance.

The parameters that define these semivariogram models are the nugget, sill, and range (Figure 5). The nugget represents small-scale variance and is equal to the semivariogram value at lag distance 0 . If the sample locations are close enough, the nugget is easily estimable. If the sample locations are located at large lag distances, the nugget is difficult to estimate. Physically, the nugget is considered to represent measurement error. A zero nugget implies that variance of the data is large compared to the measurement error. The sill is variance between pairs of values that are assumed to be independent. The estimated sill can be larger or smaller than variance of the data overall, depending on the sample locations. For many close locations, the overall variance will provide an underestimate of the sill. For many distant locations, the overall variance may overestimate the sill. Models generally specify the partial sill, which is sill minus the nugget. Range is the lag distance at which the sill is attained, or equivalently, it is the distance where values are independent.

Parameters for the various functional semivariograms models can be fit to the empirical semivariogram by automated fitting algorithms or by visual estimation. The automated fitting algorithms are generally based on least squares or maximum likelihood. The least squares method is nonparametric and can be improved by weighting semivariogram points by lag distance or number of pairs used in the estimate. The maximum likelihood methods require data to be normally distributed, which is often a problem even if they are symmetric. Regardless, these methods are often implemented in current software programs without knowledge of the intricacies of fitting a semivariogram. Fitting a semivariogram model visually is labor-intensive and requires knowledge of the models and parameters. This approach produces a model that is closer to the empirical semivariogram than automated fitting of algorithms and eliminates blatant errors. The visually estimated parameters and resultant models may not be exactly reproducible by another geostatistician, but the fits would be close. The semivariogram models in this report were all visually estimated and are contained in Table 5, with corresponding empirical variograms and model-fitted semivariograms discussed in Section 4. 


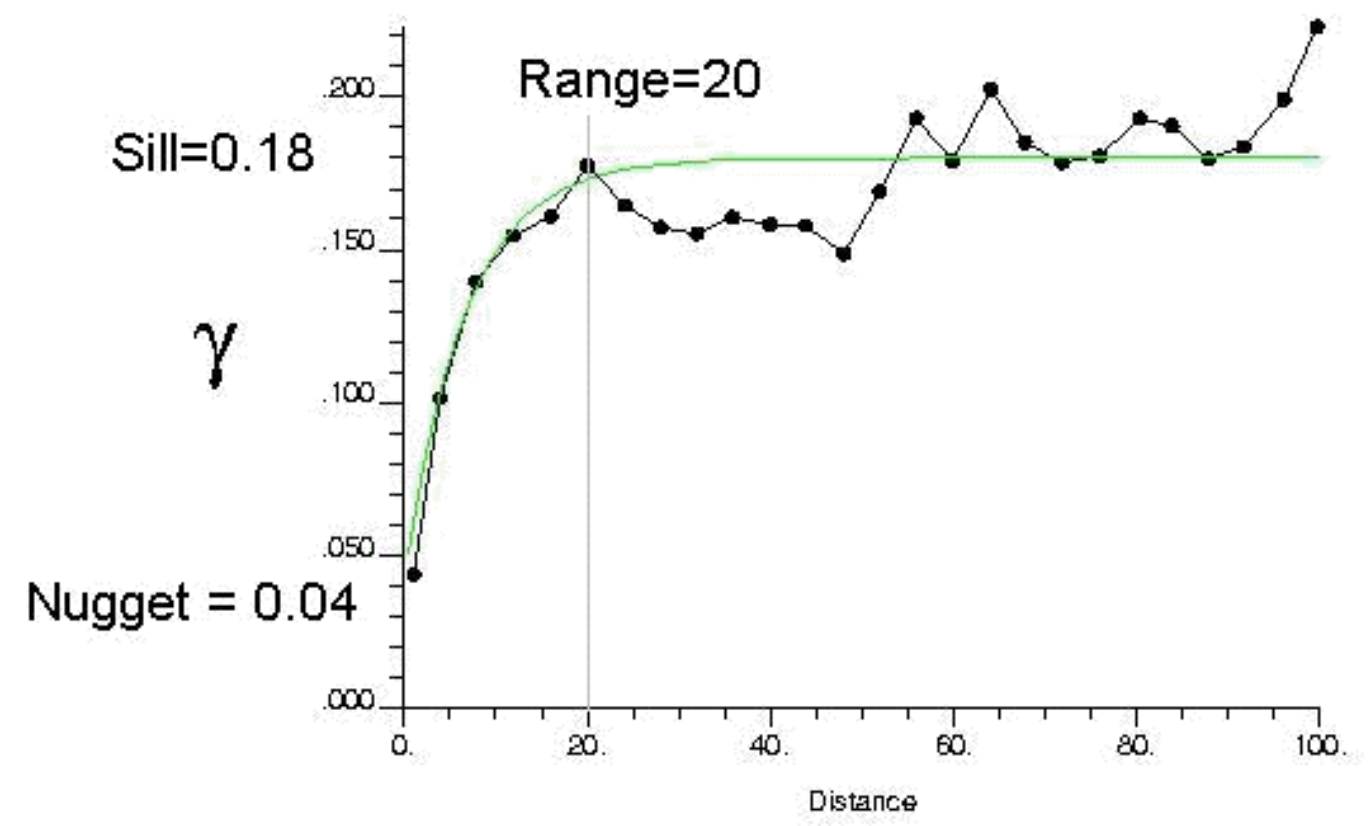

Figure 5. Example empirical semivariogram with model parameters labeled.

Table 5. Semivariogram model parameters for vadose zone lithologic units.

\begin{tabular}{ccccccccc}
\hline & \multicolumn{4}{c}{ Top Elevation } \\
& & $\begin{array}{c}\text { Nugget } \\
\text { Sedimentary Unit }\end{array}$ & $\begin{array}{c}\text { Sill } \\
\left(\mathrm{m}^{2}\right)\end{array}$ & $\begin{array}{c}\text { Range } \\
\left(\mathrm{m}^{2}\right)\end{array}$ & $\begin{array}{c}\text { Thickness } \\
(\mathrm{m})\end{array}$ & $\begin{array}{c}\text { Model } \\
\text { Nugget } \\
\left(\mathrm{m}^{2}\right)\end{array}$ & $\begin{array}{c}\text { Sill } \\
\left(\mathrm{m}^{2}\right)\end{array}$ & $\begin{array}{c}\text { Range } \\
(\mathrm{m})\end{array}$ \\
\hline Surficial Sediment & $\mathrm{E}$ & 0.0 & 46.5 & 300.0 & $\mathrm{G}$ & 0.0 & 9.3 & 487.7 \\
Unit 1 & $\mathrm{E}$ & 0.0 & 46.5 & 93.0 & $\mathrm{E}$ & 0.0 & 0.4 & 457.2 \\
Unit 2 & $\mathrm{E}$ & 0.0 & 40.0 & 457.2 & $\mathrm{E}$ & 0.0 & 6.5 & 457.2 \\
Unit 3 & $\mathrm{E}$ & 0.0 & 11.6 & 457.2 & $\mathrm{E}$ & 0.0 & 6.5 & 762.0 \\
Unit 4 & $\mathrm{E}$ & 0.0 & 37.2 & 487.7 & $\mathrm{G}$ & 0.0 & 9.3 & 609.6 \\
Unit 5 & $\mathrm{E}$ & 0.0 & 55.7 & 914.4 & $\mathrm{E}$ & 3.7 & 5.6 & 914.4 \\
Unit 6 & $\mathrm{E}$ & 0.0 & 7.4 & 457.2 & $\mathrm{E}$ & 0.0 & 3.3 & 868.7 \\
Unit 7 & $\mathrm{E}$ & 0.0 & 27.9 & 457.2 & $\mathrm{E}$ & 0.0 & 7.4 & 609.6 \\
Unit 8 & $\mathrm{E}$ & 0.0 & 46.5 & 457.2 & $\mathrm{E}$ & 0.0 & 3.3 & 1097.3 \\
\hline *E = exponential variogram and G=gaussian variogram & & & & & &
\end{tabular}

\subsection{Kriging}

Kriging is, in essence, a generalized linear regression algorithm (Goldberger 1962, Luenberger 1969). It is used to extend data to locations where data are unavailable by solving a system of equations such as:

$$
\boldsymbol{K} \cdot \boldsymbol{\lambda}=\boldsymbol{k}^{T}
$$

where $\mathbf{k}^{\mathrm{T}}$ is the data-to-unknown row covariance vector:

$$
\boldsymbol{k}^{T}=c\left(\boldsymbol{u}^{\prime}-\mathbf{u}_{\alpha}^{\prime}\right), \quad \alpha=1, n(\mathbf{u})
$$


$\mathbf{K}$ is the data-to-data square covariance matrix:

$$
\boldsymbol{K}=\left[C\left(\mathbf{u}_{\alpha}-\mathbf{u}_{\beta}\right), \quad \alpha, \beta=1, n(\mathbf{u})\right],
$$

$\lambda$ are the kriging weights and the covariance model $(\mathrm{C})$ is related to the semivariogram through:

$$
C(\mathbf{h})=\operatorname{Cov}[Z(\mathbf{u}), Z(\mathbf{u}+\mathbf{h})]=C(0)-\gamma(\mathbf{h}) .
$$

In these expressions, $\mathrm{C}(0)$ is the stationary variance:

$$
C(0)=\operatorname{Var}[Z(\mathbf{u})]
$$

and

$$
2 \gamma(\mathbf{h})=\operatorname{Var}\{Z(\mathbf{u})-Z(\mathbf{u}+\mathbf{h})\}
$$

is the corresponding variogram model. In this analysis, we assume that spatial correlation is location-invariant (i.e., stationarity) and that spatial correlation is independent of direction (i.e., isotropy). Local stationarity, instead of global stationarity, is sufficient and assumed but isotropy was verified through investigation of directional semivariograms. Additionally, continuous variables are assumed to be symmetric but not necessarily normally distributed.

In general, kriging predictions can be made at individual points or as averages over blocks for use in numerical flow and transport codes. In this analysis, the presented kriging predictions are blockaveraged values. Theoretically, kriging is a global prediction and all data points can be used to make predictions. In practice, a subset of sample points is typically used to calculate predictions. The number of data points used depends on the density of the data, coverage of the sample locations, and the smoothness desired. Use of more sample locations tends to smooth predictions toward the overall mean. In addition, a search radius can be specified. The search radius limits the data locations from being too far away from the prediction location to also prevent oversmoothing. In this analysis, the search radius was specified to be 50 times the range to ensure every grid point could be predicted (i.e., that at least one sample value was within that distance). For prediction locations far from data, this tends to assign the mean value to those locations.

\subsection{Indication of Sampling Robustness}

Kriging variance is often misrepresented as an indicator of variance in predicted value. It is computed from the semivariogram parameters and the kriging weights. However, as shown in Equation (8), the kriging variance is data independent and only considers the covariance structure and data locations:

$$
\operatorname{Var}\left(\mathrm{x}_{m}\right)=2 \sum_{i=1}^{n} \lambda_{i} \gamma\left(x_{i}, x_{m}\right)-\sum_{i=1}^{n} \sum_{j=1}^{n} \lambda_{i} \lambda_{j} \gamma\left(x_{i}, x_{j}\right)
$$

Kriging variance, being independent of the data values, only provides a comparison of alternative geometric data configuration. This would suggest, for example, that the kriging variance for the sediment unit thickness would be equal to that for the same sediment unit top elevation, given the same data locations. However, they differ because the covariance structures differ for the top versus thickness for each sediment unit. As an indication of data or sampling pattern robustness, the spatial distribution of kriging variance is summarized and presented with the kriging predictions for each variable contained in Table 2.

\section{RESULTS}

The results of the evaluation are presented separately for each of the nine sedimentary units, beginning with the surficial sediment and ending with the deepest vadose zone sediment. For each sedimentary unit, data assessment, semivariograms, kriging, model assessment, and uncertainty will be discussed. 


\subsection{Surficial Sediment}

Top elevation and thickness of the surficial sediment were defined through use of the 155 wells and boreholes shown in Figure 6. The wells and boreholes used to define the surficial sediment spatial characteristics fully penetrate the alluvial sediment within the area shown in Figure 6. The area spanned by the figure is approximately $4,000 \mathrm{~m} \mathrm{x} \mathrm{2,000} \mathrm{m}$ and the area spanned by the wells is approximately $3,500 \mathrm{~m} \mathrm{x} \mathrm{2,000} \mathrm{m.}$

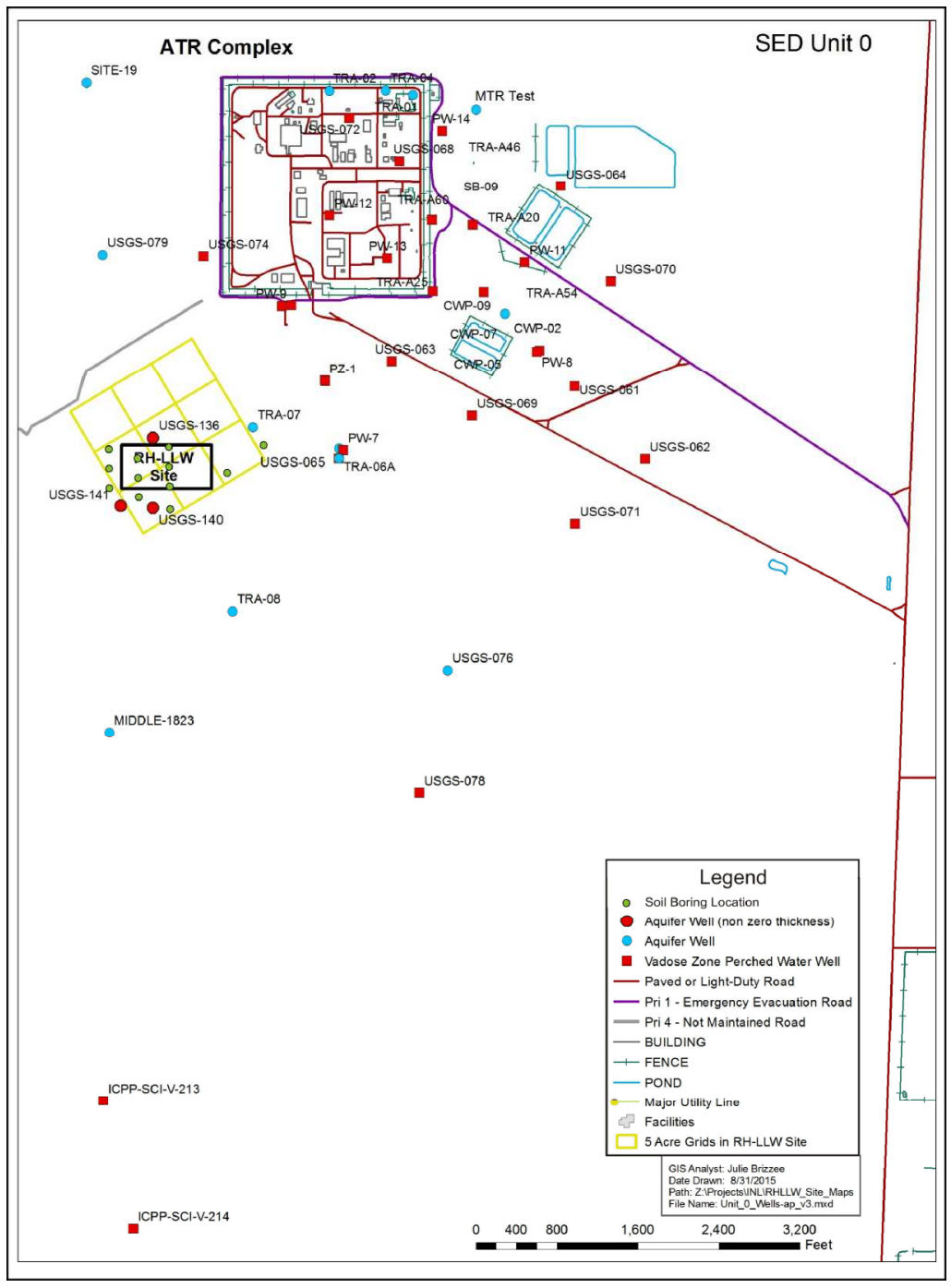

Figure 6. Wells used to define surficial sediment distributions.

\subsubsection{Geostatistical Evaluation}

Histograms for the top elevation and thickness are shown in Figure 7, along with the summary statistical distributions; semivariograms are shown in Figures 8 and 9; spatially kriged top elevation and associated kriging variance are given in Figure 10, and the kriged thickness and kriging variance are shown in Figure 11. The following bullets provide discussion of the figures:

- Data were assessed for normality and to determine whether the distribution was symmetric. The surficial sediment top elevation is slightly skewed, but not log-normal (Shapiro-Wilks test p-value $=0.55$, Table 3 ). The interbed thickness values were somewhat positively skewed (Figure 7), but also were not log-normal (Shapiro-Wilks test $p$-value $=0.99$ ). The mean elevation is roughly 
$1,500 \mathrm{~m}(4,922 \mathrm{ft})$, with a standard deviation of $3.7 \mathrm{~m}(12 \mathrm{ft})$ as shown to the right of the plotted histogram, indicating a relatively flat surface with three prominent outliers.

- Sediment thickness ranges from about 4.5 to $23.5 \mathrm{~m}(14.7$ to $77 \mathrm{ft})$ with a standard deviation of $3 \mathrm{~m}$ $(9.8 \mathrm{ft})$. The distribution of thickness is very symmetric and, as indicated by the Shapiro-Wilks test, it is not log-normal.

- In the 18 locations closest to the RH-LLW Disposal Facility site (i.e., USGS-136, USGS-140, USGS-141, USGS-065, TRA-06, TRA-07, and Borings 7 through 18), the average thickness is $13 \mathrm{~m}(42.4 \mathrm{ft})$.

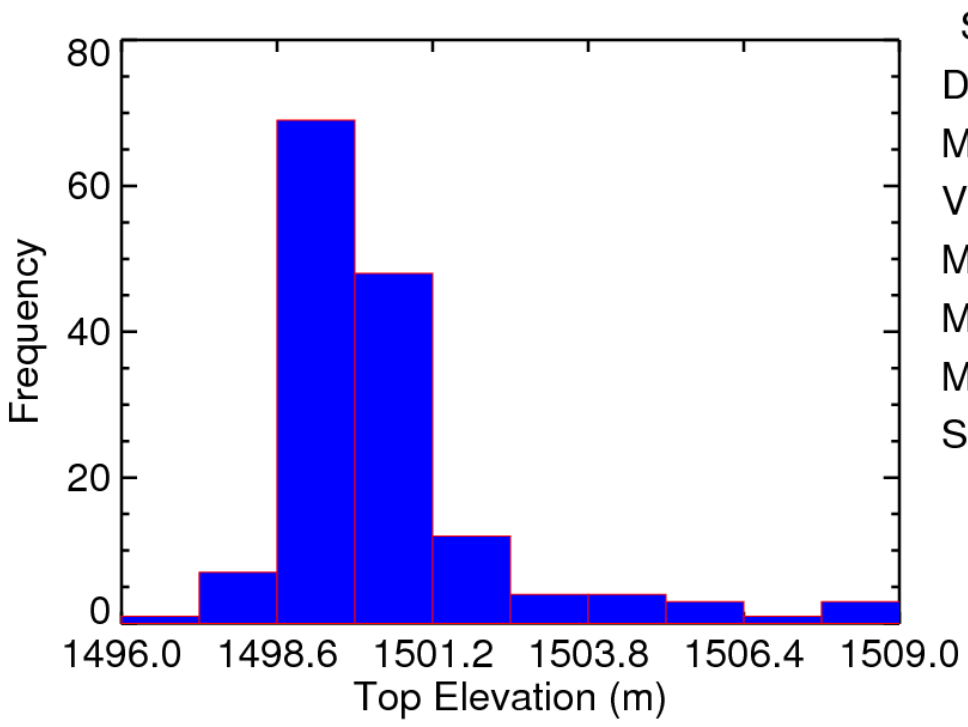

Surficial Sediments

Data Count: $\quad 155$

Mean: $\quad 1499.89$

Variance: $\quad 14.12$

Maximum: 1508.15

Median: $\quad 1499.87$

Minimum: $\quad 1470.66$

Shapiro Wilks p: 0.55

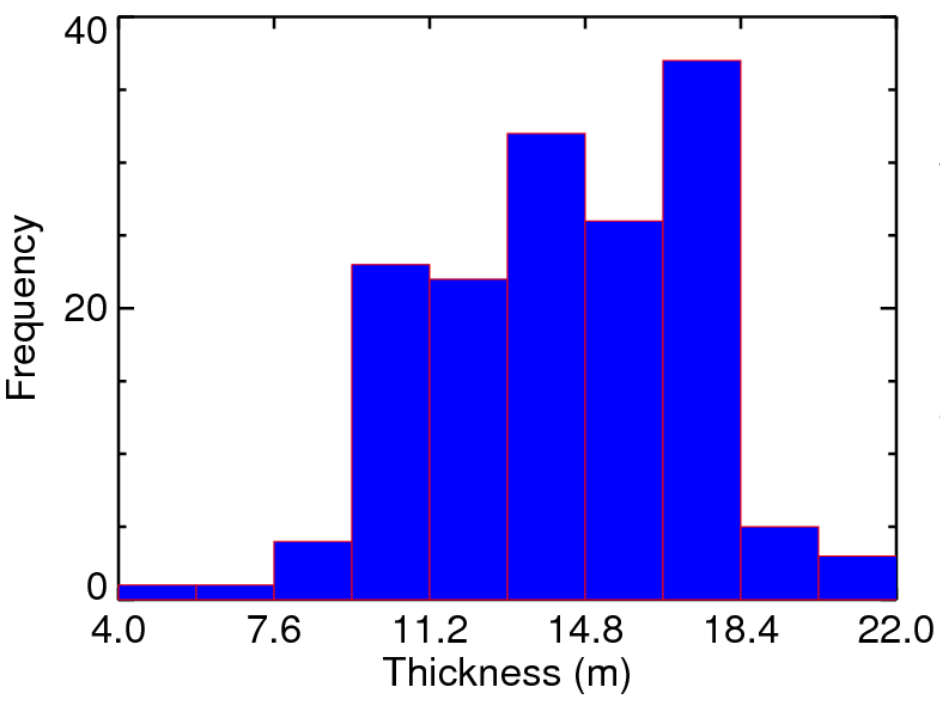

Surficial Sediments

Data Count: 155

Mean: $\quad 14.44$

Variance: $\quad 9.58$

Maximum: $\quad 23.47$

Median: $\quad 14.63$

Minimum: $\quad 4.57$

Shapiro Wilks p: 0.99

Figure 7. Histogram of surficial sediment elevation (top) and thickness (bottom). Summary statistics for both distributions are shown to the right of each plot. 
- Semivariograms for the surficial sediment top elevation are shown for the omnidirectional, northeast-to-southwest, east-to-west, and northwest-to-southeast directions in the lower plot of Figure 8, with the number of pairs at each lag shown in the upper plot. The empirical semivariogram for top elevation in the northwest to southeast direction is less variable than the data, as indicated by a lower sill (gamma) value, with the highest variability occurring in the northeast to southwest direction. This corresponds to the trending elevation indicated in Figure 10. Although there appears to be anisotropy in the sill value, the correlation length (range) is approximately the same in all directions. The model-fitted variogram (shown as the black line in Figure 8), conforms to an exponential model with zero nugget, $46.5-\mathrm{m}^{2}$ sill, and $300-\mathrm{m}$ range. The model sill is approximately twice the variance and the range (i.e., $300 \mathrm{~m}$ ) is roughly one-quarter of a mile, both indicating strong correlation at the size of the RH-LLW Disposal Facility.

- The semivariogram for surficial sediment thickness is shown in Figure 9. There is very little difference in spatial continuity as a function of direction. The omnidirectional empirical semivariogram was fit with a Gaussian model with zero nugget, sill of $9.3 \mathrm{~m}^{2}$, and range of about $500 \mathrm{~m}$

- Kriging predictions on a 20 × 30 grid for the surficial sediment top elevation are shown in Figure 10 (left), with the corresponding kriging variance (right). Although modelled with an isotropic semivariogram, limiting the search radius for kriging preserves an apparent anisotropy (trend) in elevation, with steeper gradients in the northeast to southwest direction, and more uniformity in the east-west direction. Lack of sample locations to the southeast are indicated by high kriging variance, with higher data density within the ATR Complex fence line and within the RH-LLW Disposal Facility area indicated by low kriging variances. The relatively long correlation length is represented by largely continuous values of low kriging variance. Mid-range kriging variance to the east of the RH-LLW Disposal Facility location results from lack of data in that region. The variance in surface elevation near the RH-LLW Disposal Facility location suggests the data are adequate in this region.

- The kriging predictions on a $20 \times 30$ grid for surficial sediment thickness are shown in Figure 11 (left), with the corresponding kriging variance (right).

- Thinnest surficial sediment is to the west of the ATR Complex and the RH-LLW Disposal Facility area. The thickest surficial sediment persists generally south and southeast of the ATR Complex, with a deeper pocket of sediment extending from the middle of the RH-LLW Disposal Facility area toward the ATR Complex. Mid-to-high range thicknesses of 12 to $18 \mathrm{~m}$ (40 to $60 \mathrm{ft}$ ) would be expected to exist across the RH-LLW Disposal Facility location. The kriging variance for surficial sediment thickness decreases to the south and southeast of the RH-LLW Disposal Facility location. This suggests that further data would be required prior to extending the facility southeast of the area delineated for the RH-LLW Disposal Facility prior to additional facility expansion. Based on the model-fitted variogram, well spacing on the order of the 488-m (about 1,600-ft) range would provide sufficient characterization data for expansion. 

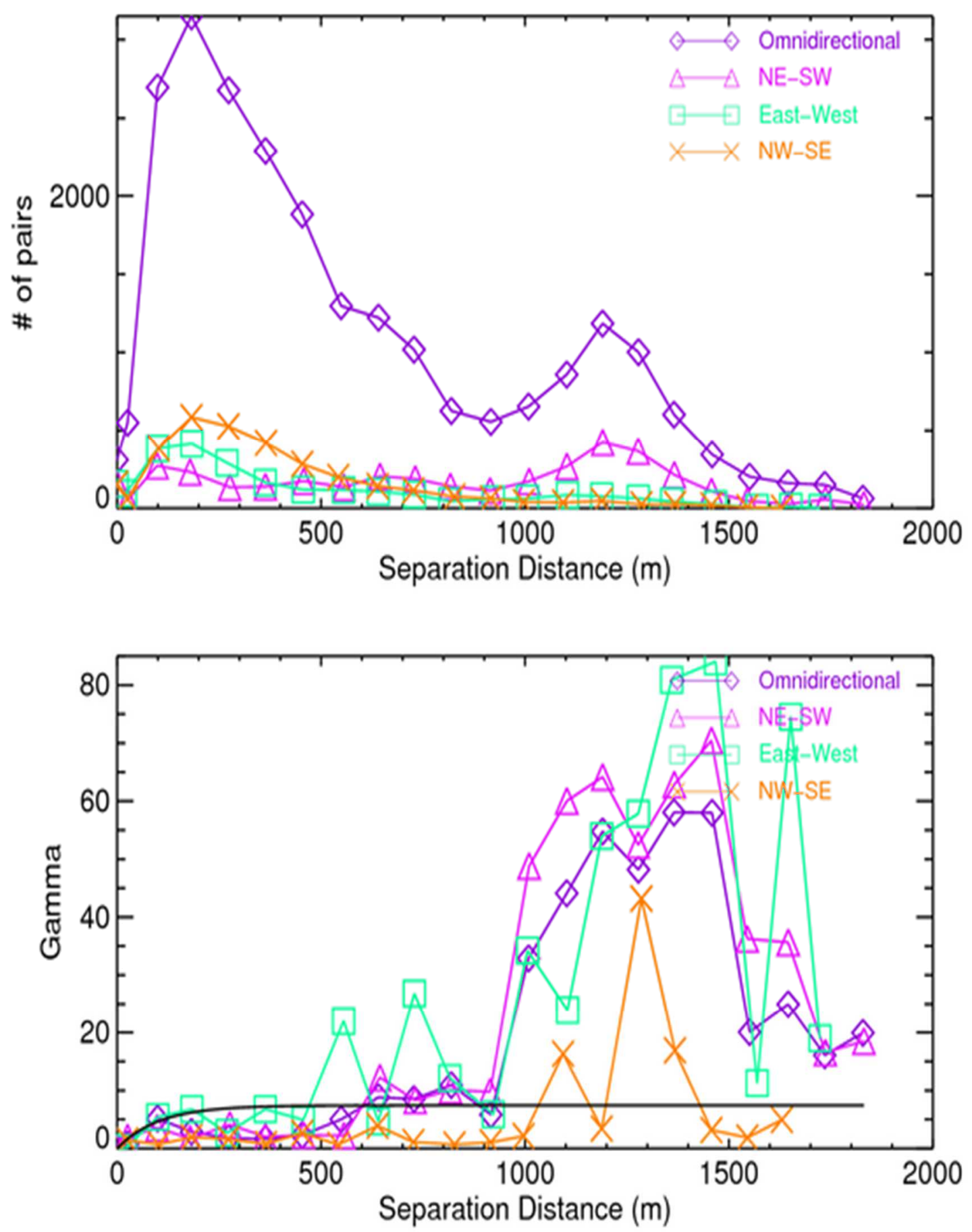

Figure 8. Anisotropic empirical (colored lines and symbols) and modelled (black lines) semivariograms for the surficial sediment top elevation. 

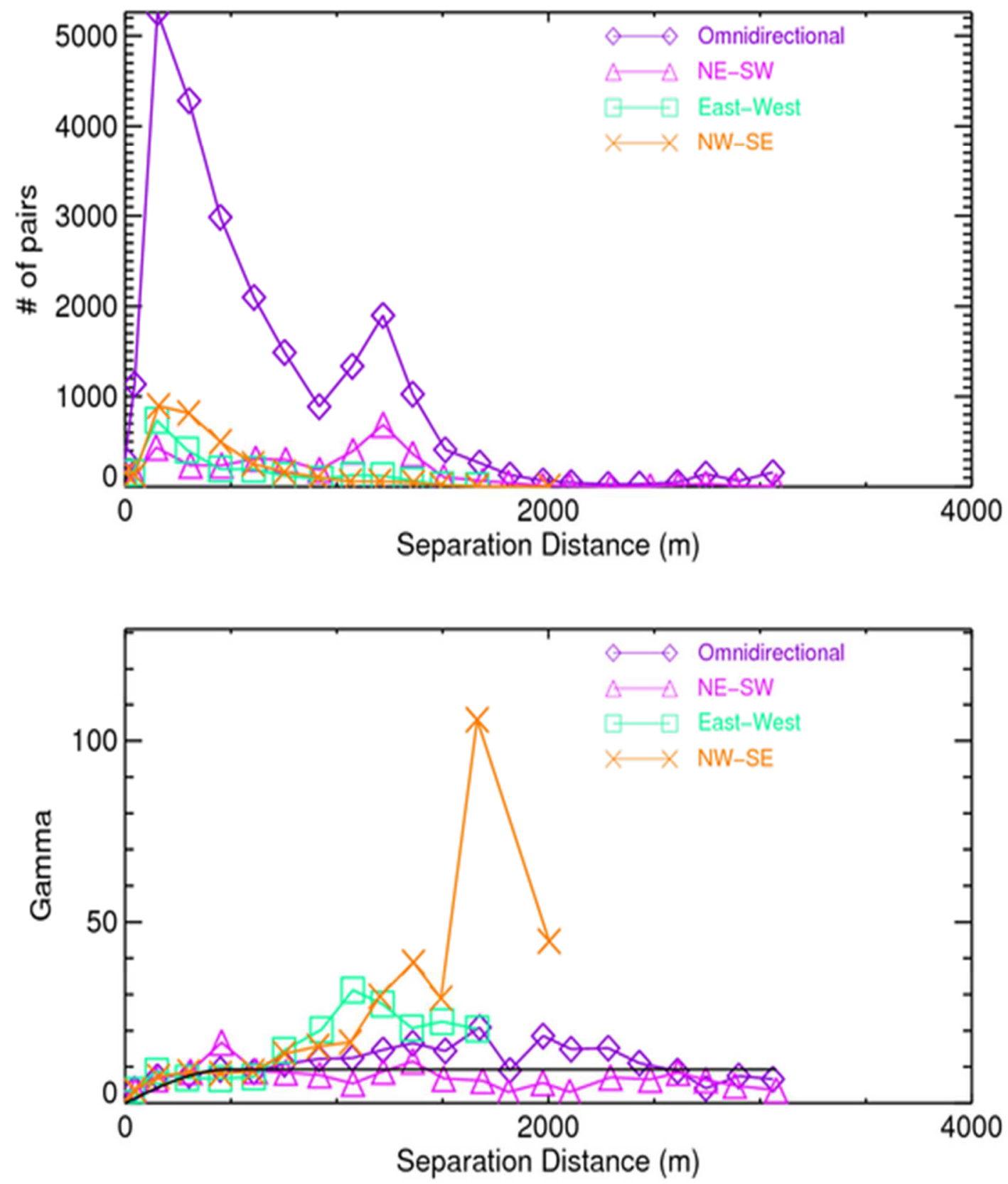

Figure 9. Anisotropic empirical (colored lines and symbols) and modelled (black lines) semivariograms for the surficial sediment thicknesses. 

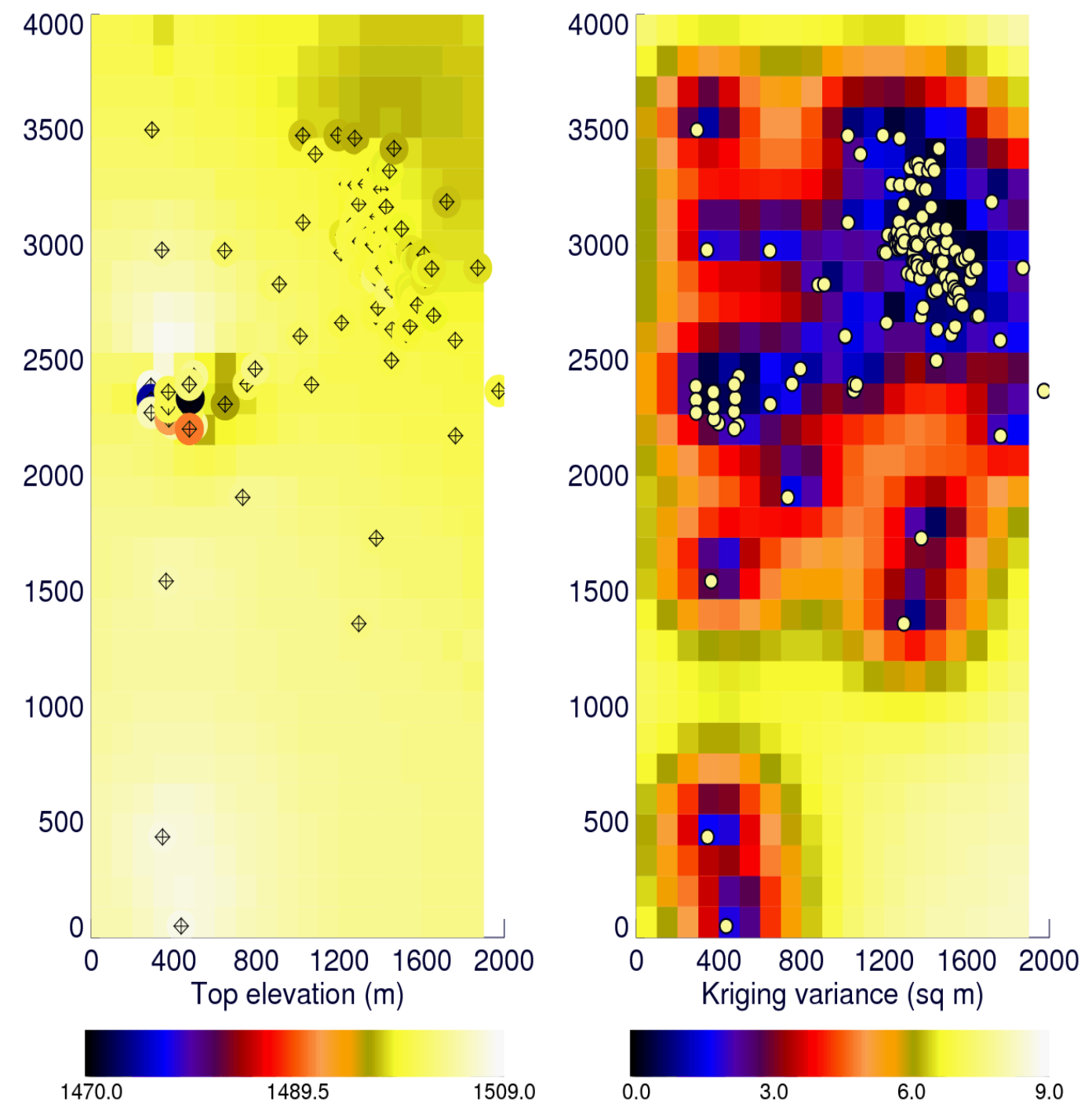

Figure 10. Kriging predictions (left) and kriging variance (right) for surficial sediment top elevation (m). Points represent sample locations. The gridded area is represented by the box in Figure 1 and the $\mathrm{x}-$ $\mathrm{y}$ distances $(\mathrm{m})$ are relative to the figure. 

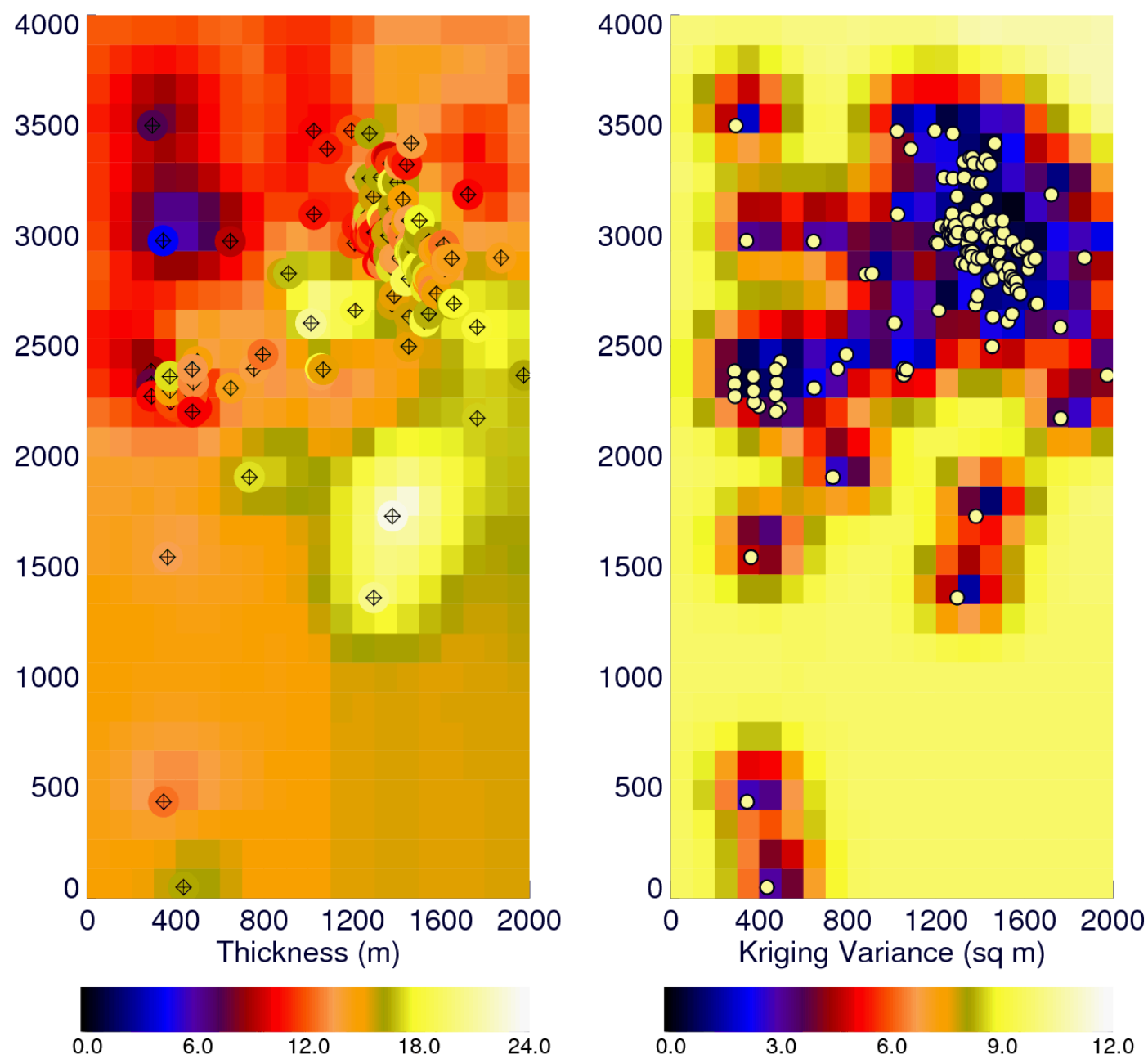

Figure 11. Kriging predictions (left) and kriging variance (right) for surficial sediment thickness (m). Points represent sample locations. The gridded area is represented by the box in Figure 1 and the $x-y$ distances $(\mathrm{m})$ are relative to the figure.

\subsection{Sediment Unit 1}

Top elevation and thickness of the uppermost sediment unit (Unit 1) were defined through use of the 38 wells (see Figure 12) with sufficient depth penetration to encounter this unit. Thirteen of the 38 wells contain this unit, but this unit was not found at 25 of the well locations. 


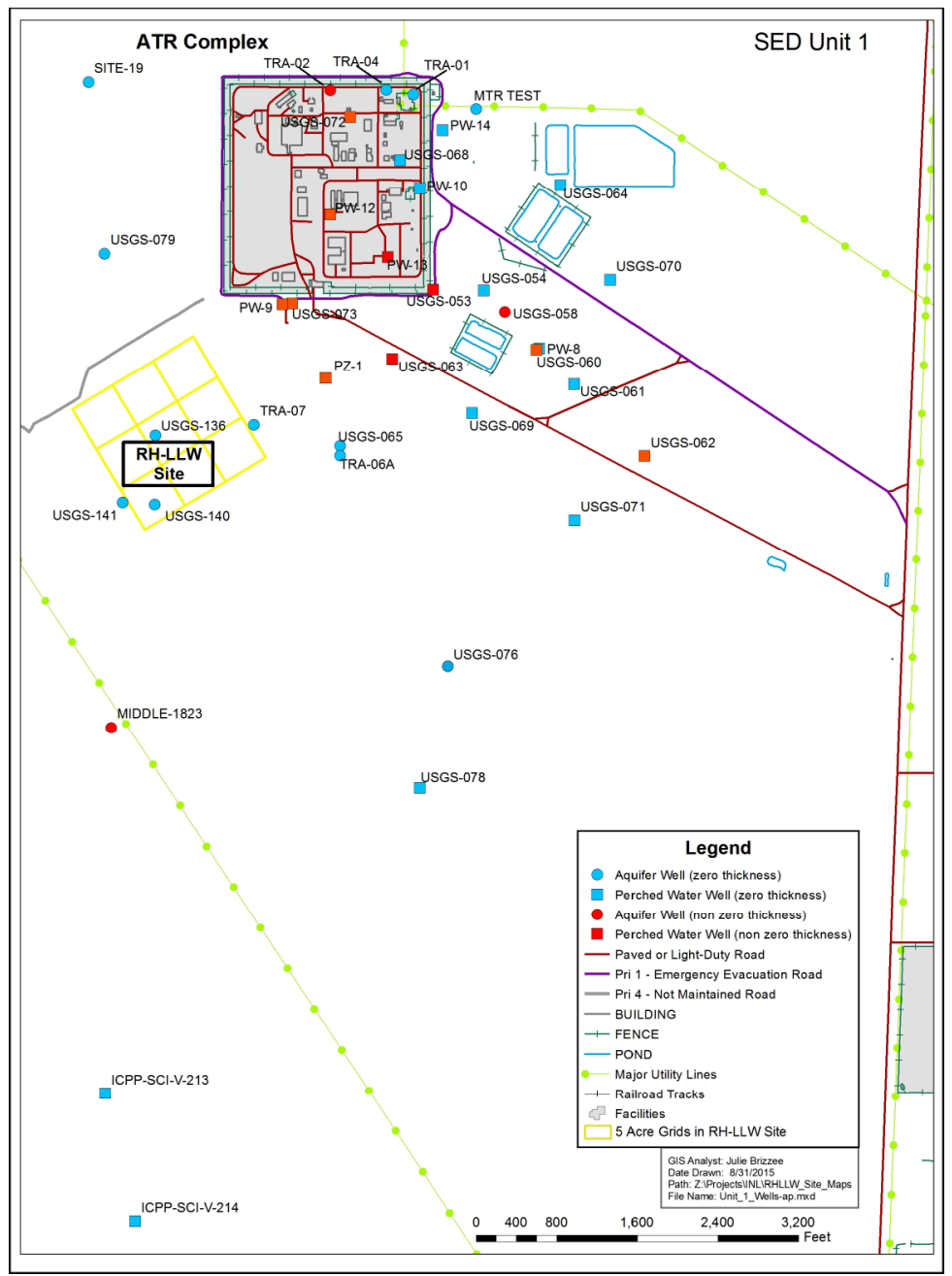

Figure 12. Wells used to define Sediment Unit 1.

\subsubsection{Geostatistical Evaluation}

Histograms for the top elevation and thickness are shown in Figure 13, along with summary statistical distributions; semivariograms are shown in Figures 14 and 15; spatially kriged top elevation and associated kriging variance are given in Figure 16, and the kriged thickness and kriging variance are shown in Figure 17. The following bullets provide discussion of the figures:

- Data were assessed for normality and to determine whether the distribution was symmetric. Unit 1 top elevation is slightly skewed, but not log-normal (Shapiro-Wilks test $p$-value $=0.72$, Table 3 ). Interbed thickness values were positively skewed (Figure 13), but also were not log-normal (Shapiro-Wilks test $\mathrm{p}$-value $=0.69)$. The mean elevation for this unit is about $1,476 \mathrm{~m}(4,843 \mathrm{ft}$ ), corresponding to an average depth of $25 \mathrm{~m}(82 \mathrm{ft})$. Standard deviation in top elevation is $5.8 \mathrm{~m}$ (19 ft) as shown to the right of the plotted histogram, contributed to by the three low elevations found in the central ATR Complex area.

- In locations where the sediment thickness was non-zero, Unit 1 ranges from 0.6 to $2.1 \mathrm{~m}$ (about 2 to $7 \mathrm{ft})$ in thickness with a standard deviation of $0.45 \mathrm{~m}(1.5 \mathrm{ft})$. As indicated in the cross-sections shown in Appendix A and in the kriged results that follow, the thicker sediment occurs in a north-to-south direction with thin or no Unit 1 occurrences to the north of ATR Complex.

- $\quad$ This unit was not located near the RH-LLW Disposal Facility site (thickness $=0.0$ ). 


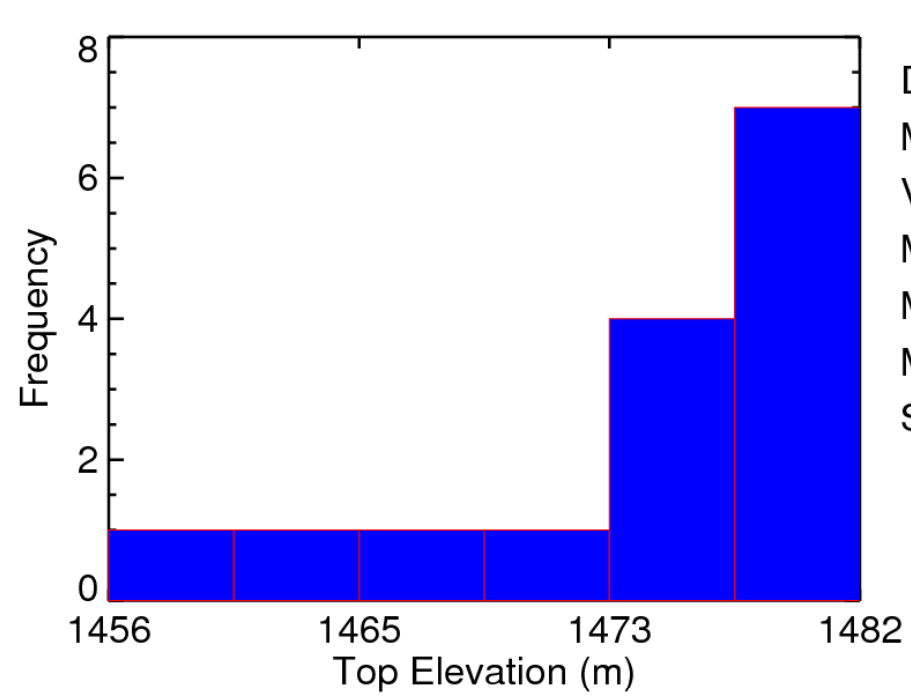

Sediment Unit 1

Data Count: 13

Mean: $\quad 1475.91$

Variance: $\quad 34.02$

Maximum: 1480.83

Median: $\quad 1478.06$

Minimum: $\quad 1458.68$

Shapiro Wilks p: 0.72

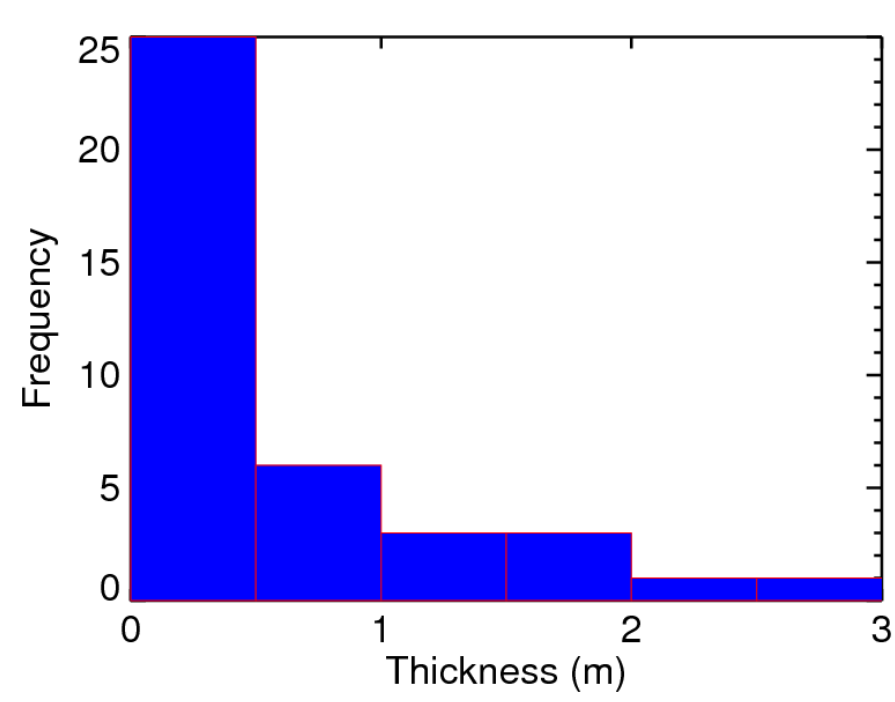

Sediment Unit 1

Data Count: $\quad 38$

Mean: $\quad 1.21$

Variance: $\quad 0.20$

Maximum: $\quad 2.13$

Median: $\quad 1.22$

Minimum: $\quad 0.61$

Shapiro Wilks p: 0.69

Figure 13. Histogram of Sediment Unit 1 elevation (top) and thickness (bottom). Summary statistics for both distributions are shown to the right of each plot.

- The semivariogram for Sediment Unit 1 top elevation is not well defined at distances greater than $1,000 \mathrm{~m}$ due to sparse data as indicated by few pairs per lag distance. Given the sparse data, the fitted exponential variogram model has a range of $93 \mathrm{~m}$ and sill of $46.5 \mathrm{~m}^{2}$ with zero nugget. This indicates the variance (i.e., sill) is as large as the estimation distance (range), making the elevation of this unit unpredictable with any reliability.

- The semivariogram for Sediment Unit 1 thickness shows very little difference in spatial continuity as a function of direction. The omnidirectional empirical semivariogram was fit with an exponential model with zero nugget, sill of $0.4 \mathrm{~m}^{2}$, and range of $457 \mathrm{~m}$. 

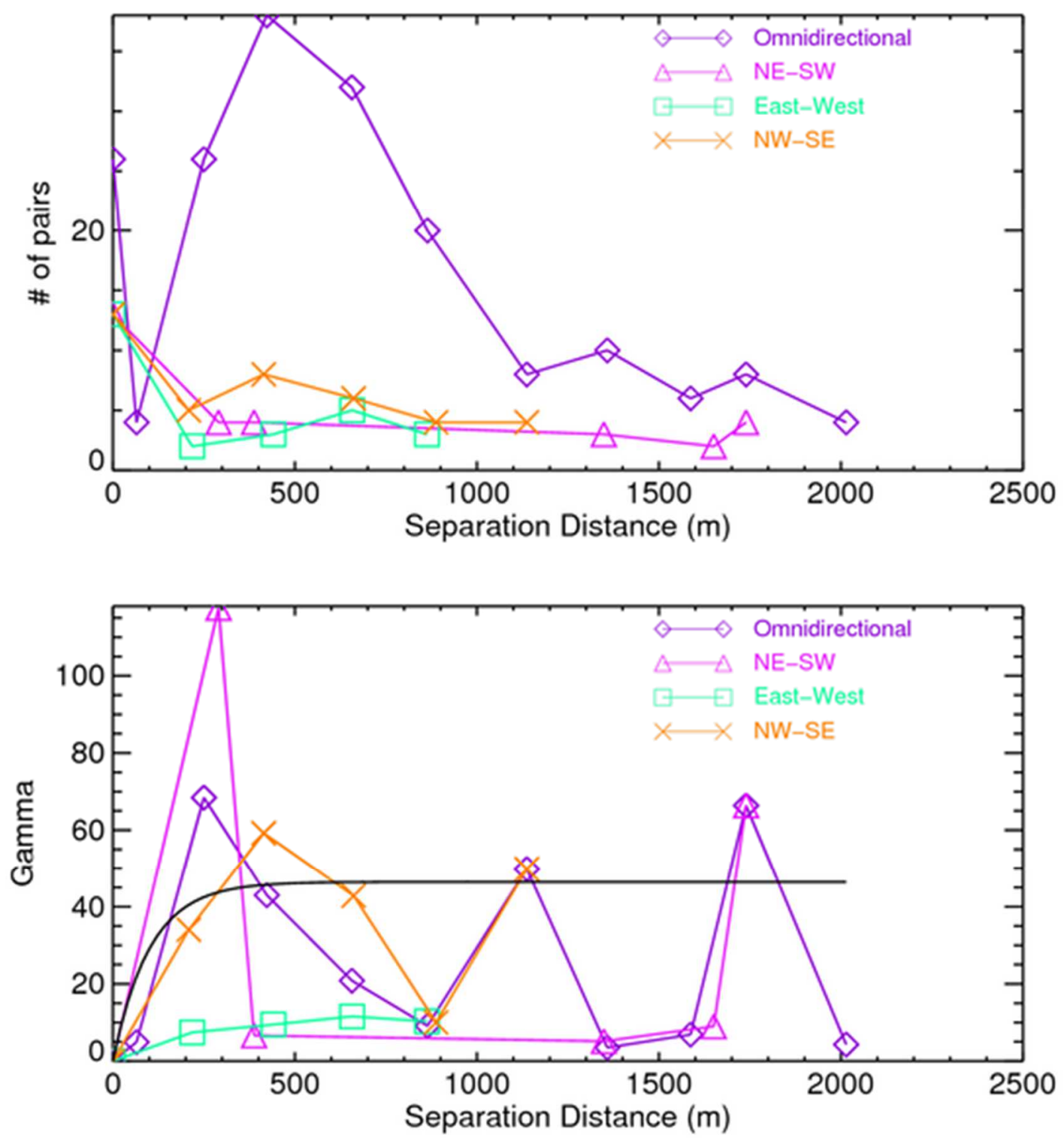

Figure 14. Anisotropic empirical (colored lines and symbols) and modelled (black lines) semivariograms for Sediment Unit 1 top elevations. 

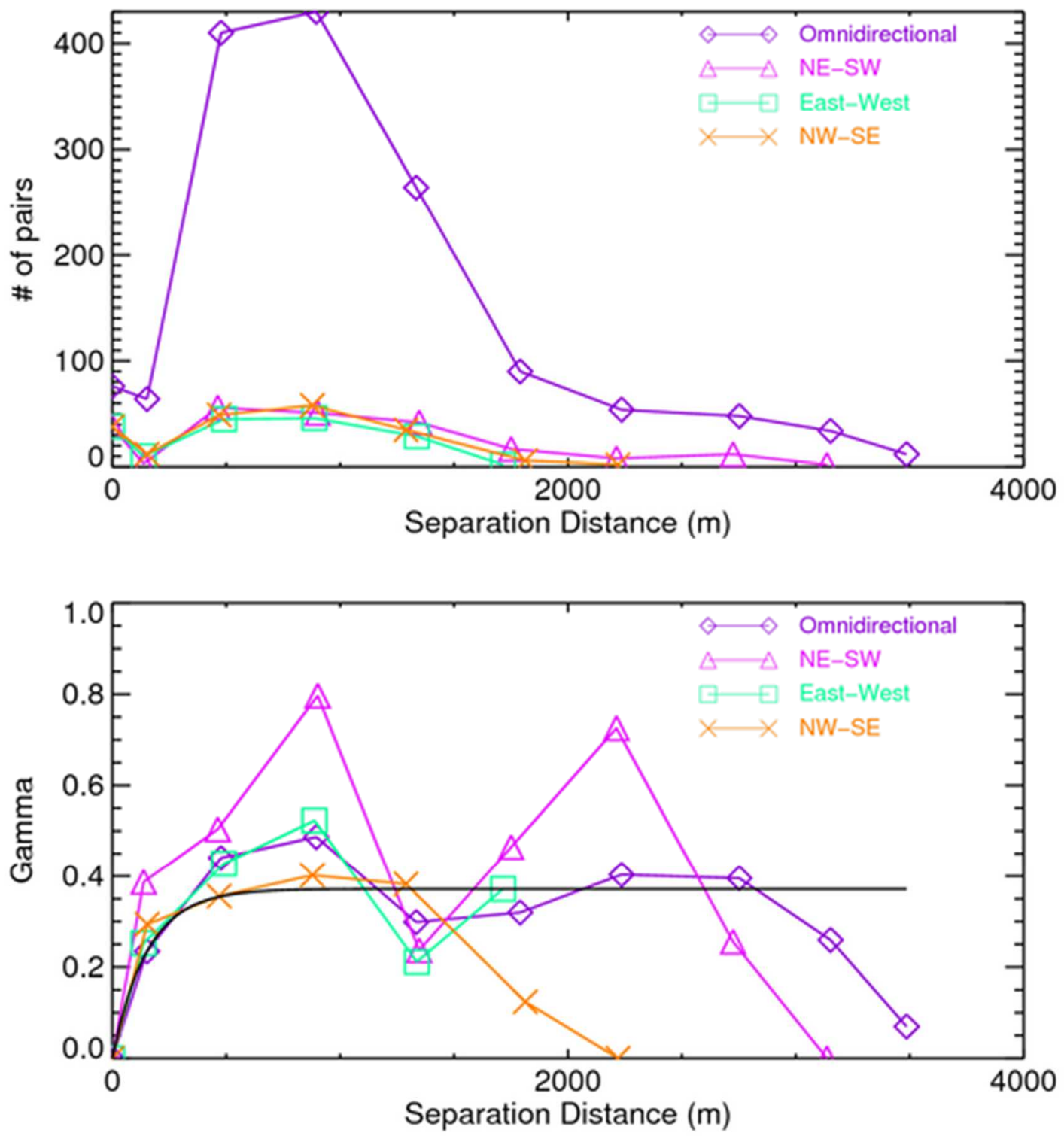

Figure 15. Anisotropic empirical (colored lines and symbols) and modelled (black lines) semivariograms for Sediment Unit 1 thicknesses (bottom).

- Kriging predictions for the sediment top elevation (Figure 16 left) and high kriging variance illustrate the effect of low sample density. The relatively short correlation length is represented by largely discontinuous values of kriging variance. High kriging variance near the RH-LLW Disposal Facility location results from lack of data in that region. Coupled with relatively high elevation variance, predicting surface elevation for this unit in the RH-LLW Disposal Facility location is problematic. 
- The kriging predictions for Sediment Unit 1 thickness (Figure 17 left), along with the corresponding kriging variance (right), indicate the sediment unit appears to be narrowly confined to a region running north-to-south through the ATR Complex. This unit is likely to be less than $0.5 \mathrm{~m}(1.6 \mathrm{ft})$ in thickness near the RH-LLW Disposal Facility area. Given the range of $457 \mathrm{~m}$, well spacing sufficient to define this unit will be similar to that necessary to define the surficial sediment thickness outside of previously characterized areas.
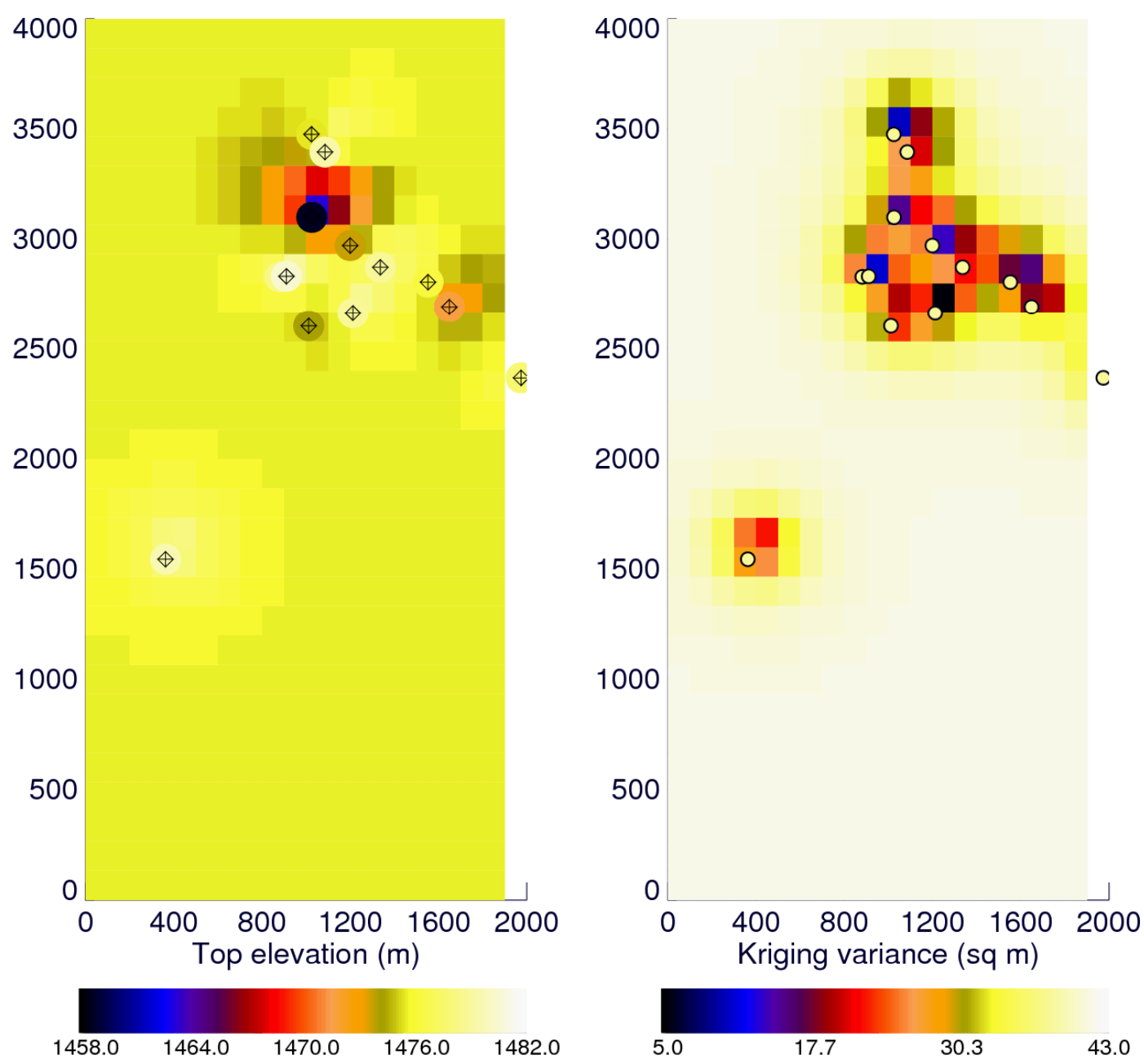

Figure 16. Kriging predictions (left) and kriging variance (right) for Sediment Unit 1 top elevation (m). Points represent sample locations. The gridded area is represented by the box in Figure 1 and the $x-y$ distances $(\mathrm{m})$ are relative to the figure. 

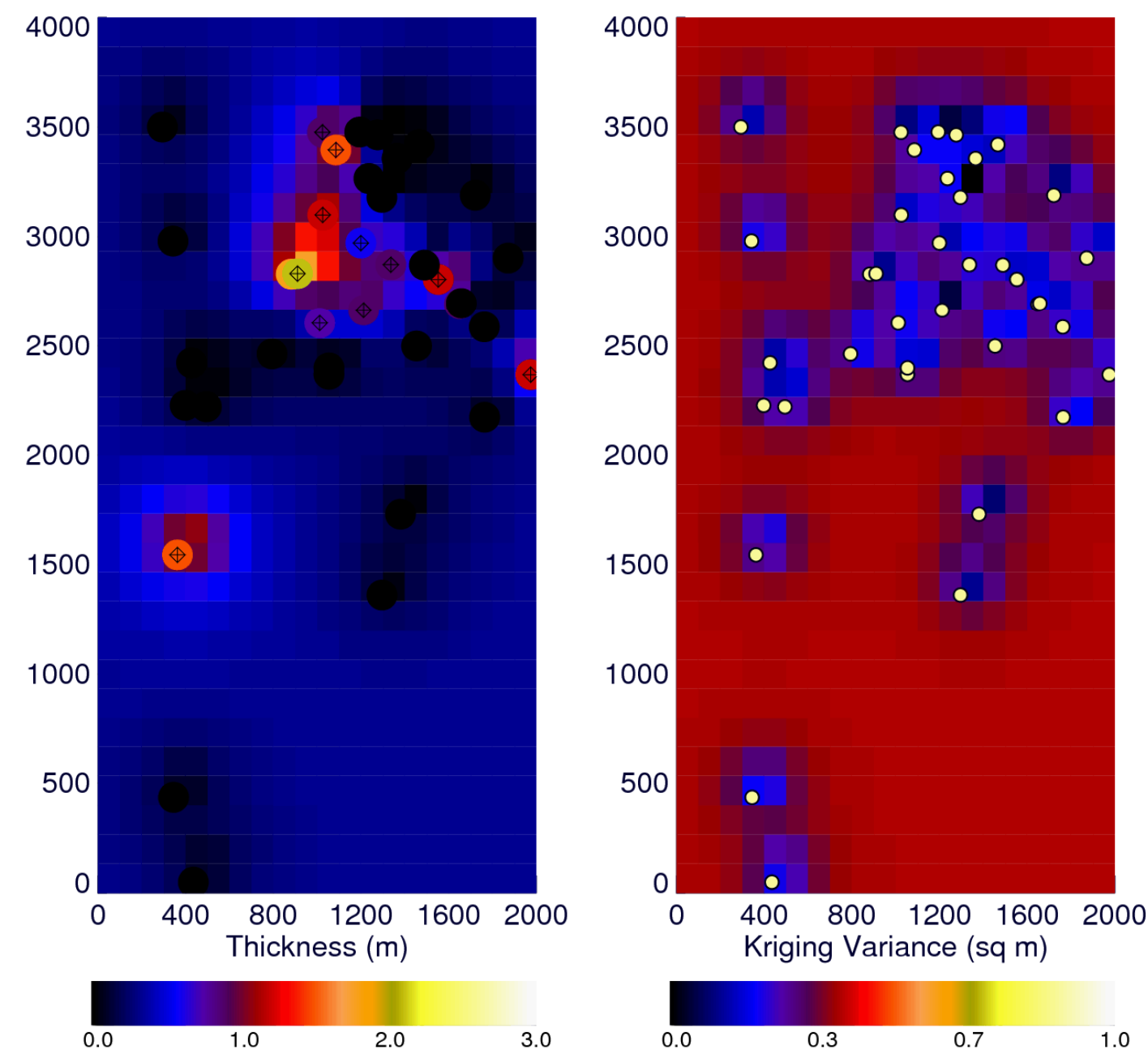

Figure 17. Kriging predictions (left) and kriging variance (right) for Sediment Unit 1 thickness (m). Points represent sample locations. The gridded area is represented by the box in Figure 1 and the $x-y$ distances $(\mathrm{m})$ are relative to the figure.

\subsection{Sediment Unit 2}

Top elevation and thickness of Sediment Unit 2 were defined through the use of 39 wells with sufficient depth penetration to encounter this unit. Of these wells, 22 wells contain Sediment Unit 2. These wells are shown in Figure 18. Wells in which this unit is ambiguous are not shown and were not used in this analysis. 


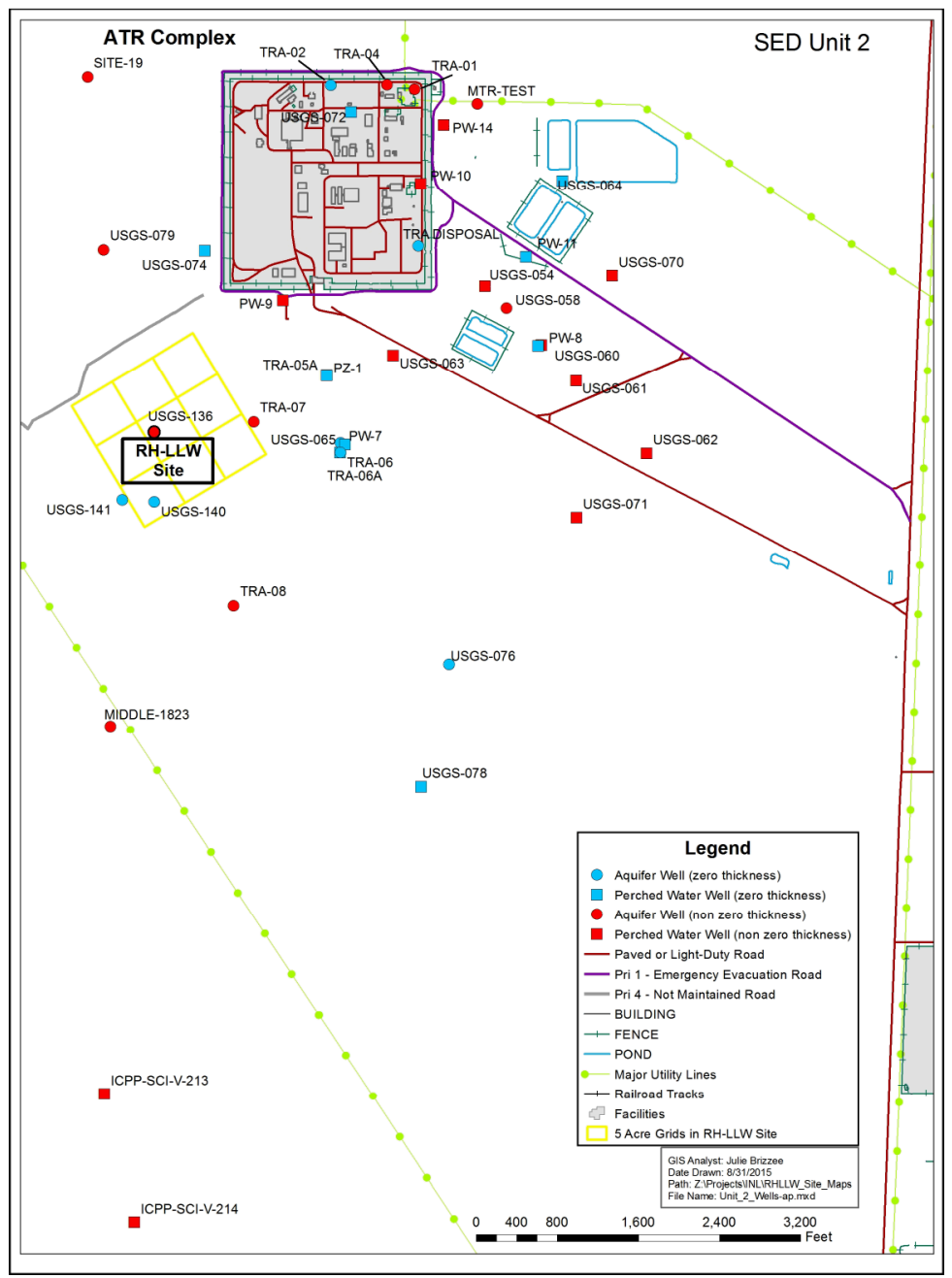

Figure 18. Wells used to define Sediment Unit 2.

\subsubsection{Geostatistical Evaluation}

Histograms for the top elevation and thickness are shown in Figure 19, along with the summary statistical distributions; semivariograms are shown in Figures 20 and 21; spatially kriged top elevation and associated kriging variance are given in Figure 22; and the kriged thickness and kriging variance are shown in Figure 23. The following bullets provide discussion of the figures:

- Top elevation of Sediment Unit 2 approaches a Gaussian shape and not log-normal as indicated by a Shapiro-Wilks test $\mathrm{p}$-value of 0.93 . The mean elevation for this unit is about $1,471 \mathrm{~m}(4823 \mathrm{ft})$, corresponding to an average depth of $29 \mathrm{~m}(95 \mathrm{ft})$. Standard deviation in top elevation is $6.4 \mathrm{~m}$ $(21 \mathrm{ft})$ as shown to the right of the plotted histogram.

- Where found, the thickness of Sediment Unit 2 ranges from about 0.5 to $9.1 \mathrm{~m}$ (up to about $30 \mathrm{ft}$ ), with a standard deviation of $2.5 \mathrm{~m}$ (about $8.2 \mathrm{ft}$ ). As indicated in the cross-sections shown in Appendix A and in the kriged results below, the thicker sediment occurs to the west and to the north of the ATR Complex. The thinnest sediment is found east-to-southeast of the ATR Complex.

- In the 18 locations closest to the RH-LLW Disposal Facility site (i.e., USGS-136, USGS-140, USGS-141, USGS-065, TRA-06, TRA-07, and Borings 7 through 18), this unit was only found in USGS-136 (1.75 ft) and TRA-07 (10 ft). 
This unit was not located near the RH-LLW Disposal Facility site (thickness $=0.0$ ).

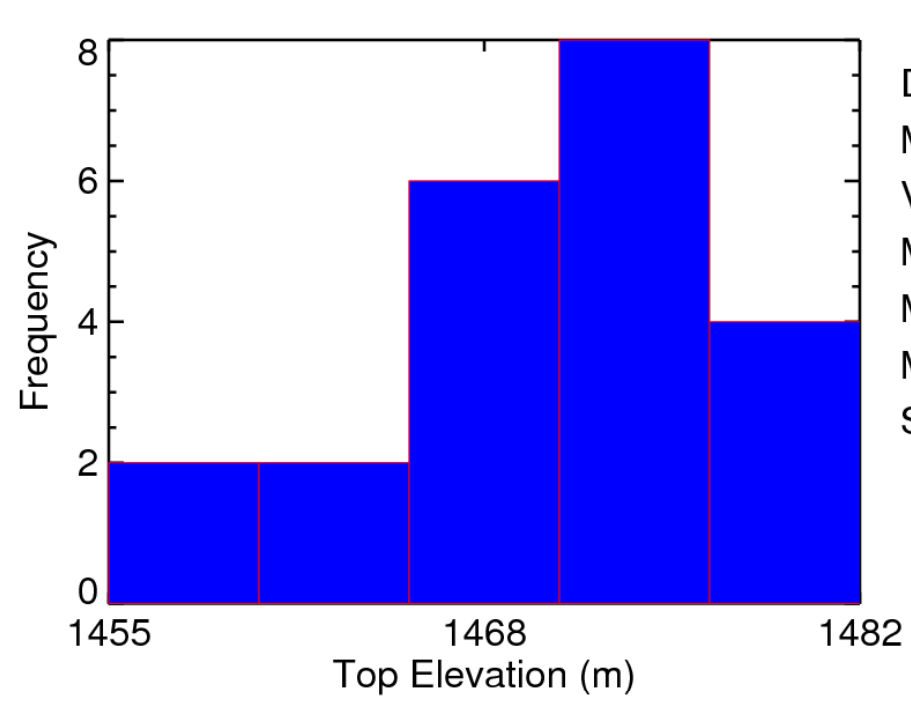

Sediment Unit 2

Data Count: 22

Mean: $\quad 1470.97$

Variance: $\quad 41.02$

Maximum: 1481.33

Median: $\quad 1472.18$

Minimum: 1457.73

Shapiro Wilks p: 0.93

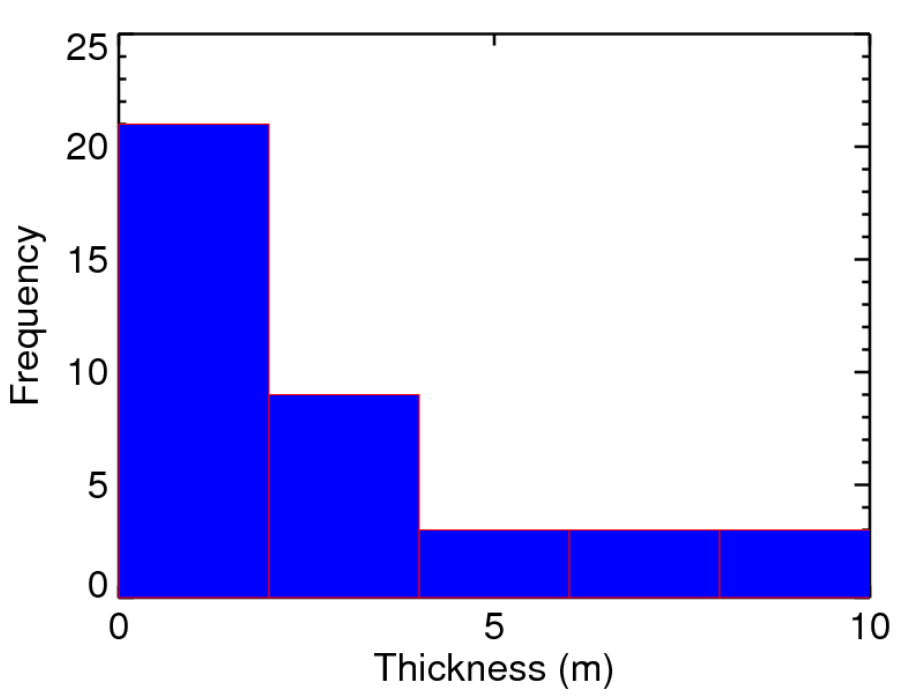

Sediment Unit 2

Data Count: $\quad 39$

Mean: $\quad 4.07$

Variance: $\quad 6.59$

Maximum: $\quad 9.14$

Median: $\quad 3.05$

Minimum: $\quad 0.53$

Shapiro Wilks p: 0.79

Figure 19. Histogram of Sediment Unit 2 elevation (top) and thickness (bottom). Summary statistics for both distributions are shown to the right of each plot.

- The semivariogram for Sediment Unit 2 top elevation (Figure 20) is reasonably well defined. The empirical semivariogram was fit with an exponential model, $457-\mathrm{m}$ range, $40-\mathrm{m}^{2}$ sill, and zero nugget.

- The semivariogram for Sediment Unit 2 thickness (Figure 21) indicates that the unit has very little difference in spatial continuity as a function of direction. The omnidirectional empirical semivariogram was fit with an exponential model with zero nugget, $6.5-\mathrm{m}^{2}$ sill, and $457-\mathrm{m}$ range. 

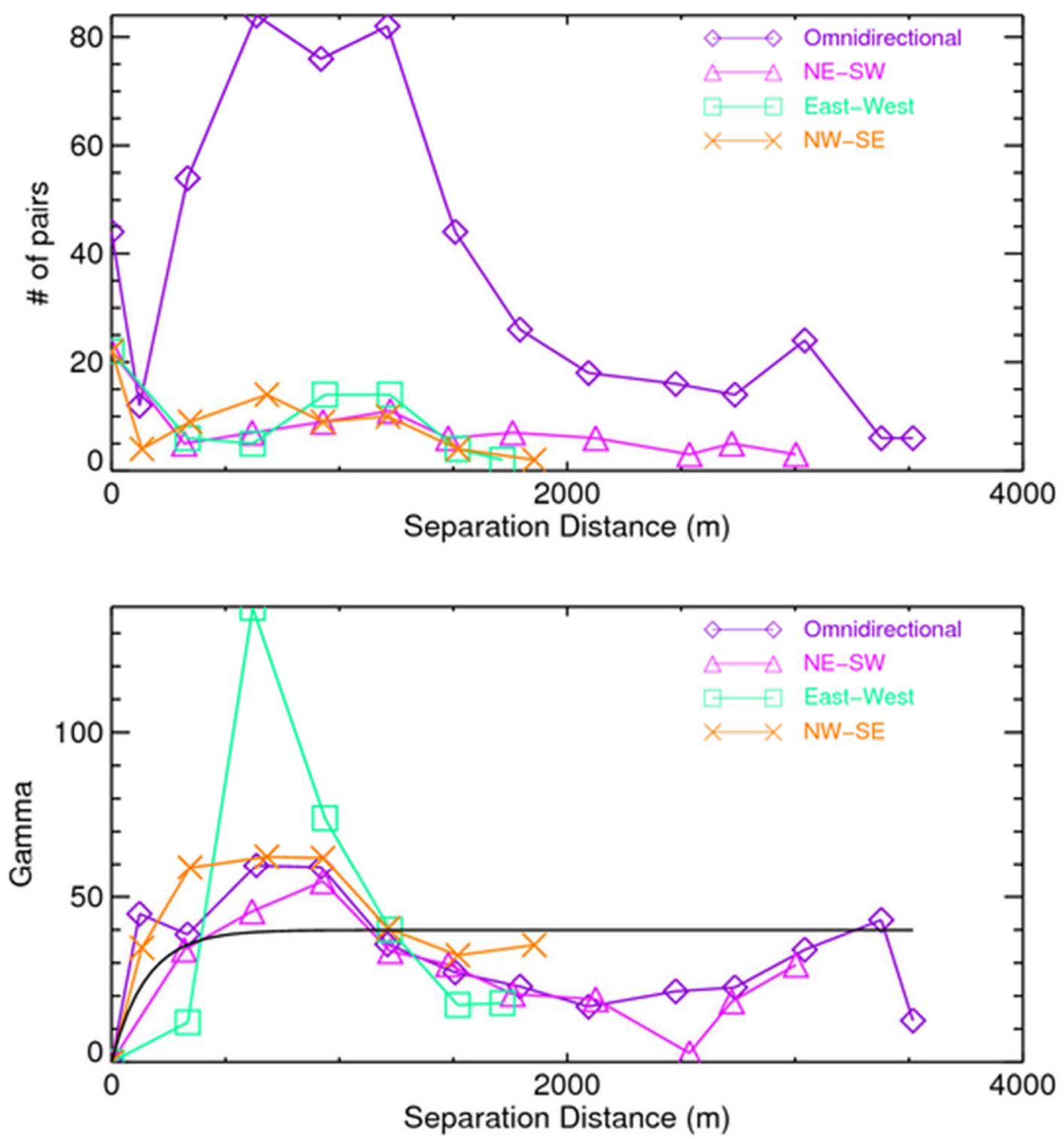

Figure 20. Anisotropic empirical (colored lines and symbols) and modelled (black lines) semivariograms for Sediment Unit 2 top elevation. 

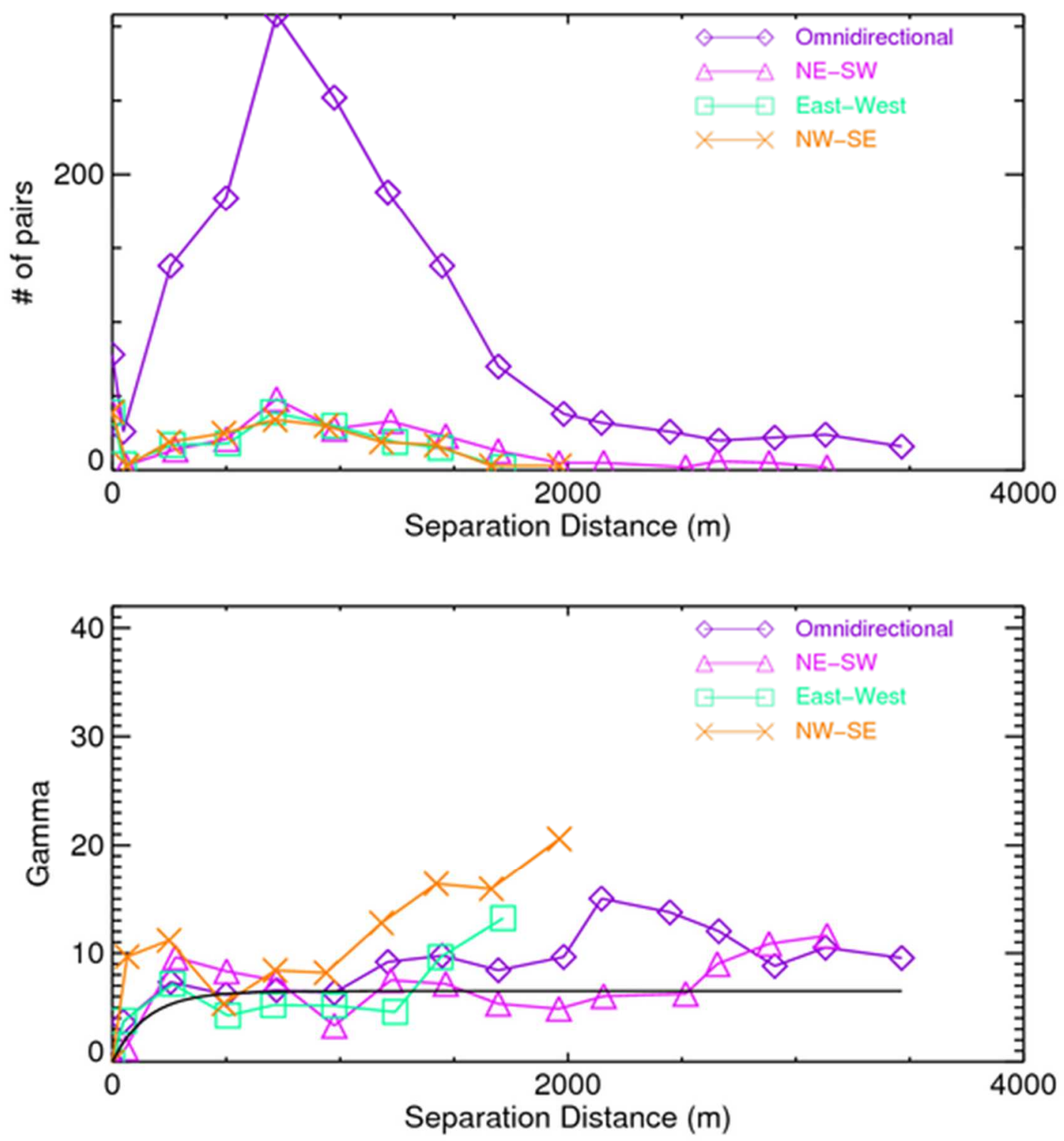

Figure 21. Anisotropic empirical (colored lines and symbols) and modelled (black lines) semivariograms for Sediment Unit 2 thicknesses.

- Kriging predictions for Sediment Unit 2 top elevation are shown in Figure 22 (left), along with the corresponding kriging variance (right). The kriging variances throughout much of the modelled area result from data spacing with higher values, indicating a lack of data. Where the data are spaced closer, the variances are quite low, indicating the combined effect of variogram range and data location. The relatively low elevation variance allows predicting surface elevation for this unit, with reasonable confidence near the RH-LLW Disposal Facility location. 
- The kriging predictions for Sediment Unit 2 thickness are shown in Figure 23 (left), along with the corresponding kriging variance (right). This sediment unit appears to extend throughout a region extending from the north-central area of the ATR Complex well to the south along the western study area.

- If the RH-LLW Disposal Facility is expanded in the future, well spacing sufficient to define this unit should be on the order of the 457-m range.
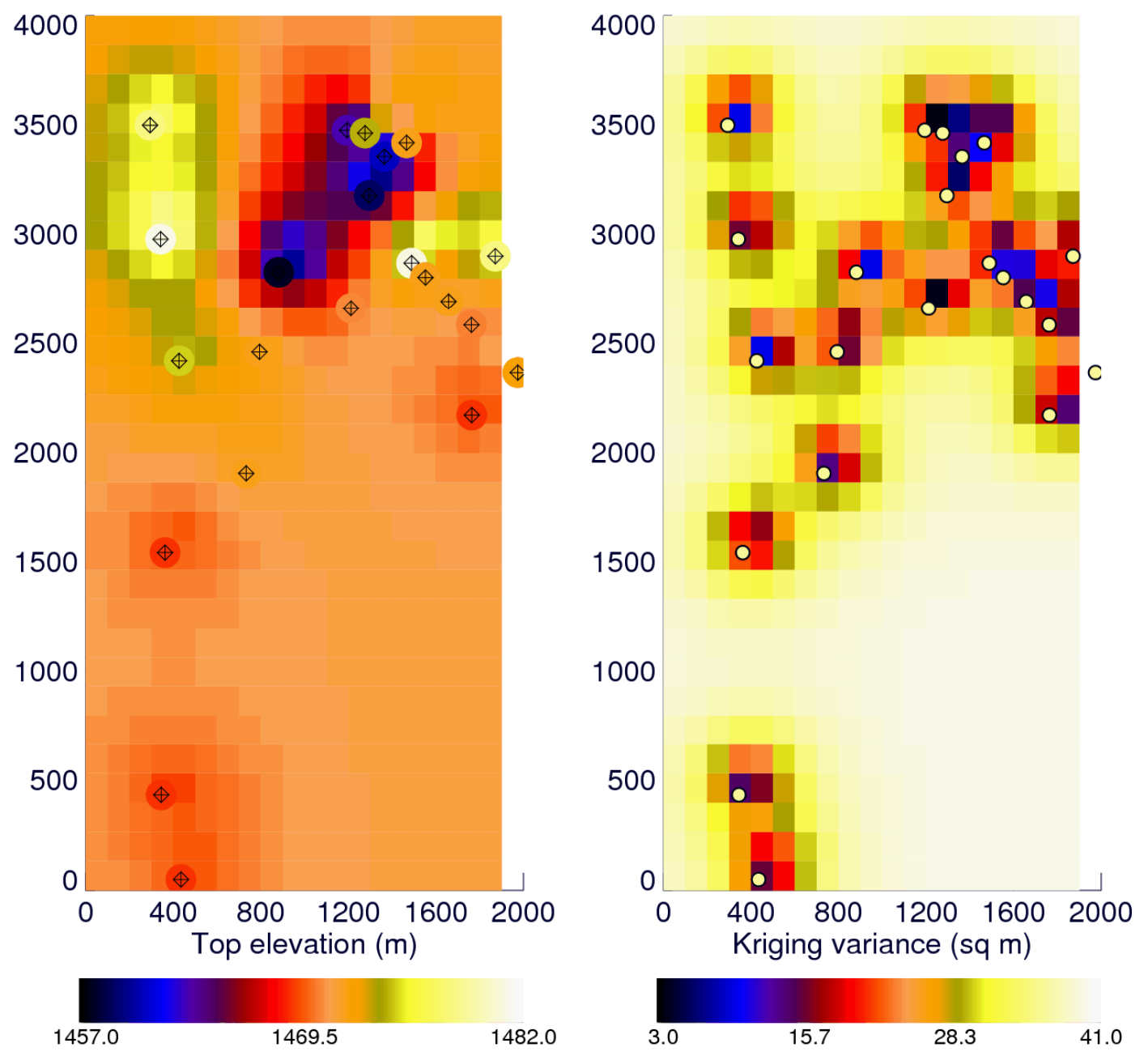

Figure 22. Kriging predictions (left) and kriging variance (right) for Sediment Unit 2 top elevation (m). Points represent sample locations. The gridded area is represented by the box in Figure 1 and the $x-y$ distances (m) are relative to the figure. 

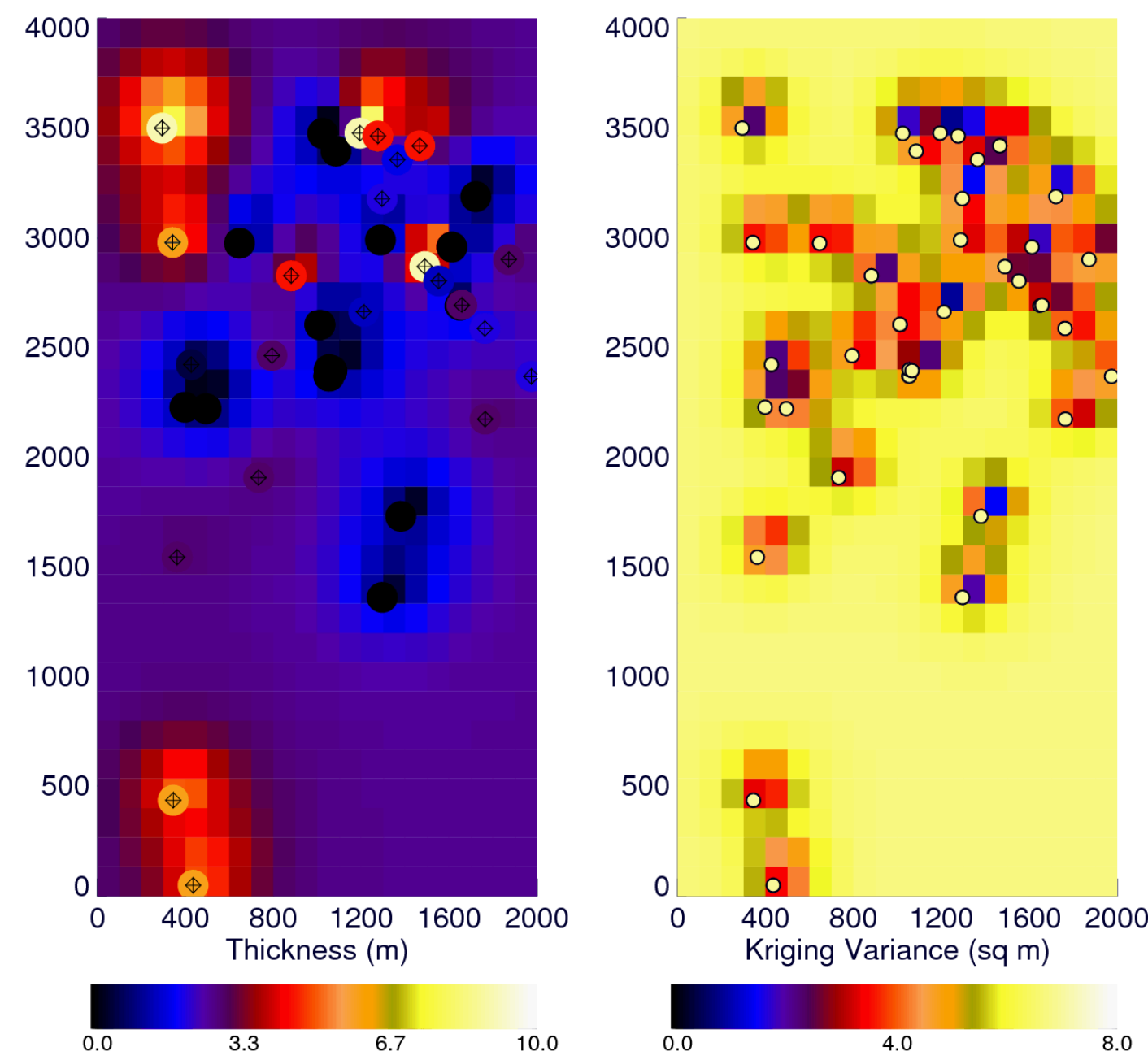

Figure 23. Kriging predictions (left) and kriging variance (right) for Sediment Unit 2 thickness (m). Points represent sample locations. The gridded area is represented by the box in Figure 1 and the $x-y$ distances $(\mathrm{m})$ are relative to the figure.

\subsection{Sediment Unit 3}

Top elevation and thickness of Sediment Unit 3 were defined through the use of 31 wells, providing positive indication of the unit's existence in all 31 locations shown in Figure 24. 


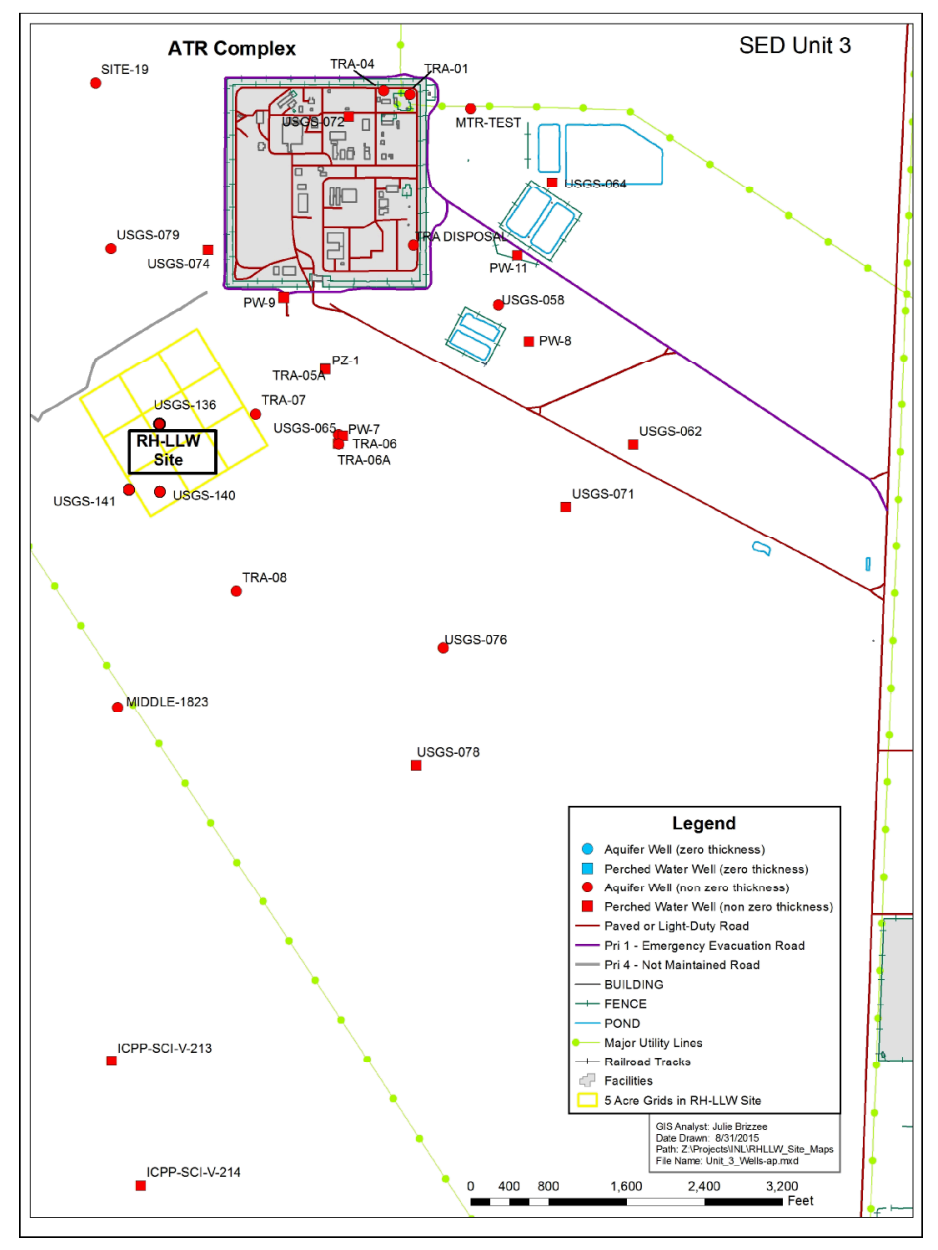

Figure 24. Wells used to define Sediment Unit 3.

\subsubsection{Geostatistical Evaluation}

The distribution of elevation and thicknesses derived from these data are shown in Figure 25, along with the summary statistics. Empirical semivariograms are shown in Figures 26 and 27; spatially kriged top elevation and associated kriging variances are given in Figure 28, with those for thickness shown in Figure 29. The following bullets provide discussion of the figures:

- The distribution of Sediment Unit 3 top elevation (Figure 25 top) approaches a Gaussian shape and is neither significantly skewed or log-normal (Shapiro-Wilks test $\mathrm{p}$-value $=0.96$ ). The interbed thicknesses are similarly distributed (Figure 25 bottom) and also are not log-normal (Shapiro-Wilks test $\mathrm{p}$-value $=0.94)$. The mean elevation for this unit is about $1,456 \mathrm{~m}(4,777 \mathrm{ft})$ corresponding to an average depth of $44 \mathrm{~m}(144 \mathrm{ft})$. This unit is relatively horizontal, exhibiting little trend in elevation and having a relatively small $3.3-\mathrm{m}$ standard deviation.

- Sediment thickness of Unit 3 ranges from 1.2 to $10.4 \mathrm{~m}$ (or up to about $35 \mathrm{ft}$ ), with a standard deviation of $2.3 \mathrm{~m}(7.6 \mathrm{ft})$. As indicated in the cross-sections shown in Appendix A and in the kriged results presented here, the thinnest occurrences of Sediment Unit 3 are found northeast of the ATR Complex.

- The thickest Sediment Unit 3 region exists roughly through the center of the RH-LLW Disposal Facility location. In the 18 locations closest to the RH-LLW Disposal Facility site (i.e., USGS-136, USGS-140, USGS-141, USGS-065, TRA-06, TRA-07, and Borings 7 through 18), the average thickness is $5.8 \mathrm{~m}(19.1 \mathrm{ft})$. 


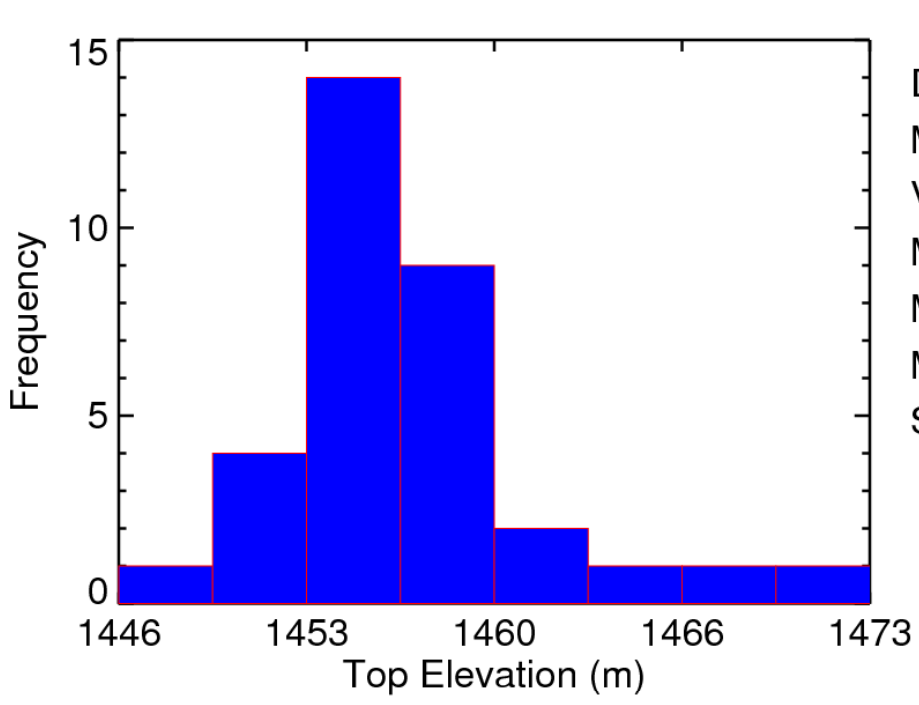

Sediment Unit 3

Data Count: $\quad 31$

Mean: $\quad 1455.83$

Variance: $\quad 10.59$

Maximum: 1463.95

Median: $\quad 1455.42$

Minimum: 1449.32

Shapiro Wilks p: 0.96

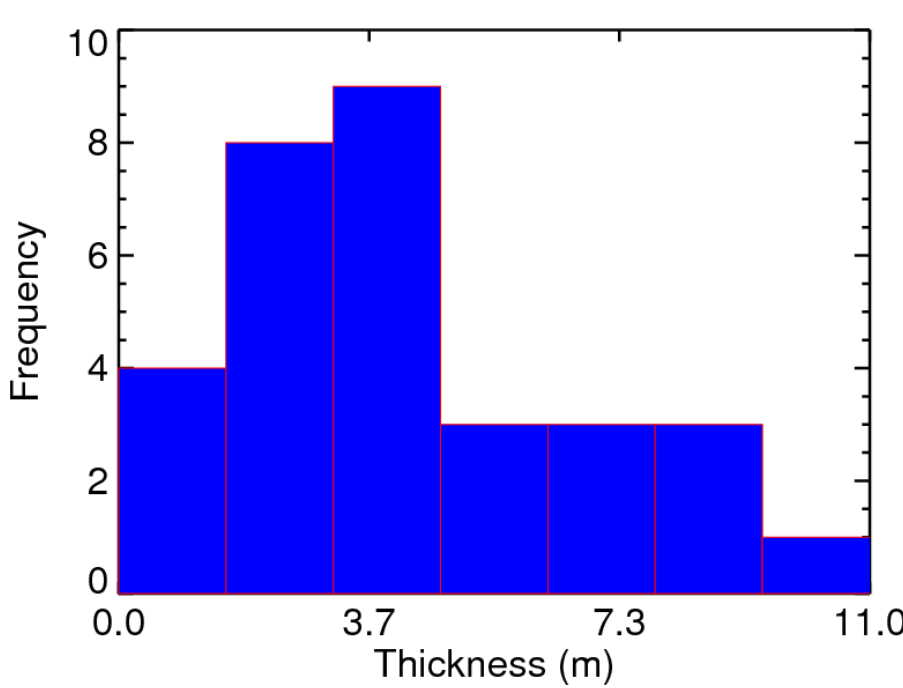

Sediment Unit 3

Data Count: $\quad 31$

Mean: $\quad 4.52$

Variance: $\quad 5.29$

Maximum: $\quad 10.36$

Median: $\quad 3.96$

Minimum: $\quad 1.22$

Shapiro Wilks p: 0.94

Figure 25. Histogram of Sediment Unit 3 elevation (top) and thickness (bottom). Summary statistics for both distributions are shown to the right of each plot.

- The semivariogram for Sediment Unit 3 top elevation (Figure 26) is reasonably well defined, showing little directional difference. An exponential variogram with a $457-\mathrm{m}$ range, $11.6-\mathrm{m}^{2}$ sill, and zero nugget was fitted to the omnidirectional empirical semivariogram.

- The semivariogram for Sediment Unit 3 thickness (Figure 27) suggests there is very little difference in spatial continuity as a function of direction. The omnidirectional empirical semivariogram was fit with an exponential model with zero nugget, $6.5-\mathrm{m}^{2}$ sill, and $762-\mathrm{m}$ range. 

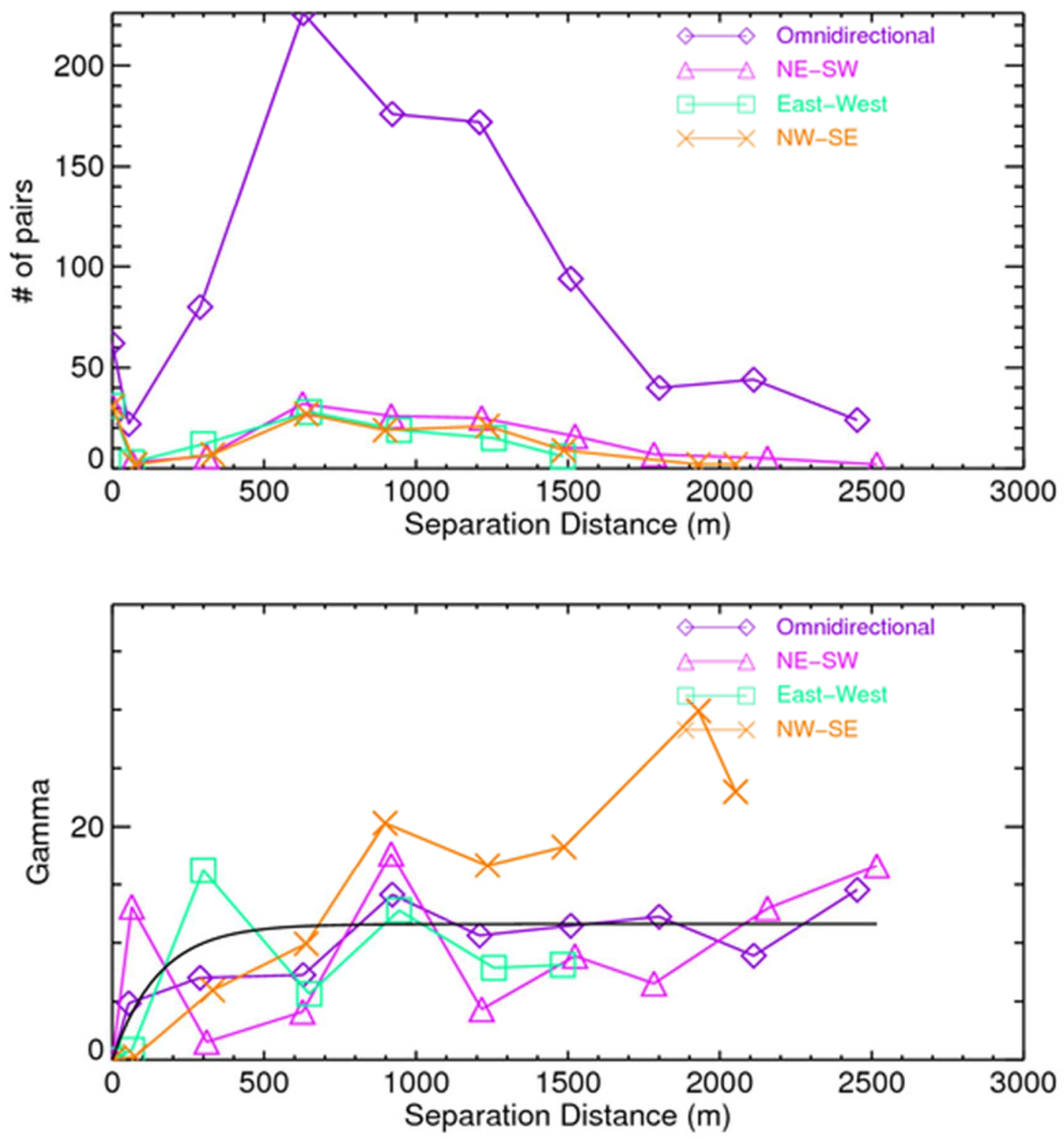

Figure 26. Anisotropic empirical (colored lines and symbols) and modelled (black lines) semivariograms for Sediment Unit 3 top elevation. 

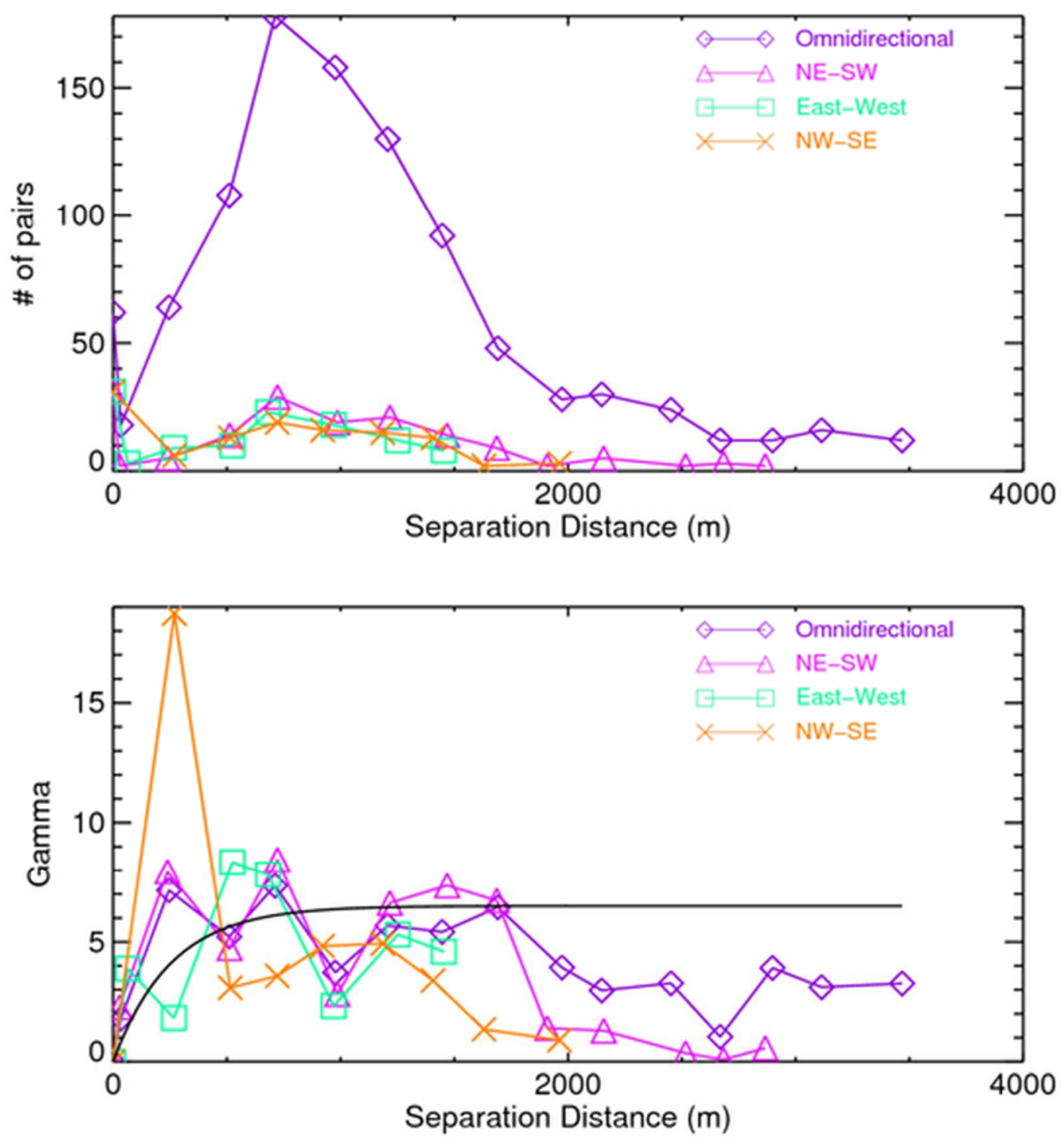

Figure 27. Anisotropic empirical (colored lines and symbols) and modelled (black lines) semivariograms for Sediment Unit 3 thicknesses.

- Kriging predictions for the sediment top elevation are shown in Figure 28 (left), along with the corresponding kriging variance (right). The relatively long correlation length is represented by largely continuous values of kriging variance. The kriging variance near the RH-LLW Disposal Facility location is low, indicating sufficient data in that region. Coupled with relatively low elevation variance, it is likely that this unit will exist throughout the RH-LLW Disposal Facility location.

- The kriging predictions for Sediment Unit 3 thickness are shown in Figure 29 (left), along with the corresponding kriging variance (right). This sediment unit appears to form a C-shape, running around the west perimeter of the ATR Complex and RH-LLW Disposal Facility site. 
- If the RH-LLW Disposal Facility is expanded in the future, well spacing sufficient to define the surficial sediment and Sediment Unit 2 should be sufficient to define this unit as well.
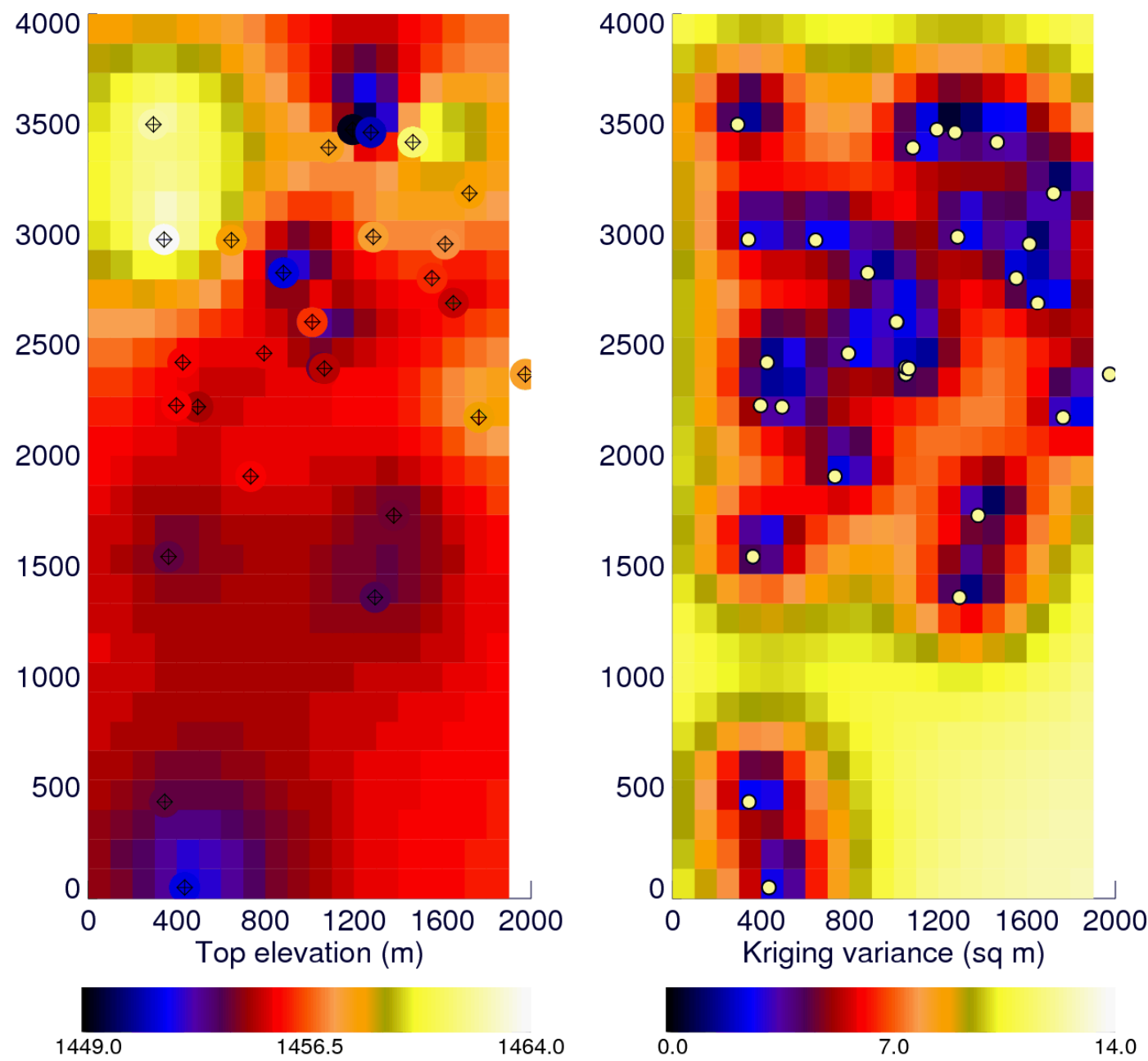

Figure 28. Kriging predictions (left) and kriging variance (right) for Sediment Unit 3 top elevation (m). Points represent sample locations. The gridded area is represented by the box in Figure 1 and the $x-y$ distances (m) are relative to the figure. 

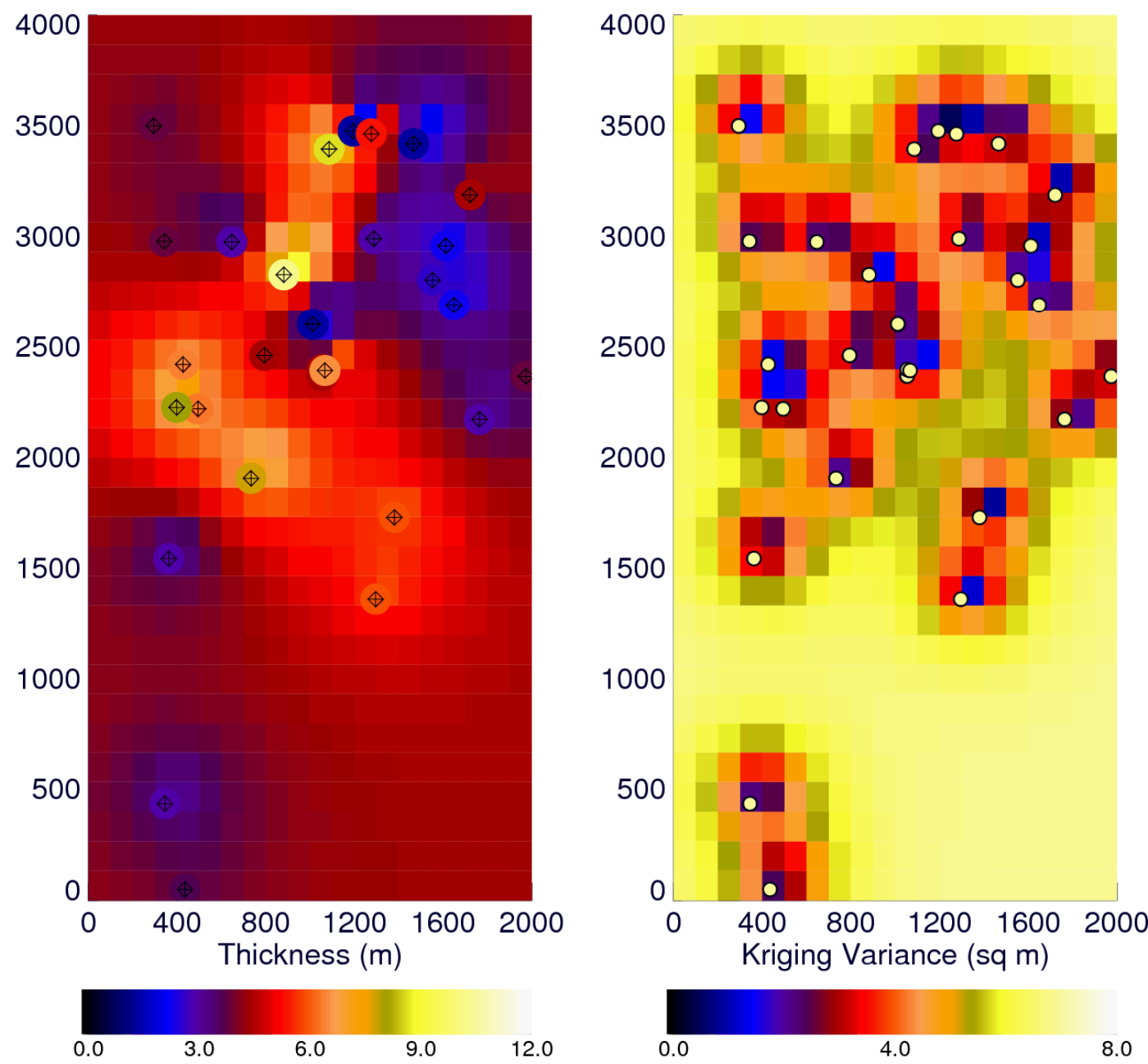

Figure 29. Kriging predictions (left) and kriging variance (right) for Sediment Unit 3 thickness (m). Points represent sample locations. The gridded area is represented by the box in Figure 1 and the $x-y$ distances (m) are relative to the figure.

\subsection{Sediment Unit 4}

Top elevation and thickness of Sediment Unit 4 were defined through the use of 23 wells with sufficient depth penetration to encounter this interbed. These wells are shown in Figure 30. This unit was located in 14 of these wells. 


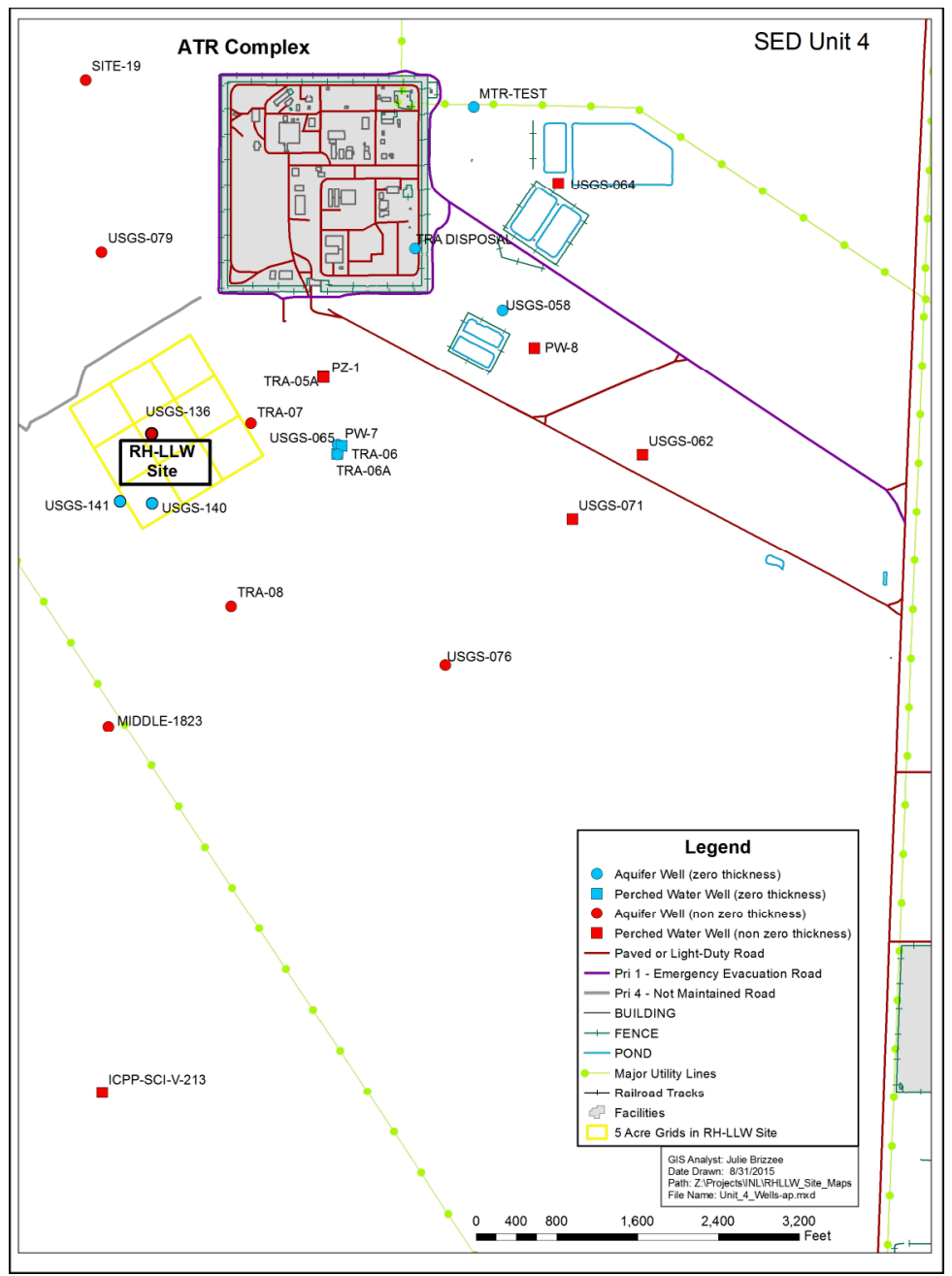

Figure 30. Wells used to define Sediment Unit 4.

\subsubsection{Geostatistical Evaluation}

The distribution of elevation and thicknesses derived from these data are shown in Figure 31, along with the summary statistics. Semivariograms for this unit are shown in Figures 32 and 33. Spatially kriged top elevation and associated kriging variance are given in Figure 34, and the kriged thickness and kriging variance are shown in Figure 35. The following bullets provide discussion of the figures:

- Unit 4 top elevation distribution exhibits little directional trend, but contains three lower elevation values south of the ATR Complex. The top elevation is not log-normal (Shapiro-Wilks test $\mathrm{p}$-value $=0.82)$. The mean elevation for this unit is about $1,450 \mathrm{~m}(4,757 \mathrm{ft})$, corresponding to an average depth of $50 \mathrm{~m}(164 \mathrm{ft})$.

- As illustrated by the distribution of thickness (Figure 31), this unit is one of the more prominent in the ATR Complex region. The interbed thicknesses are skewed, with several higher than average values, but also are not log-normal (Shapiro-Wilks test $\mathrm{p}$-value $=0.84$ ). Unit 4 sediment thickness ranges from 1 to $9.1 \mathrm{~m}$ (about 3.3 to $30 \mathrm{ft}$ ), with a standard deviation of $2.3 \mathrm{~m}(7.5 \mathrm{ft})$ where it is present, making this unit one of the thickest underlying the ATR Complex region.

- As indicated in the cross-sections shown in Appendix A and in the kriged results presented here, the thinnest occurrences of Sediment Unit 4 run north-to-south along the eastern fence line of the ATR Complex, with the thicker region existing to the west of the ATR Complex and through the RH- 
LLW Disposal Facility site. In the 18 locations closest to the RH-LLW Disposal Facility site (i.e., USGS-136, USGS-140, USGS-141, USGS-065, TRA-06, TRA-07, and Borings 7 through 18), the average thickness is $1 \mathrm{~m}(3 \mathrm{ft})$.

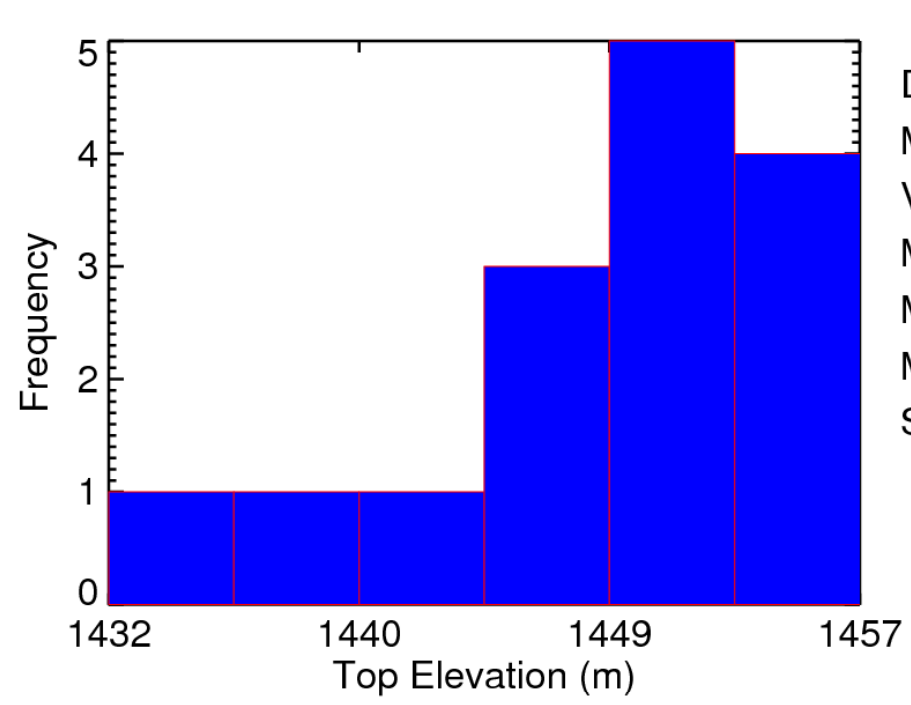

Sediment Unit 4

Data Count: $\quad 14$

Mean: $\quad 1449.52$

Variance: $\quad 28.17$

Maximum: 1454.73

Median: $\quad 1450.99$

Minimum: 1434.91

Shapiro Wilks p: 0.82

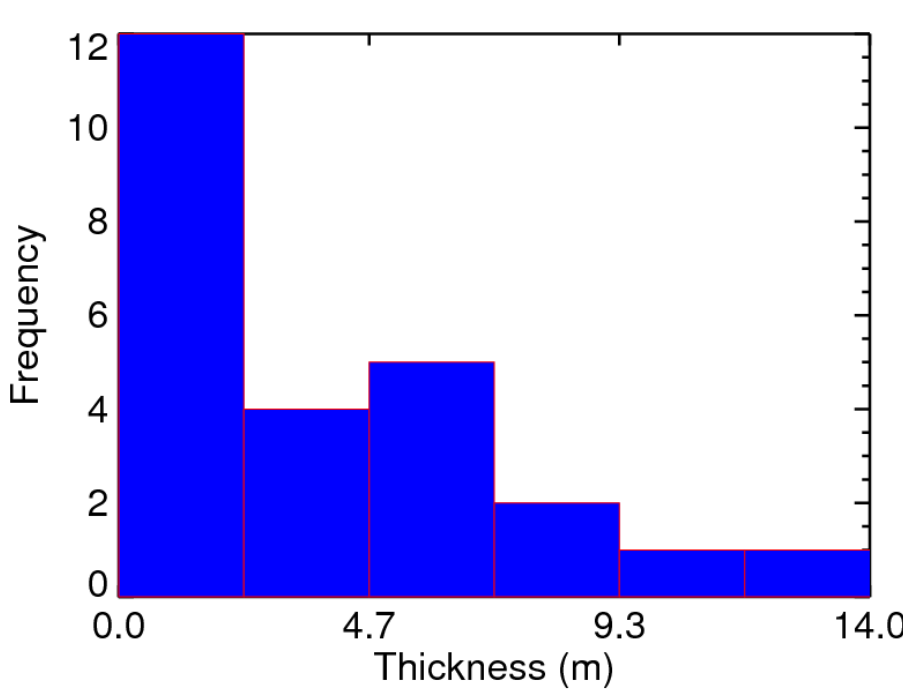

Sediment Unit 4

Data Count: $\quad 23$

Mean: $\quad 4.97$

Variance: $\quad 5.59$

Maximum: $\quad 9.14$

Median: $\quad 5.03$

Minimum: $\quad 0.99$

Shapiro Wilks p: 0.84

Figure 31. Histogram of Sediment Unit 4 elevation (top) and thickness (bottom). Summary statistics for both distributions are shown to the right of each plot.

- Semivariograms for Sediment Unit 4 top elevation are shown in Figure 32 with those for the thickness given in Figure 33. The semivariogram of top elevation is somewhat variable at short lags because of fewer data pairs used in its definition. The empirical semivariograms for thickness are well defined and exhibit little directional difference. An exponential variogram with a 488-m range, $37-\mathrm{m}^{2}$ sill, and zero nugget was fitted to the omnidirectional empirical elevation semivariogram, and thickness was fit with a Gaussian model with zero nugget, $9.3-\mathrm{m}^{2}$ sill, and $610-\mathrm{m}$ range. 

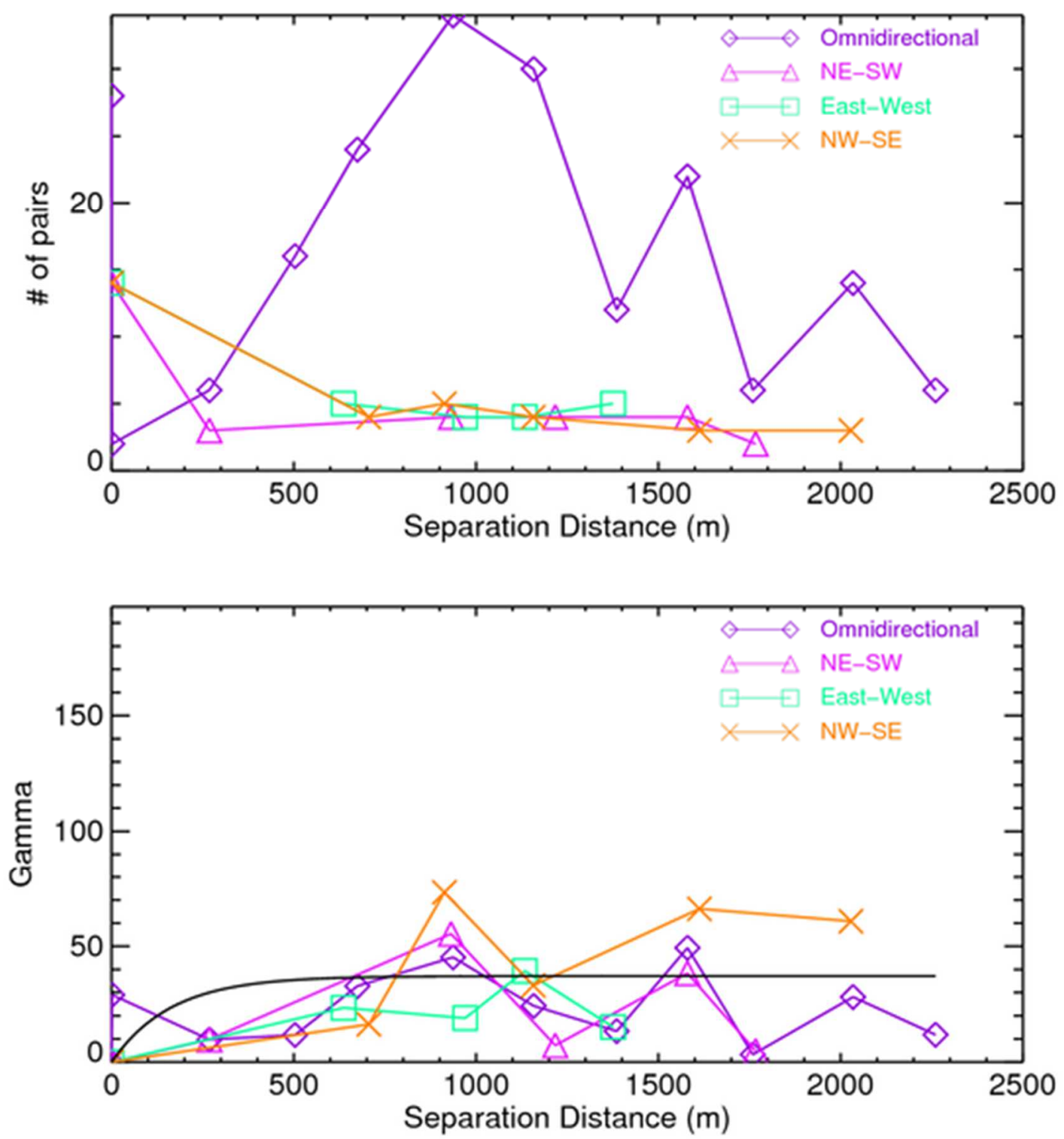

Figure 32. Anisotropic empirical (colored lines and symbols) and modelled (black lines) semivariograms for Sediment Unit 4 top elevation. 

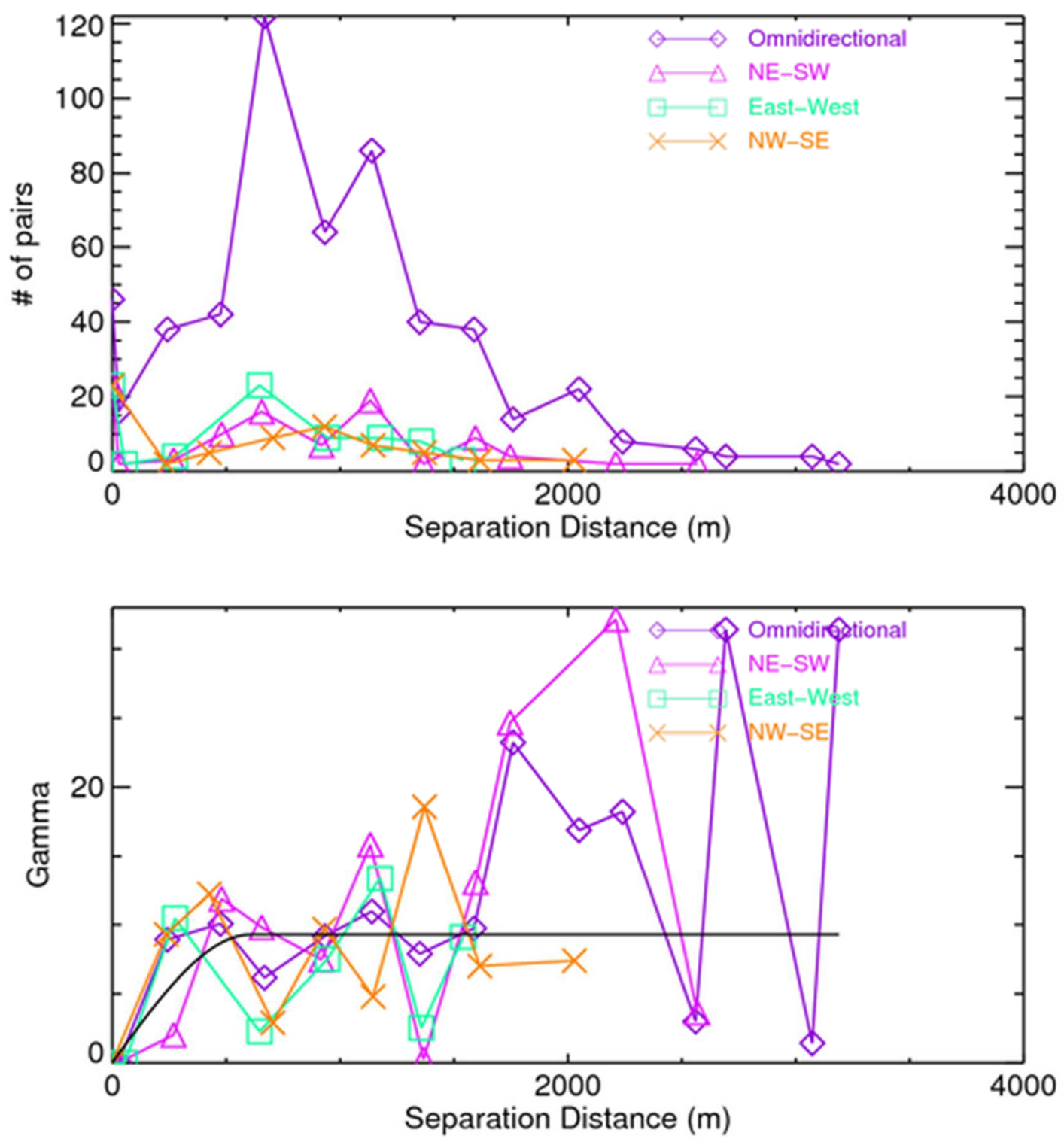

Figure 33. Anisotropic empirical (colored lines and symbols) and modelled (black lines) semivariograms for Sediment Unit 4 thickness.

- Kriging predictions for the sediment top elevation are shown in Figure 34 (left) along with the corresponding kriging variance (right). There is an apparent depression in the top elevation of this unit southeast of the ATR Complex as indicated by the darker region. However, the remaining elevation is quite uniform.

- The kriging predictions for Sediment Unit 4 thickness are shown in Figure 35 (left), along with the corresponding kriging variance (right). This sediment unit appears be thinnest in a north-south trending line running east of the ATR Complex. 
- Given this unit's range $(610 \mathrm{~m})$ and relatively small variance in thickness, wells located near the perimeter of the RH-LLW Disposal Facility location should be sufficient to confirm its existence throughout the facility.
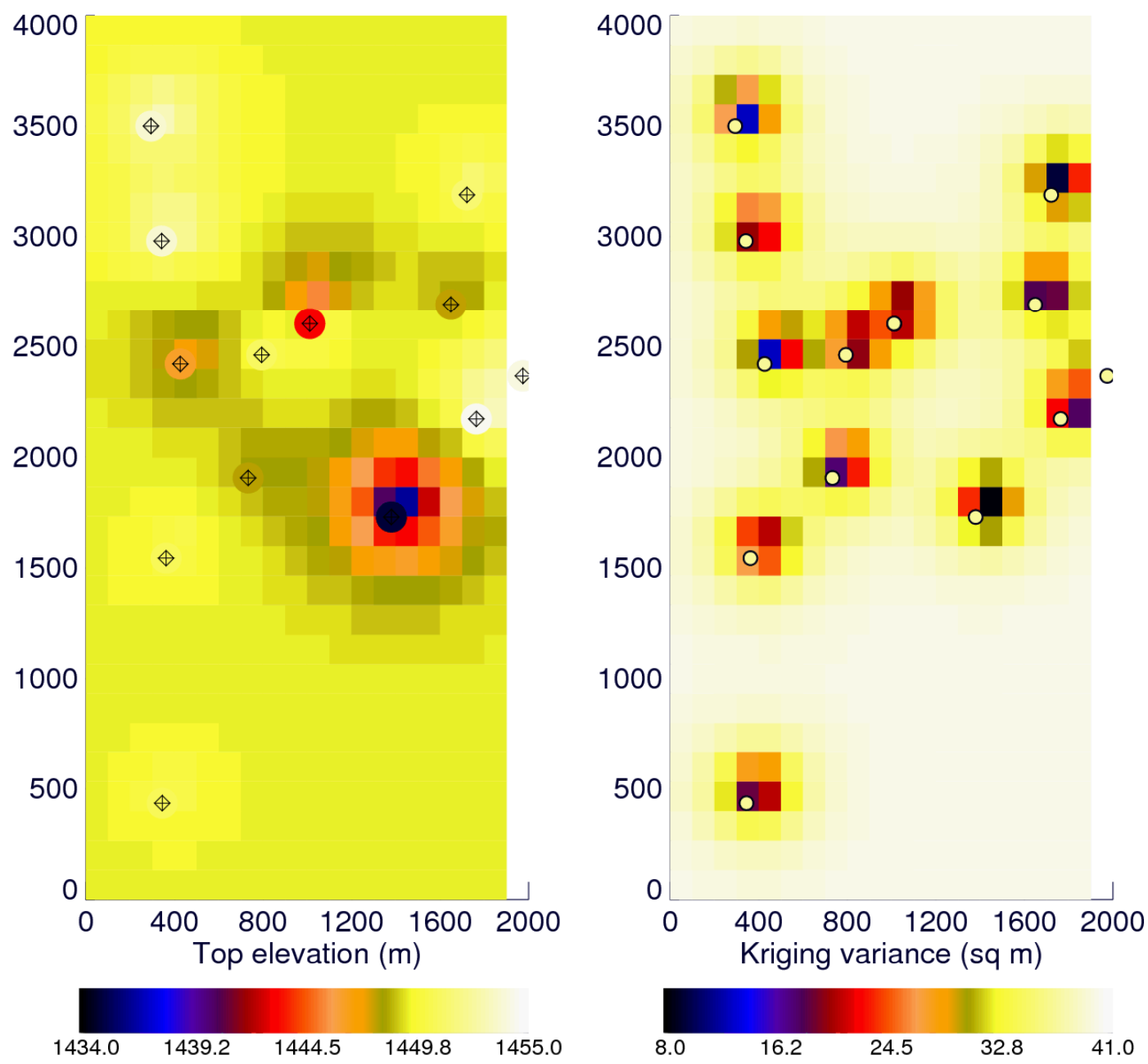

Figure 34. Kriging predictions (left) and kriging variance (right) for Sediment Unit 4 top elevation (m). Points represent sample locations. The gridded area is represented by the box in Figure 1 and the $x-y$ distances (m) are relative to the figure. 

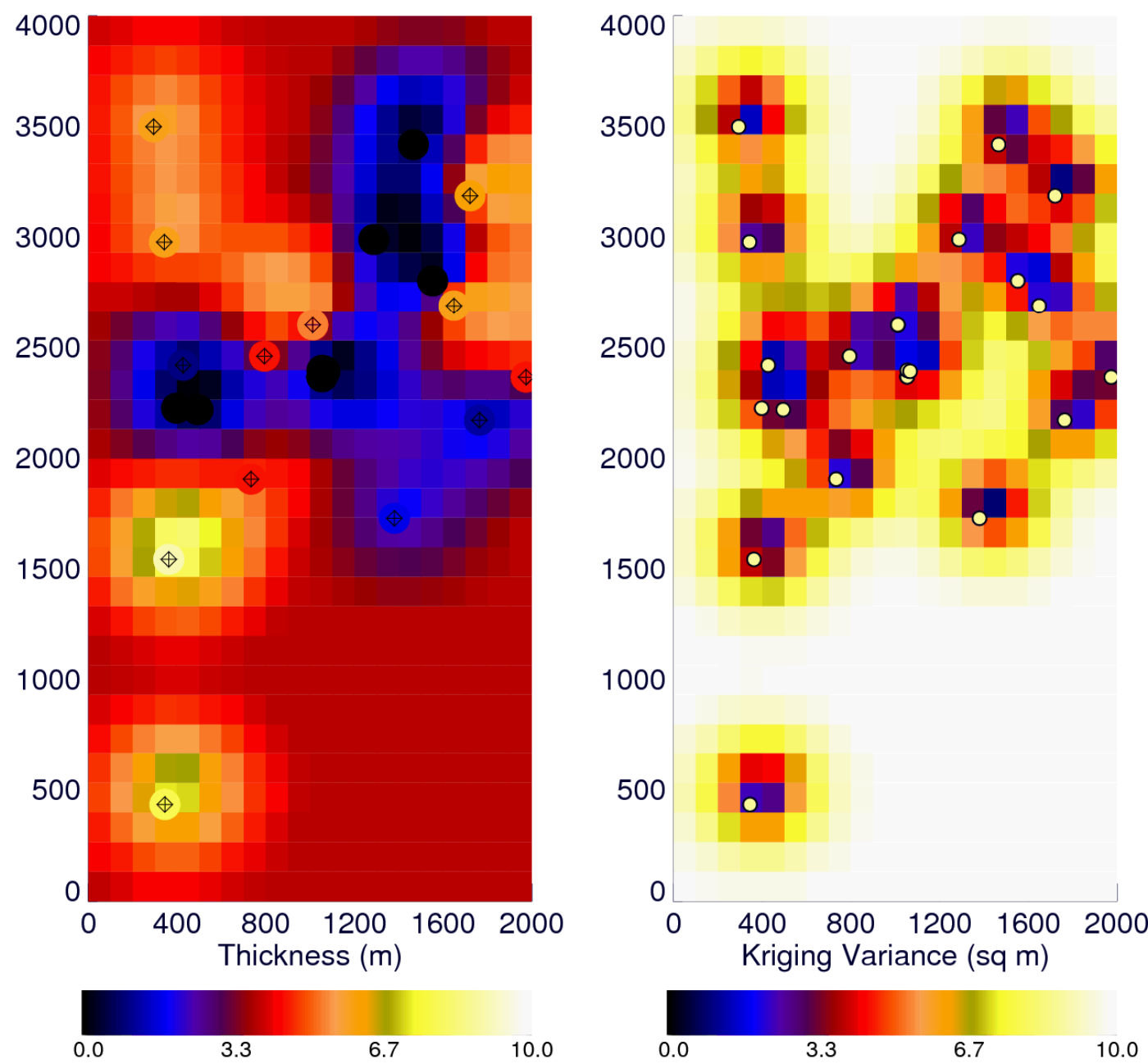

Figure 35. Kriging predictions (left) and kriging variance (right) for Sediment Unit 4 thickness (m). Points represent sample locations. The gridded area is represented by the box in Figure 1 and the $x-y$ distances $(\mathrm{m})$ are relative to the figure.

\subsection{Sediment Unit 5}

Top elevation and thickness of Sediment Unit 5 were defined though the use of 22 wells shown in Figure 36. It was found in 19 of these wells. 


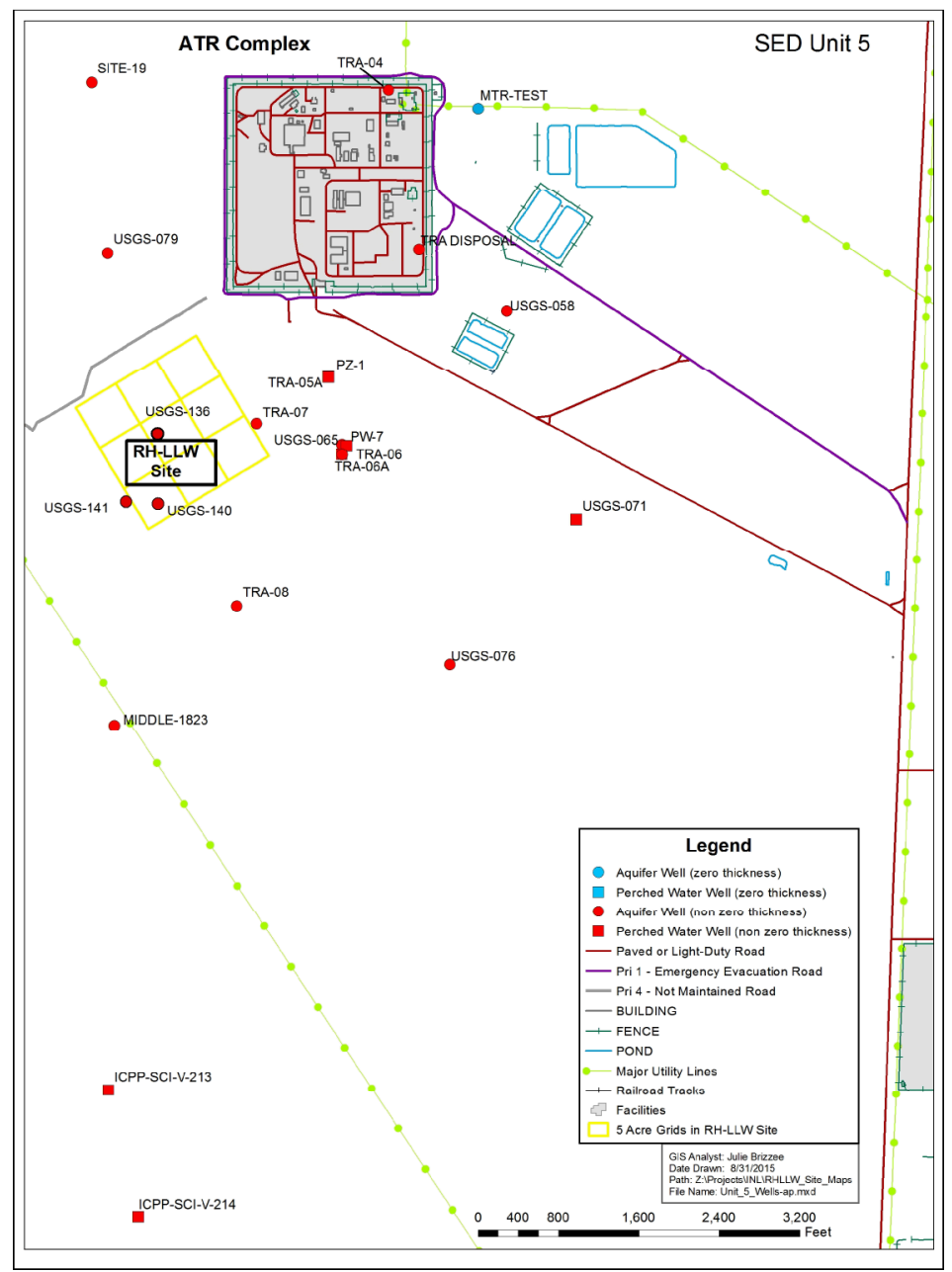

Figure 36. Wells used to define Sediment Unit 5.

\subsubsection{Geostatistical Evaluation}

Histograms for the top elevation and thickness are shown in Figure 37, along with the summary statistical distributions; semivariograms are shown in Figures 38 and 39; spatially kriged top elevation and associated kriging variance are given in Figure 40; and the kriged thickness and kriging variance are shown in Figure 41. The following bullets provide discussion of the figures:

- Sedimentary Unit 5 top elevation approaches a uniform distribution, with several wells containing this unit at an elevation of about $1,440 \mathrm{~m}(4,724 \mathrm{ft})$. This unit appears to become shallower east of the model extent. The top elevation is not log-normal (Shapiro-Wilks test $\mathrm{p}$-value $=0.901$ ).

- The interbed thicknesses exhibit a skewed Gaussian shape but are not log-normal (Figure 37). The average depth of Sediment Unit 5 is about $60 \mathrm{~m}(200 \mathrm{ft})$, roughly $10 \mathrm{~m}$ lower than Sediment Unit 4 and $16 \mathrm{~m}$ deeper than Sediment Unit 3. These three sediment units were likely deposited closely in time and were determined here to represent different units based on clay/cinder content and material color, indicating different source materials as indicated by the fence diagrams contained in Appendix A. They were separated to represent thin interspersed basalt.

- Unit 5 sediment thickness ranges up to $8.5 \mathrm{~m}$ (about $28 \mathrm{ft}$ ), with standard deviation of $2 \mathrm{~m}(6.5 \mathrm{ft})$ where present, making this unit one of the thickest underlying the study area. As indicated in the cross-sections shown in Appendix A and in the kriged results that follows, the thinnest occurrences of Sediment Unit 5 are found north and east of the ATR Complex. 
- In the 18 locations closest to the RH-LLW Disposal Facility site (i.e., USGS-136, USGS-140, USGS-141, USGS-065, TRA-06, TRA-07, and Borings 7 through 18), the average thickness is $5.5 \mathrm{~m}(17.9 \mathrm{ft})$.

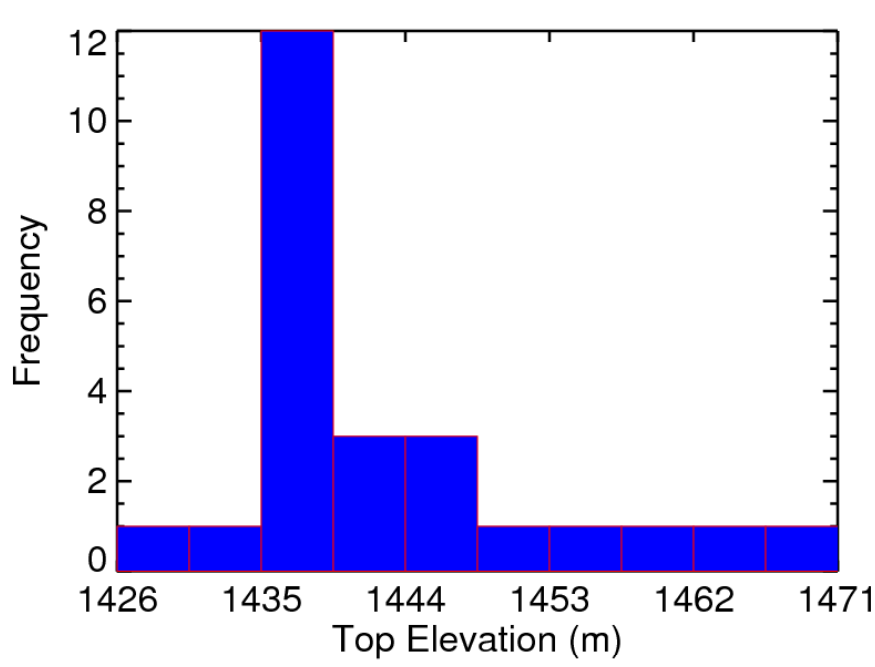

Sediment Unit 5

Data Count: $\quad 21$

Mean: $\quad 1439.65$

Variance: $\quad 43.82$

Maximum: 1454.67

Median: $\quad 1438.94$

Minimum: 1421.42

Shapiro Wilks p: 0.90

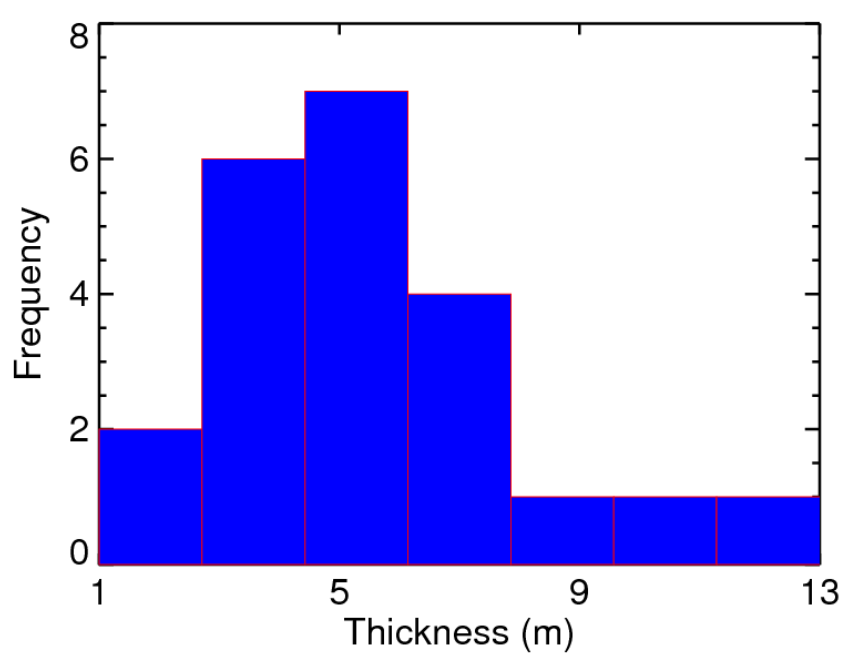

Sediment Unit 5

Data Count: $\quad 22$

Mean: $\quad 4.61$

Variance: $\quad 4.20$

Maximum: $\quad 8.53$

Median: $\quad 4.57$

Minimum: $\quad 0.61$

Shapiro Wilks p: 0.98

Figure 37. Histogram of Sediment Unit 5 elevation (top) and thickness (bottom). Summary statistics for both distributions are shown to the right of each plot.

- Semivariograms for Sediment Unit 5 top elevation are shown in Figure 38. The omnidirectional semivariogram was fit with an exponential model with a 55.8- $\mathrm{m}^{2}$ sill, 914-m range, and zero nugget. The semivariogram for Sediment Unit 5 thickness is shown in Figure 39. Increased data density at short lag distances is apparent for thickness versus top elevation. There is very little difference in thickness spatial continuity as a function of direction. The omnidirectional empirical semivariogram was fit with an exponential model with 3.7-m nugget, 5.6- $\mathrm{m}^{2}$ sill, and 914-m range. 

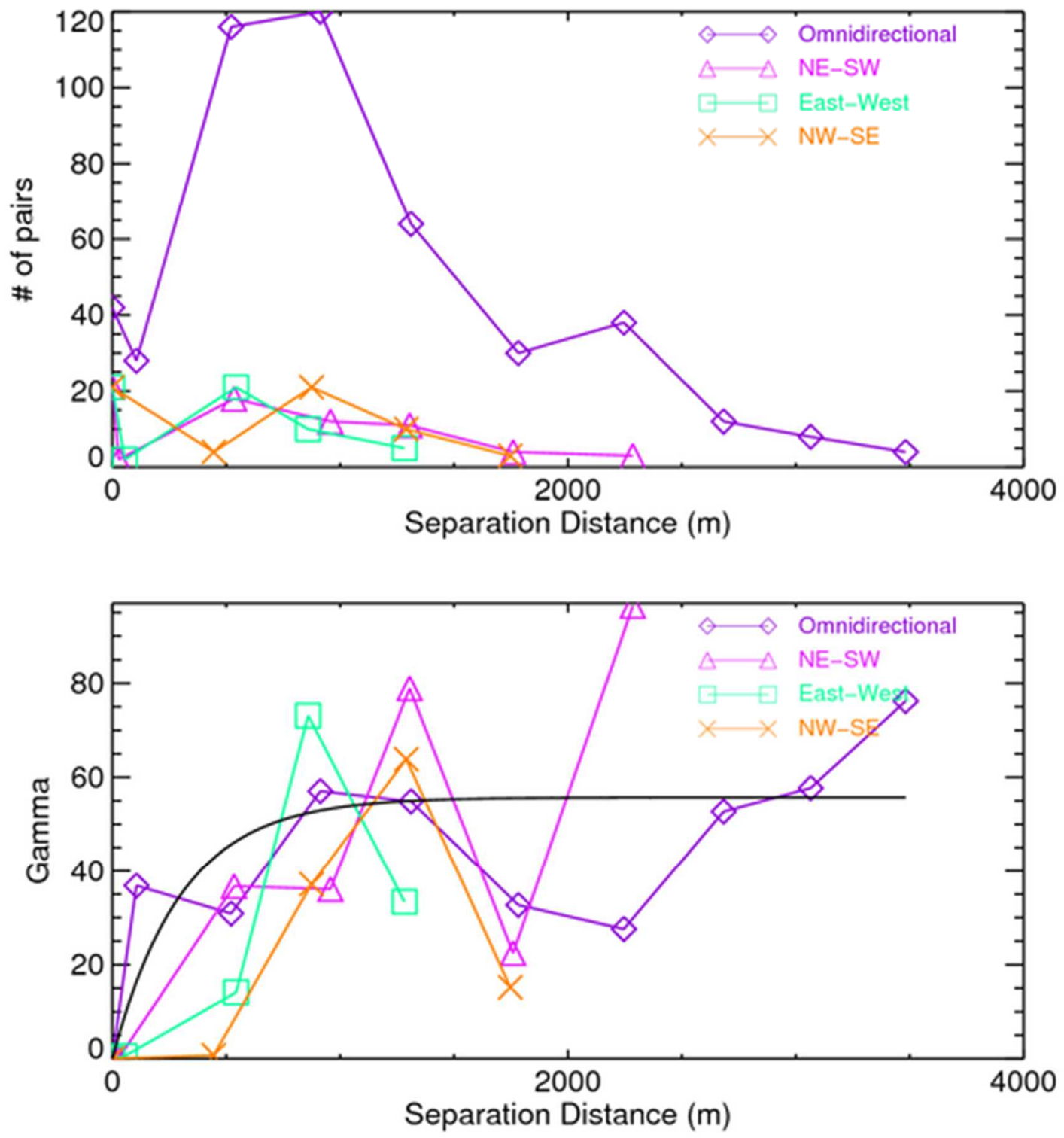

Figure 38. Anisotropic empirical (colored lines and symbols) and modelled (black lines) semivariograms for Sediment Unit 5 top elevation. 

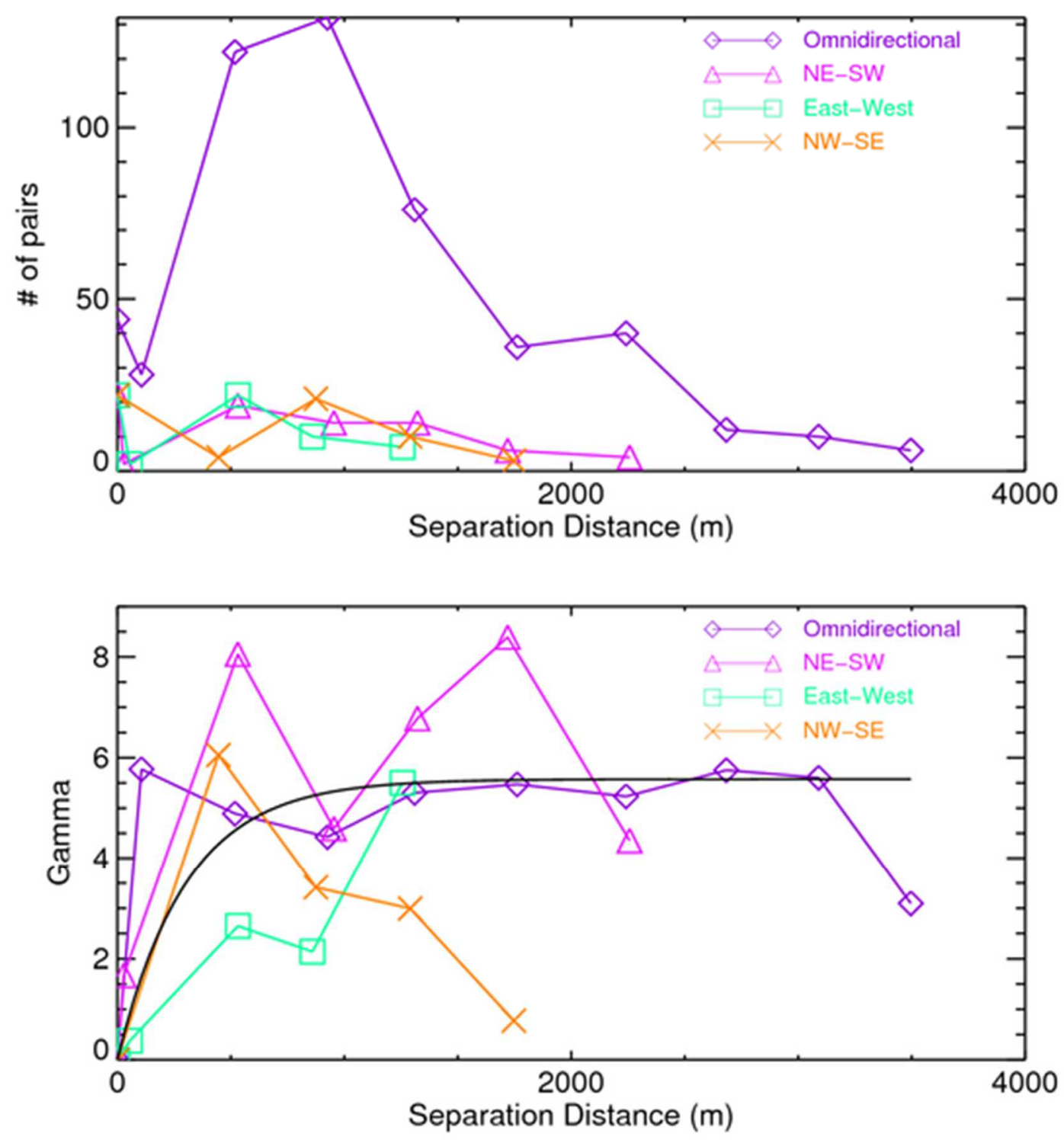

Figure 39. Anisotropic empirical (colored lines and symbols) and modelled (black lines) semivariograms for Sediment Unit 5 thickness.

- Kriging predictions for the sediment top elevation are shown in Figure 40 (left), along with the corresponding kriging variance (right). The variogram was fit with a $6.9-\mathrm{m}$ standard deviation for elevation and 914-m range.

- The kriging predictions for Sediment Unit 5 thickness are shown in Figure 41 (left), along with the corresponding kriging variance (right). The thickness of this sediment unit appears be relatively uniform throughout the central study area. However, there is a small trough of thicker sediment along a northeast to southwest trending line running southeast of the RH-LLW Disposal Facility area. 
- Additional wells should be spaced at the range distance (about $914 \mathrm{~m}$ ) for additional characterization if the RH-LLW Disposal Facility is expanded.
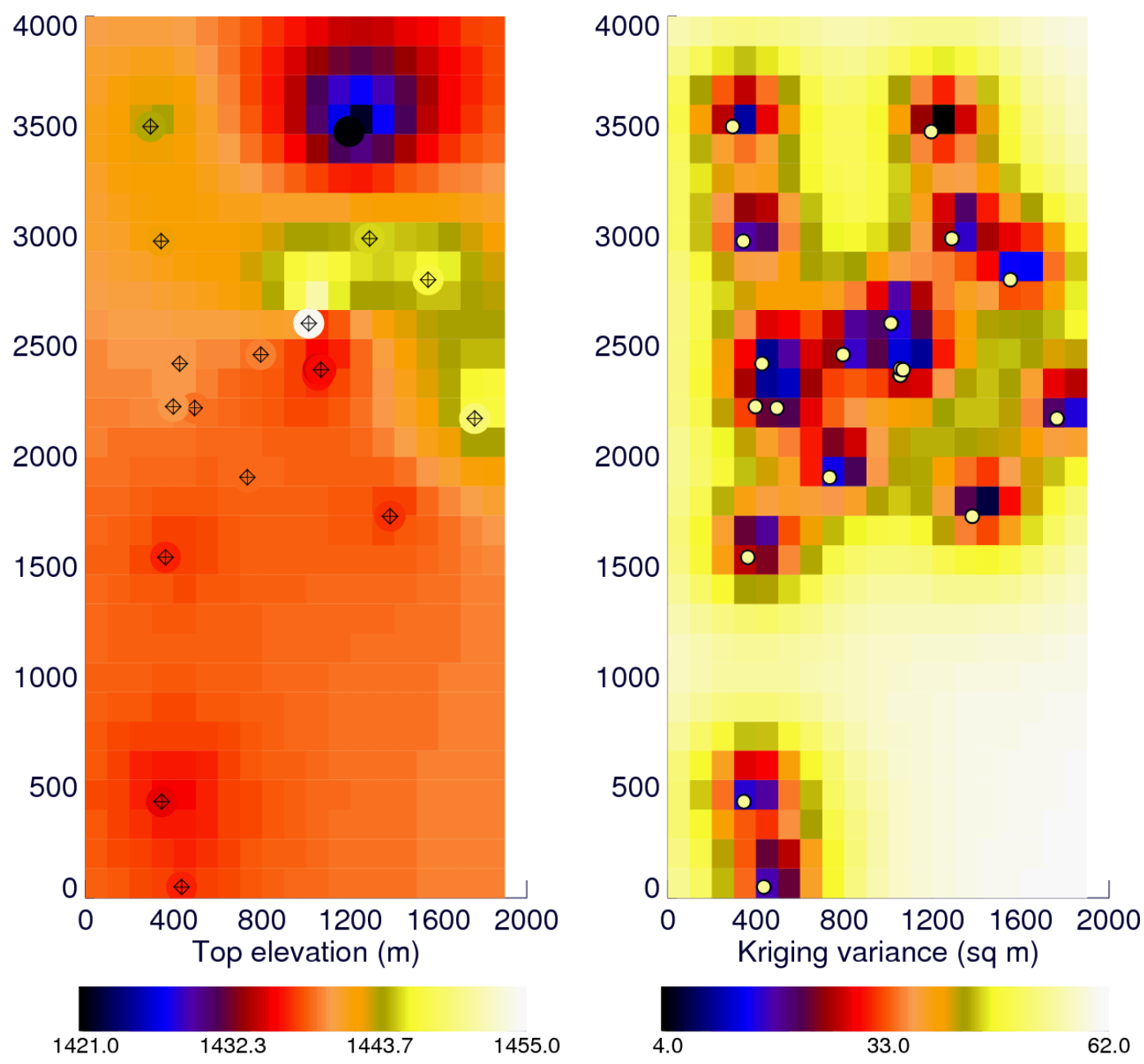

Figure 40. Kriging predictions (left) and kriging variance (right) for Sediment Unit 5 top elevation (m). Points represent sample locations. The gridded area is represented by the box in Figure 1 and the $x-y$ distances (m) are relative to the figure. 

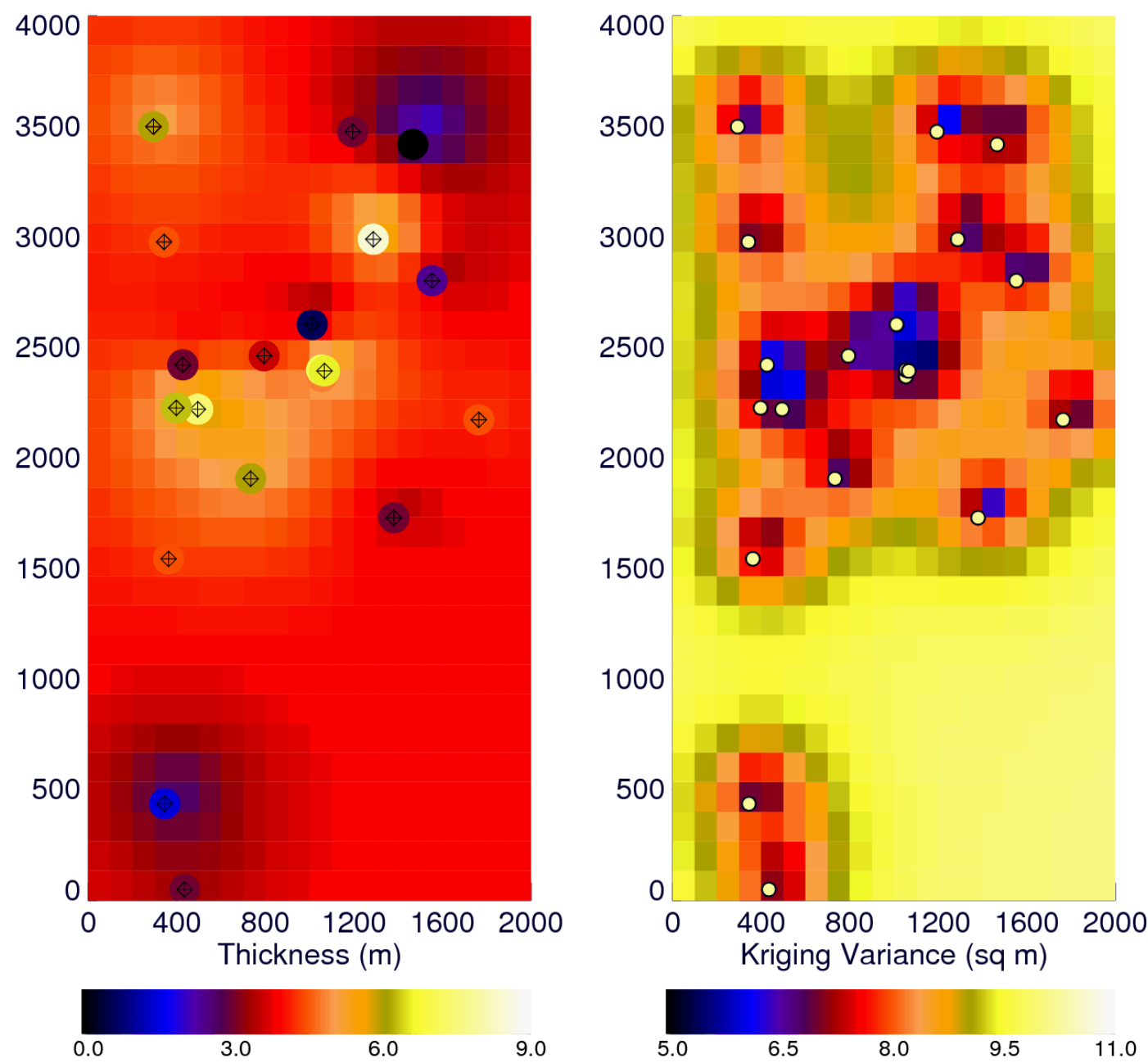

Figure 41. Kriging predictions (left) and kriging variance (right) for Sediment Unit 5 thickness (m). Points represent sample locations. The gridded area is represented by the box in Figure 1 and the $x-y$ distances $(\mathrm{m})$ are relative to the figure.

\subsection{Sediment Unit 6}

Sediment Unit 6 was present in eight of the 18 wells with depth sufficient to penetrate this unit. The wells deep enough to define the thickness and extent of this unit are shown in Figure 42. 


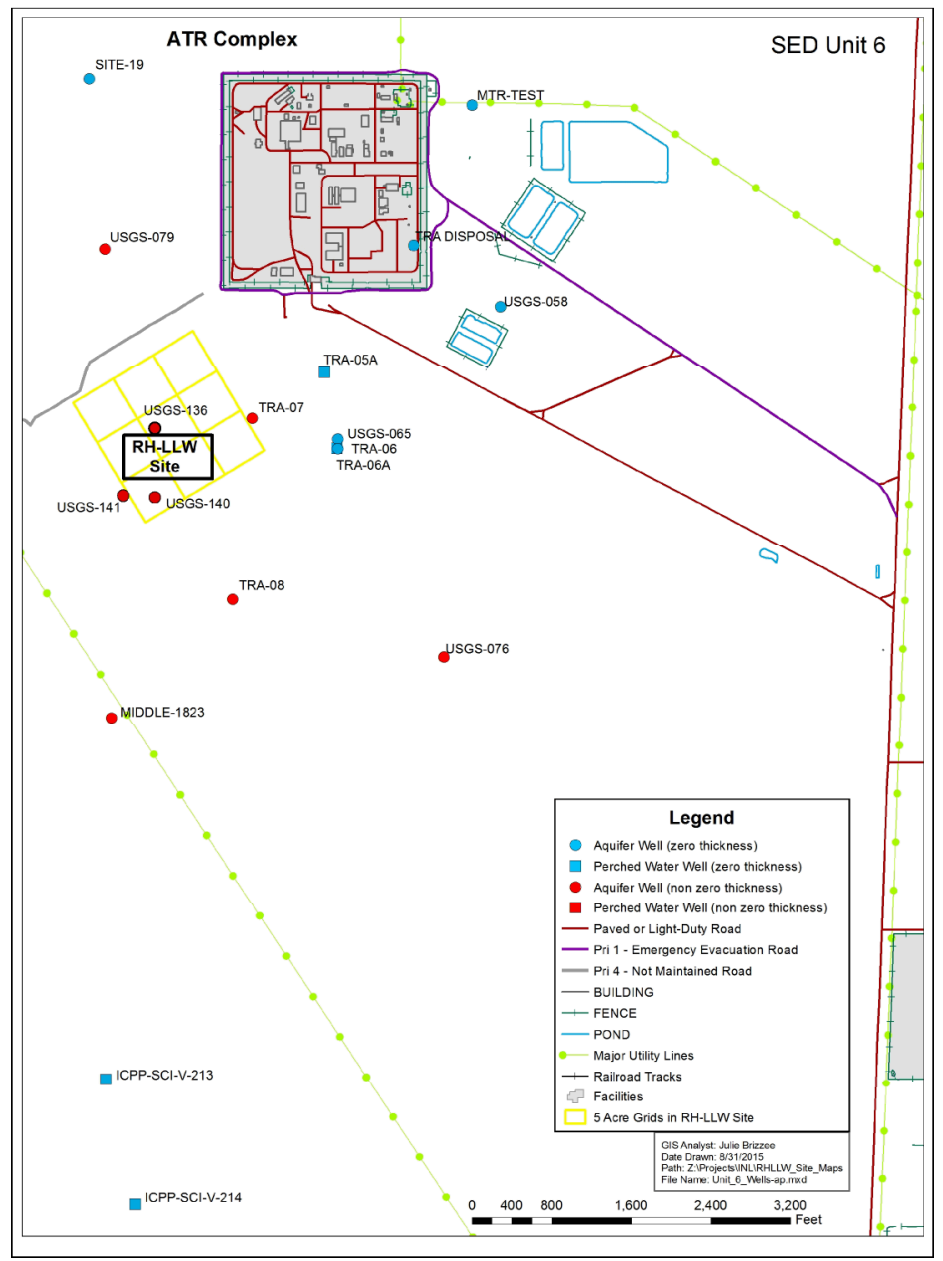

Figure 42. Wells used to define Sediment Unit 6.

\subsubsection{Geostatistical Evaluation}

Histograms for the top elevation and thickness are shown in Figure 43, along with the summary statistical distributions; semivariograms are shown in Figures 44 and 45; spatially kriged top elevation and associated kriging variance are given in Figure 46; and the kriged thickness and kriging variance are shown in Figure 47. The following bullets provide discussion of the figures:

- In the eight wells containing this unit, the mean top elevation is $1,427 \mathrm{~m}(4,682 \mathrm{ft})$, with a standard deviation of $2.4 \mathrm{~m}(7.9 \mathrm{ft})$. The standard deviation in thickness is lower and equal to $1.4 \mathrm{~m}$ $(4.6 \mathrm{ft})$ where the unit exists, with a mean thickness of $3 \mathrm{~m}(9.9 \mathrm{ft})$.

- The statistical distribution of top elevation is relatively uniform, corresponding to the base of Sediment Unit 5 in wells TRA-08 and Middle-1823, as shown in the fence diagrams in Appendix A. This suggests that this unit might merge with Sediment Unit 5 to the south, but the well logs are not sufficiently detailed to allow distinction from Sediment Unit 5

- In the wells containing this unit, the interbed thickness ranges up to $4.6 \mathrm{~m}$ (about $15 \mathrm{ft}$ ) east of the ATR Complex.

- In the 18 locations closest to the RH-LLW Disposal Facility site (i.e., USGS-136, USGS-140, USGS-141, USGS-065, TRA-06, TRA-07, and Borings 7 through 18), the average thickness is $1.3 \mathrm{~m}(4.4 \mathrm{ft})$. 


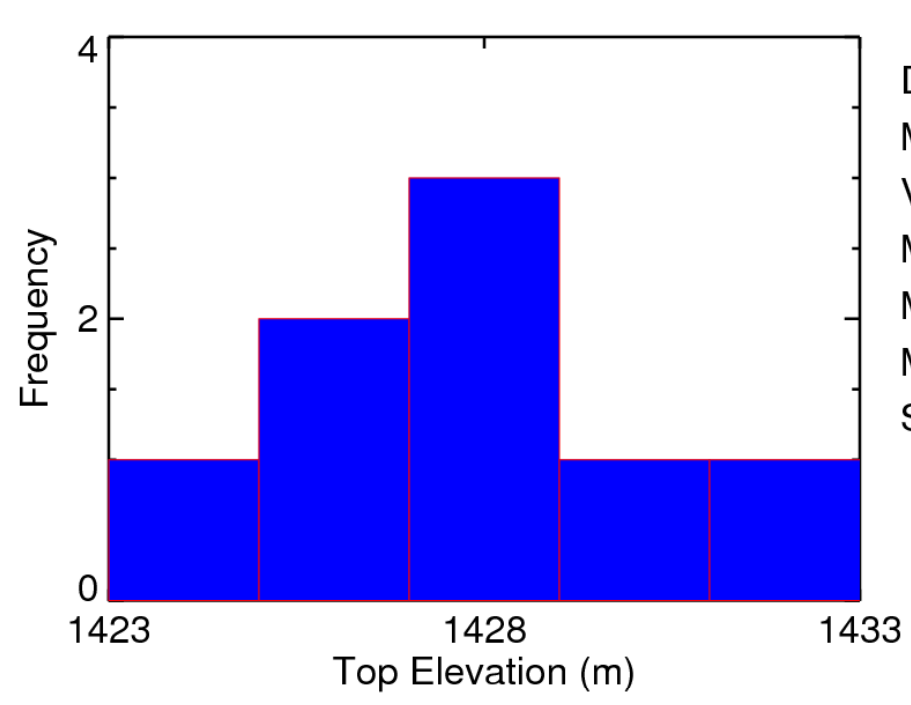

Sediment Unit 6

Data Count: $\quad 8$

Mean: $\quad 1427.22$

Variance: $\quad 5.80$

Maximum: 1431.04

Median: $\quad 1427.11$

Minimum: 1423.27

Shapiro Wilks p: 0.99

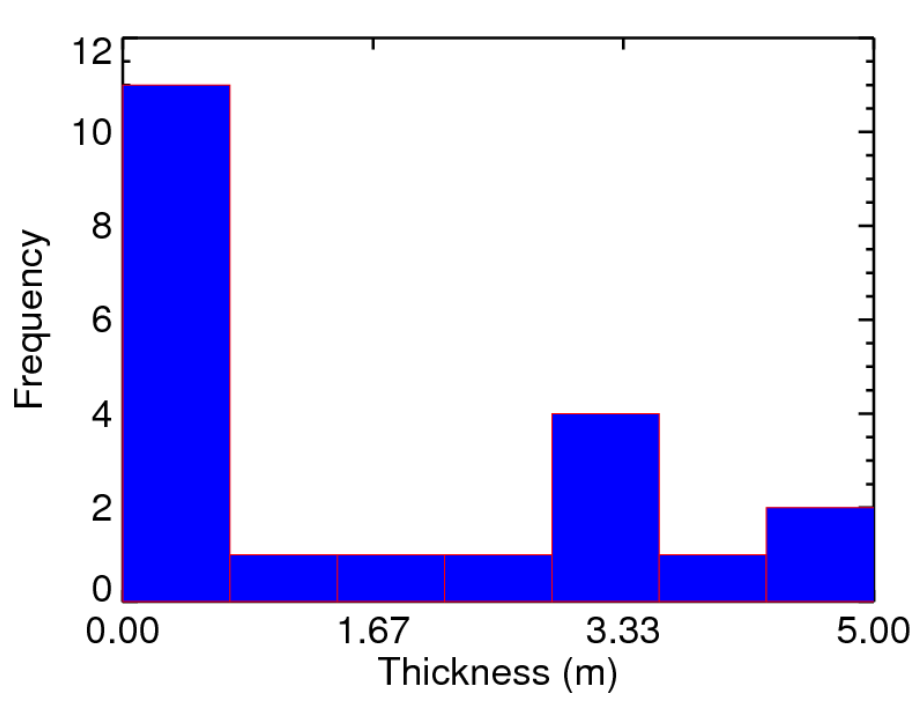

Sediment Unit 6

Data Count: 18

Mean: $\quad 2.95$

Variance: $\quad 2.02$

Maximum: $\quad 4.57$

Median: $\quad 3.05$

Minimum: $\quad 0.23$

Shapiro Wilks p: 0.73

Figure 43. Histogram of Sediment Unit 6 elevation (top) and thickness (bottom). Summary statistics for both distributions are shown to the right of each plot.

- The semivariograms for Sediment Unit 6 top elevation are shown in Figure 44. The omnidirectional semivariogram was fit with an exponential model with a $7.4-\mathrm{m}^{2}$ sill, 457-m range, and zero nugget.

- The semivariogram for Sediment Unit 6 thickness is shown in Figure 45. The exponential model sill for thickness was estimated to be $3.3 \mathrm{~m}^{2}$, the range is on the order of $869 \mathrm{~m}$, and a zero nugget was used. 

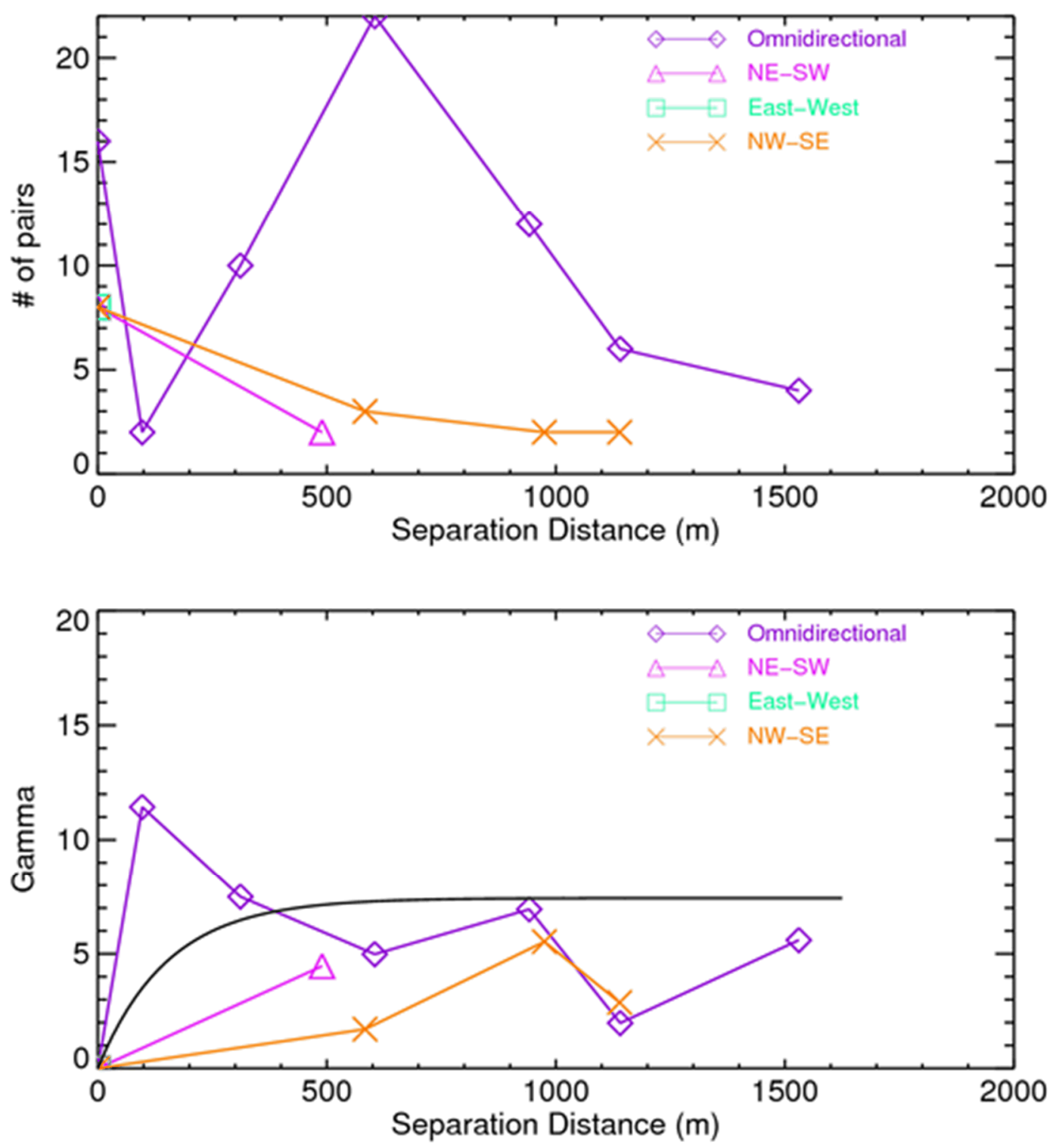

Figure 44. Anisotropic empirical (colored lines and symbols) and modelled (black lines) semivariograms for Sediment Unit 6 top elevation. 

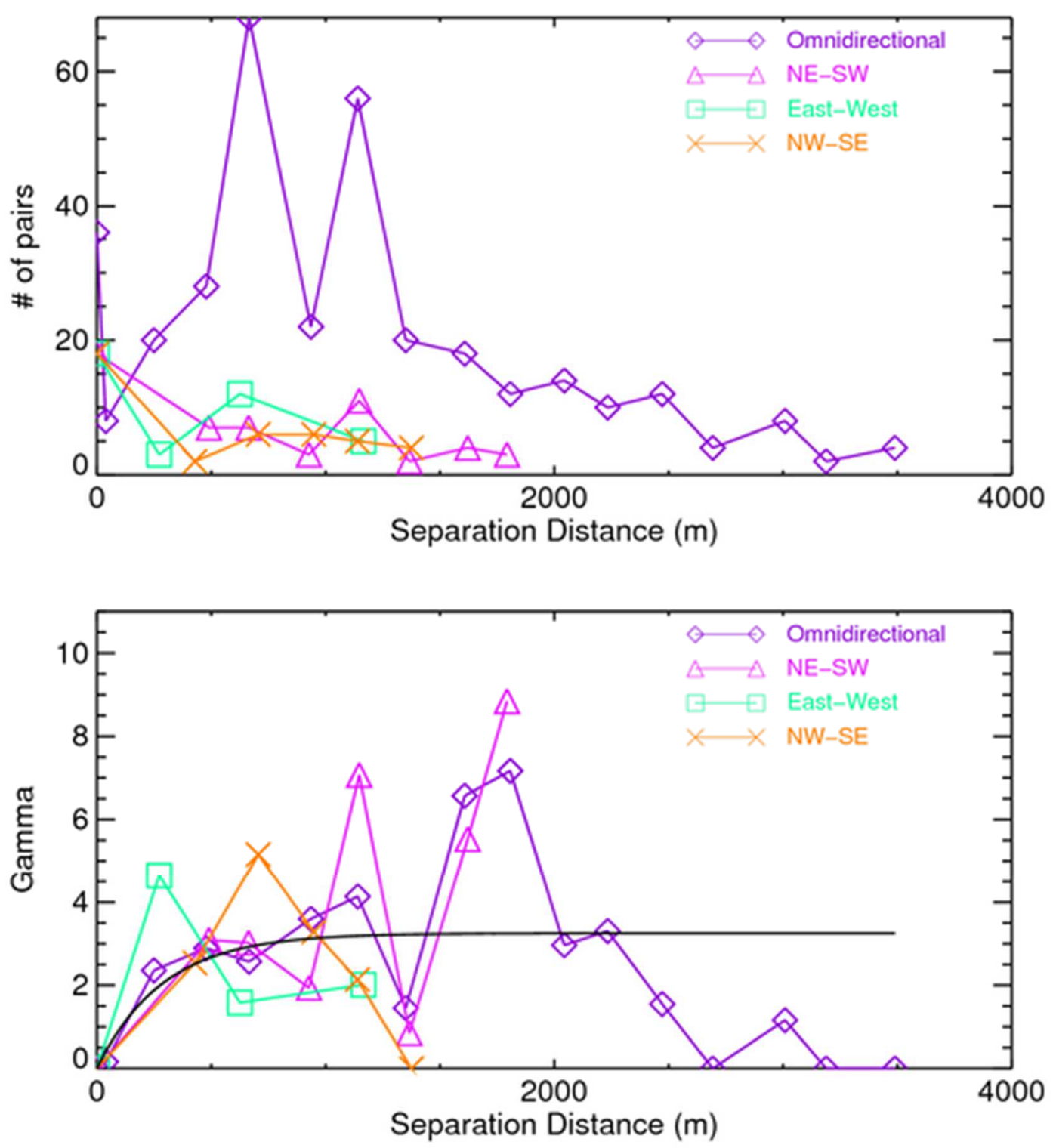

Figure 45. Anisotropic empirical (colored lines and symbols) and modelled (black lines) semivariograms for Sediment Unit 6 thickness.

- Kriging predictions on a $20 \times 30$ grid for the sediment top elevation are shown in Figure 46 (left), along with the corresponding kriging variance (right).

- The kriging predictions for Sediment Unit 6 thickness are shown in Figure 47 (left), along with the corresponding kriging variance (right). This sediment unit appears be localized to a region south to southeast of the RH-LLW Disposal Facility. 

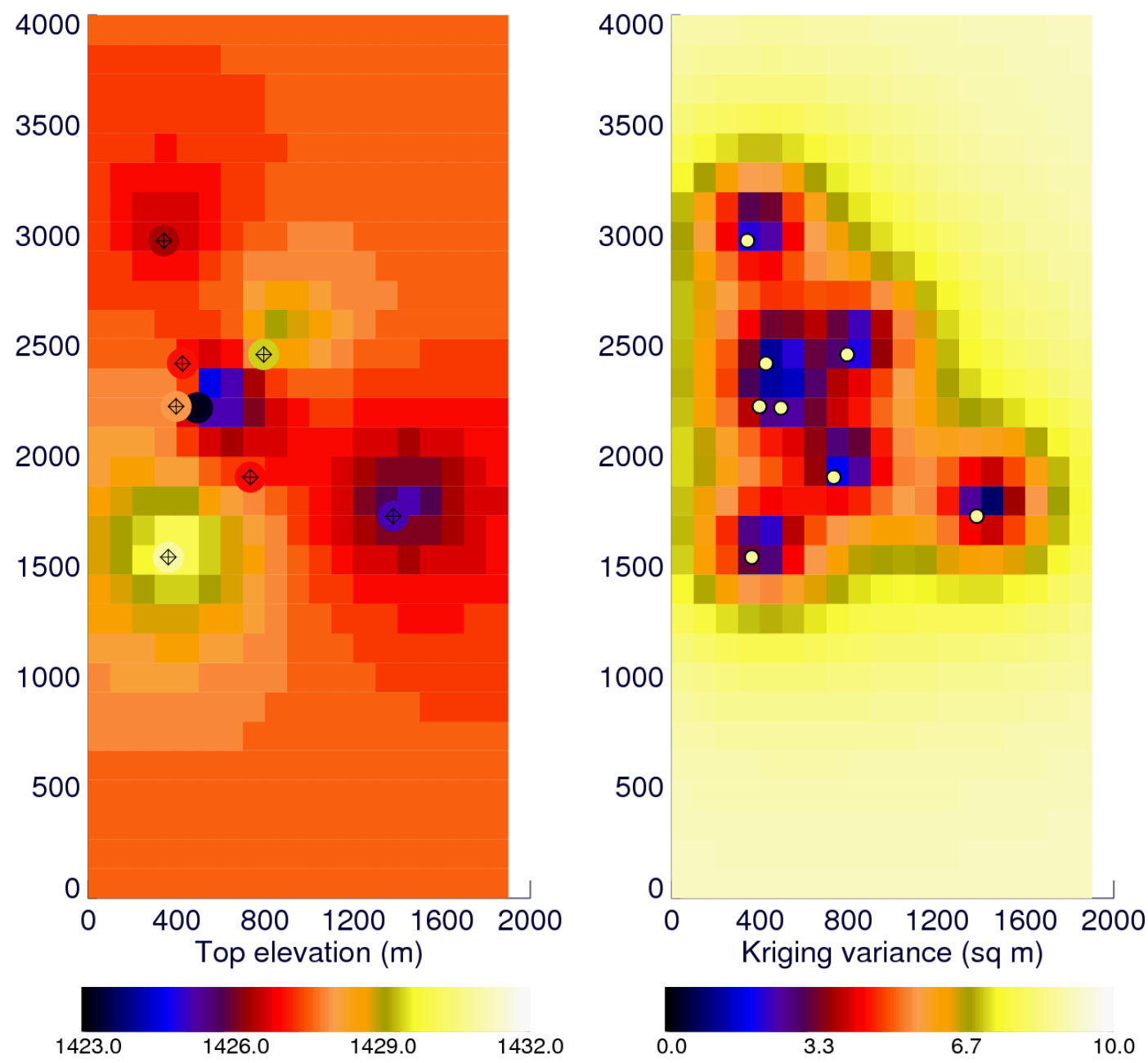

Figure 46. Kriging predictions (left) and kriging variance (right) for Sediment Unit 6 top elevation (m). Points represent sample locations. The gridded area is represented by the box in Figure 1 and the $x-y$ distances $(\mathrm{m})$ are relative to the figure. 

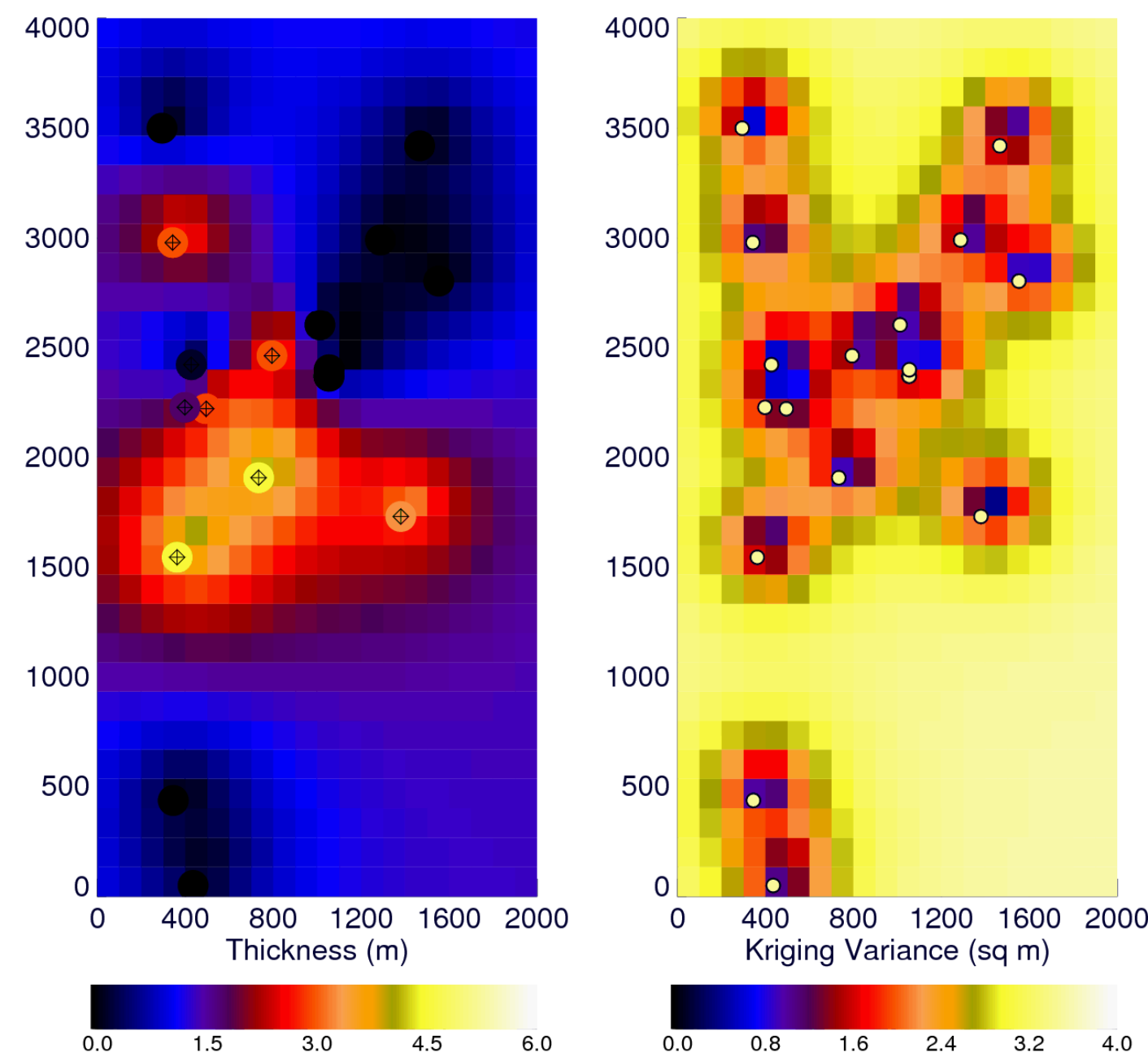

Figure 47. Kriging predictions (left) and kriging variance (right) for Sediment Unit 6 thickness (m). Points represent sample locations. The gridded area is represented by the box in Figure 1 and the $x-y$ distances $(\mathrm{m})$ are relative to the figure.

\subsection{Sediment Unit 7}

The 21 wells used in analysis of Sediment Unit 7 are shown in Figure 48. Sediment Unit 7 was found in 17 of the 21 wells. 


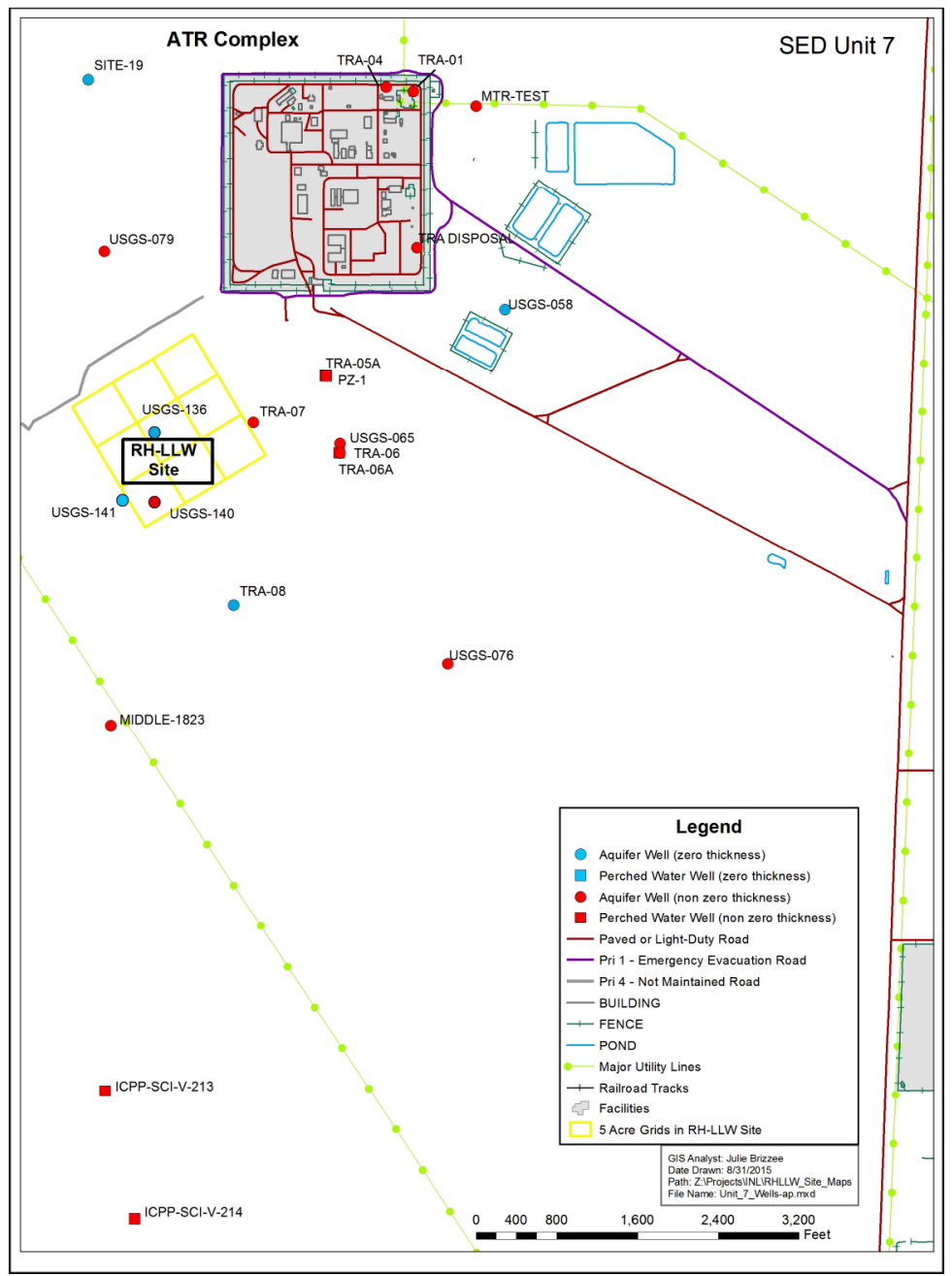

Figure 48. Wells used to define Sediment Unit 7.

\subsubsection{Geostatistical Evaluation}

Histograms for the top elevation and thickness are shown in Figure 49, along with the summary statistical distributions; semivariograms are shown in Figures 50 and 51; spatially kriged top elevation and associated kriging variance are given in Figure 52; and the kriged thickness and kriging variance are shown in Figure 53. The following bullets provide discussion of the figures:

- In the 18 locations closest to the RH-LLW Disposal Facility site (i.e., USGS-136, USGS-140, USGS-141, USGS-065, TRA-06, TRA-07, and Borings 7 through 18), the average thickness is $2.7 \mathrm{~m}(9 \mathrm{ft})$.

- The statistical distribution of top elevation approaches a gaussian distribution, with two outlying lower elevations northeast of the ATR Complex. The average top elevation is $1,417 \mathrm{~m}(4,649 \mathrm{ft})$, corresponding to a depth of $83 \mathrm{~m}(270 \mathrm{ft})$ with a standard deviation of $6.1 \mathrm{~m}$.

- The overall mean interbed thickness is $3.1 \mathrm{~m}(10 \mathrm{ft})$, with a standard deviation of $2.6 \mathrm{~m}(8.5 \mathrm{ft})$. Unit 7 sediment thickness ranges up to $9.1 \mathrm{~m}$ (about $30 \mathrm{ft}$ ), with thickest sediment due south of the ATR Complex. The unit is thinner to the west and south of the ATR Complex, making this unit one of the thinner connected units underlying the study area. 


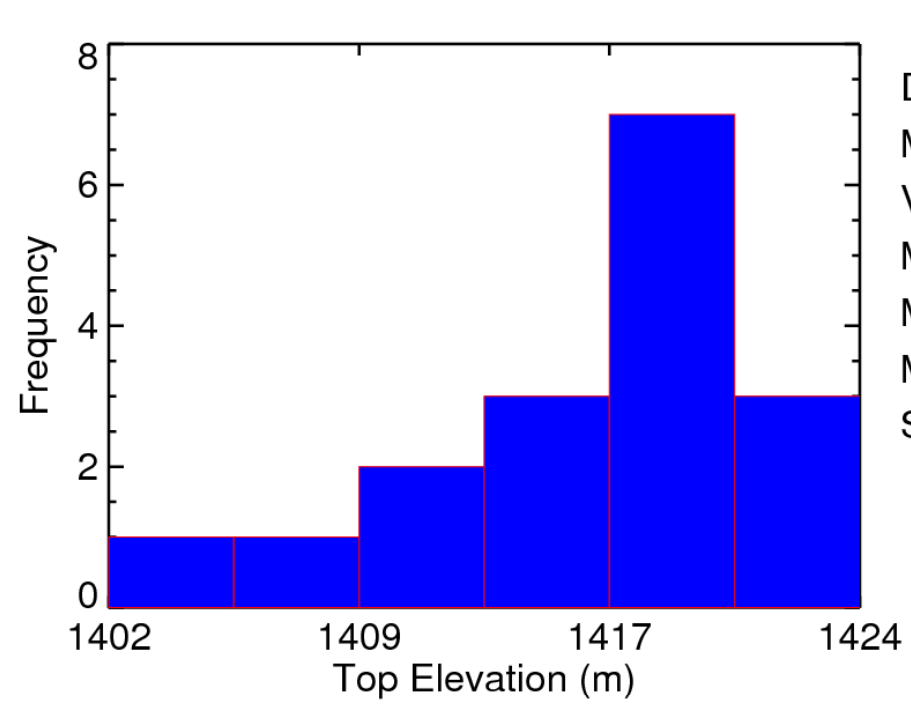

Sediment Unit 7

Data Count: $\quad 17$

Mean: $\quad 1415.50$

Variance: $\quad 36.16$

Maximum: 1421.42

Median: $\quad 1417.32$

Minimum: 1396.91

Shapiro Wilks p: 0.80

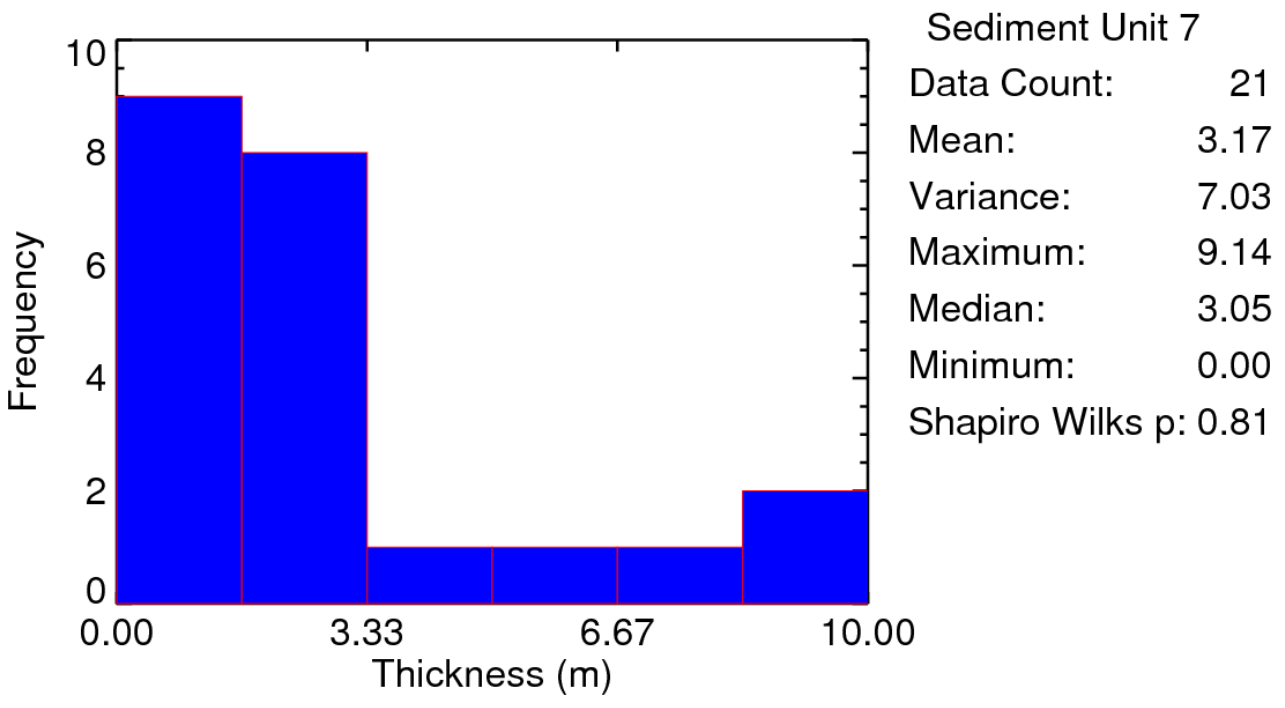

Figure 49. Histogram of Sediment Unit 7 elevation (top) and thickness (bottom). Summary statistics for both distributions are shown to the right of each plot.

- The semivariogram for Sediment Unit 7 top elevation is shown in Figure 50. The omnidirectional semivariogram was fit with an exponential model with a $27.9-\mathrm{m}^{2}$ sill, $457-\mathrm{m}$ range, and zero nugget.

- The semivariogram for Sediment Unit 7 thickness is shown in Figure 51. The apparent range is longer for thickness $(610 \mathrm{~m})$ and was fit with an exponential model with 7.4-m sill and zero nugget. 

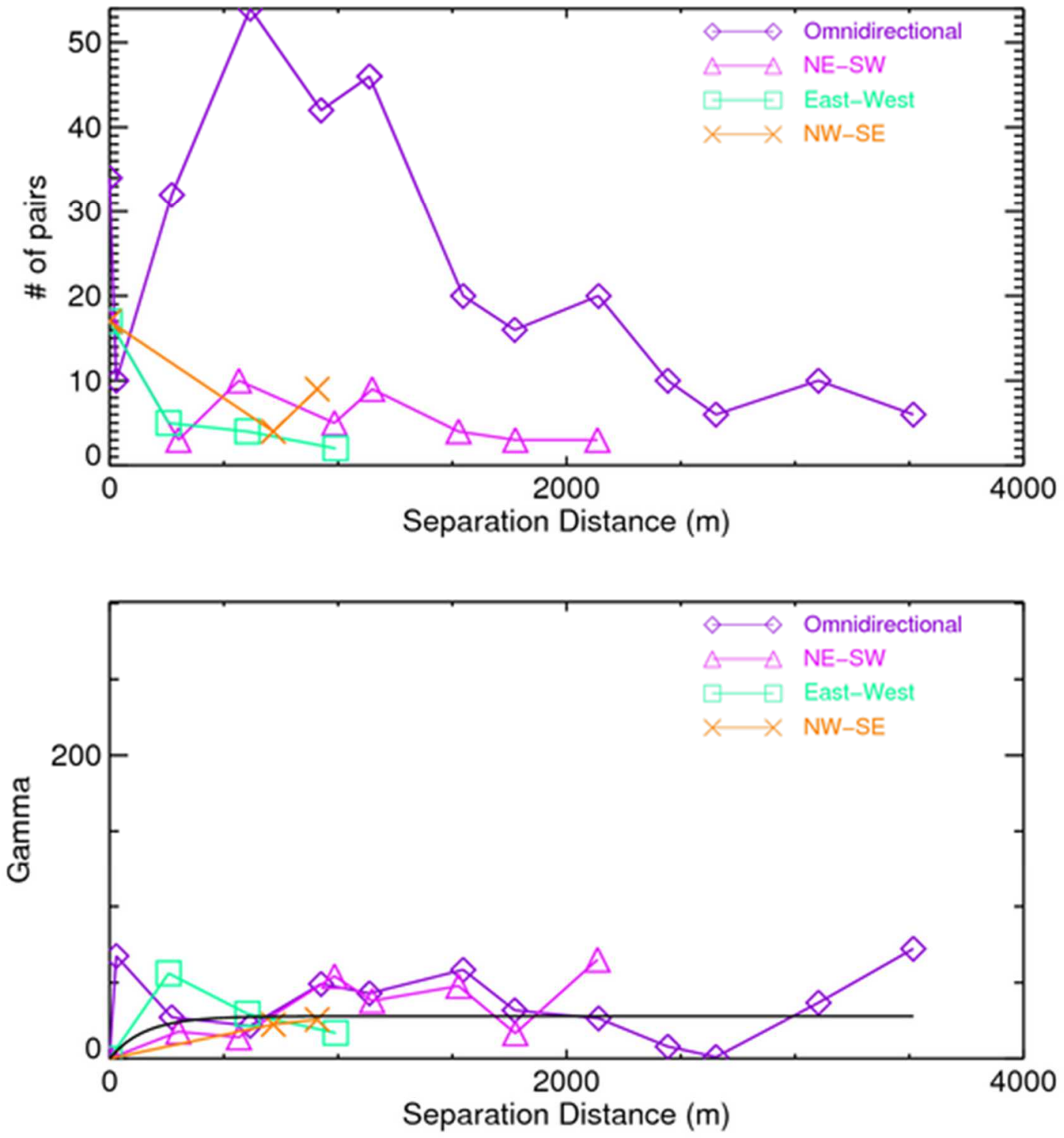

Figure 50. Anisotropic empirical (colored lines and symbols) and modelled (black lines) semivariograms for Sediment Unit 7 top elevation. 

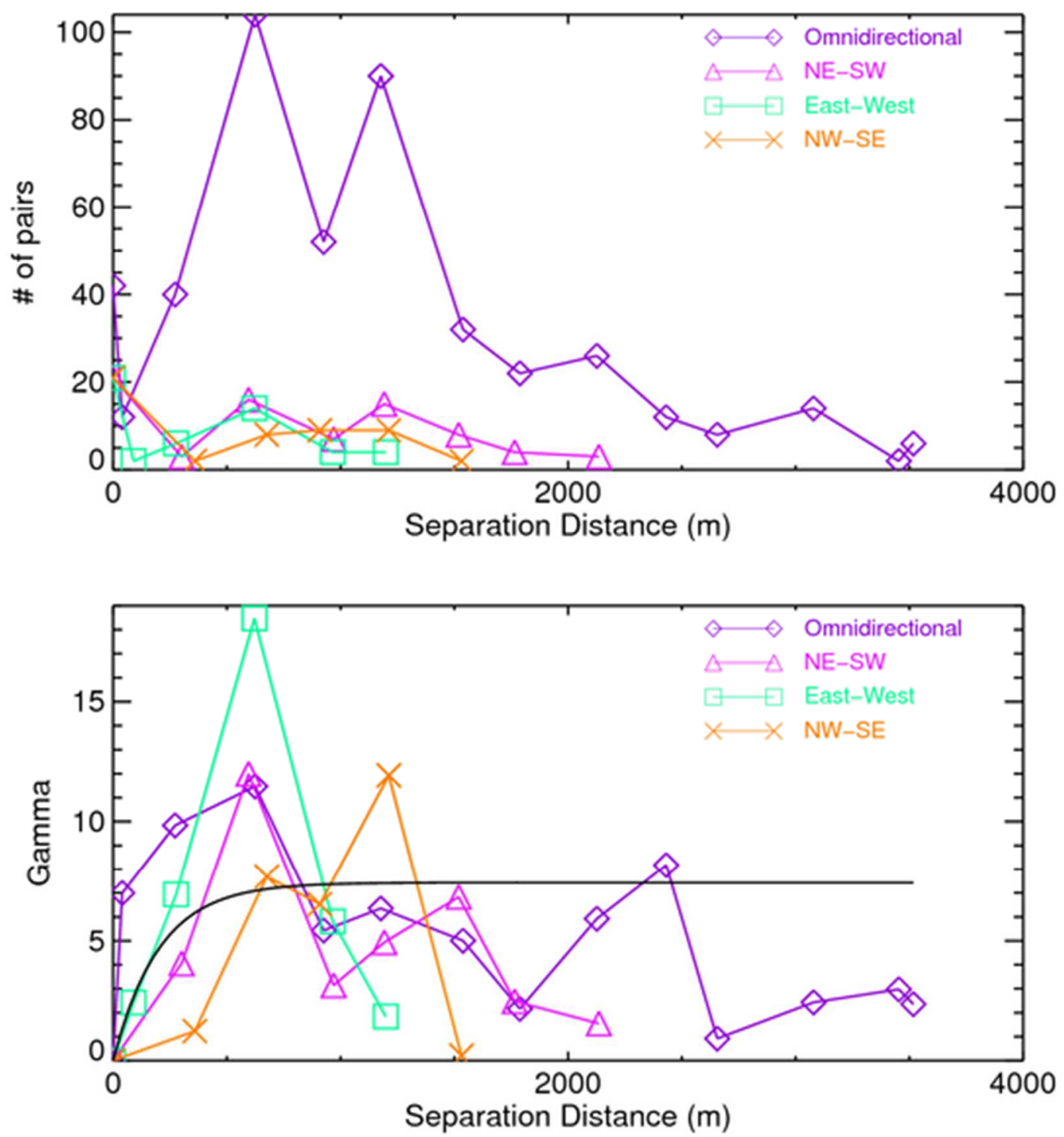

Figure 51. Anisotropic empirical (colored lines and symbols) and modelled (black lines) semivariograms for Sediment Unit 7 thickness.

- Kriging predictions for the sediment top elevation are shown in Figure 52 (left), along with the corresponding kriging variance (right). Sample density throughout the study area is fairly uniform. The relatively long top elevation correlation length is represented by largely connected intermediate-to-low relative values of kriging variance. The high standard deviation in elevation is likely biased high by wells TRA-01 and USGS-058, located northeast of the ATR Complex.

- The kriging predictions for Sediment Unit 7 thickness are shown in Figure 53 (left), with the corresponding kriging variance (right). This sediment unit is relatively uniform in thickness, with the exception of well MTR-Test where the thickness is $17 \mathrm{ft}$. It is likely that this unit extends further north, intersecting well USGS-079. 

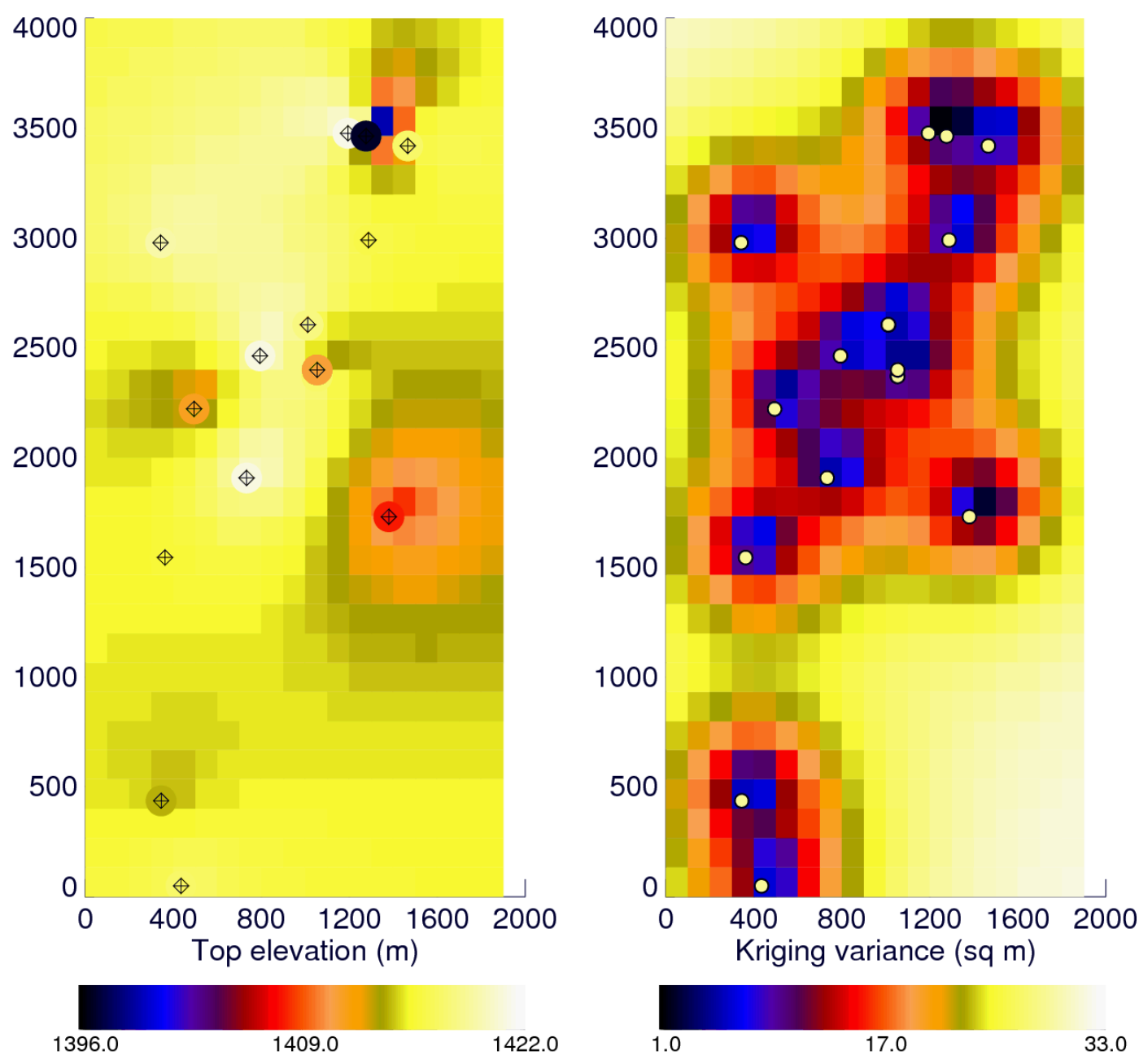

Figure 52. Kriging predictions (left) and kriging variance (right) for Sediment Unit 7 top elevation (m). Points represent sample locations. The gridded area is represented by the box in Figure 1 and the $x-y$ distances $(\mathrm{m})$ are relative to the figure. 

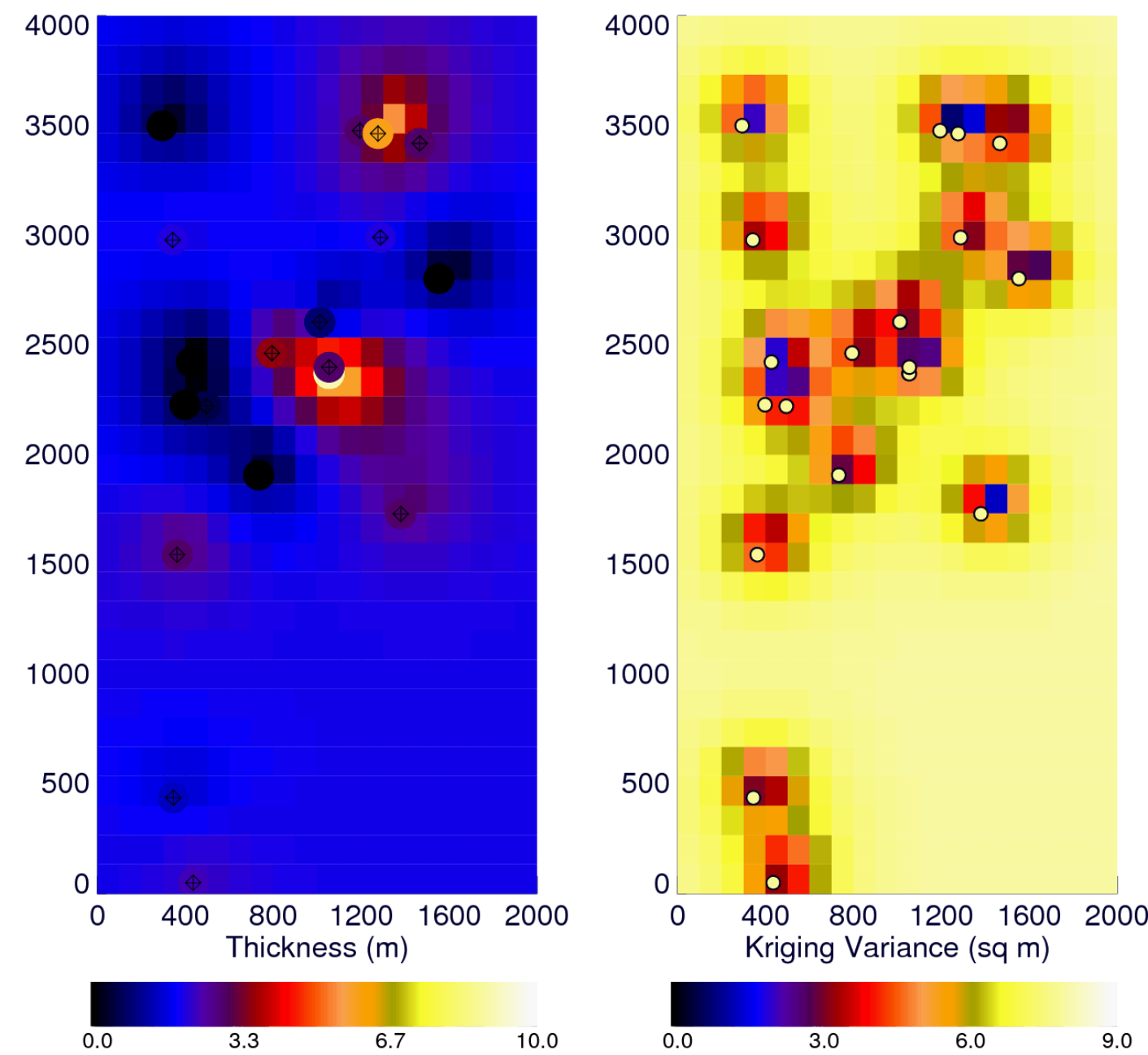

Figure 53. Kriging predictions (left) and kriging variance (right) for Sediment Unit 7 thickness (m). Points represent sample locations. The gridded area is represented by the box in Figure 1 and the $x-y$ distances $(\mathrm{m})$ are relative to the figure.

\subsection{Sediment Unit 8}

The 19 wells used in analysis of Sediment Unit 8 are shown in Figure 54. Sediment Unit 8 was found in 15 of these wells. 


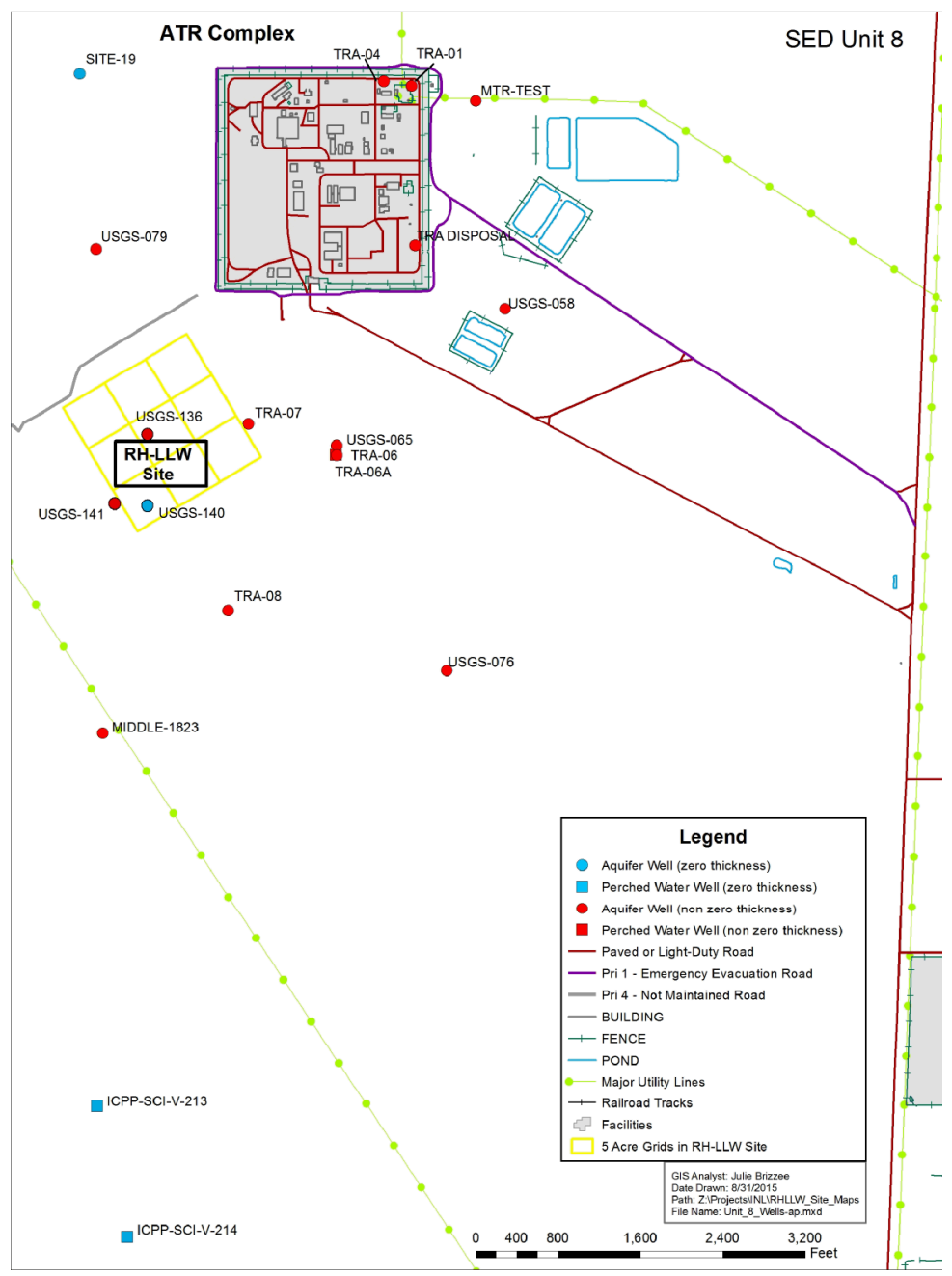

Figure 54. Wells used to define Sediment Unit 8.

\subsubsection{Geostatistical Evaluation}

Histograms for the top elevation and thickness are shown in Figure 55, along with the summary statistical distributions; semivariograms are shown in Figures 56 and 57; spatially kriged top elevation and associated kriging variance are given in Figure 58; and the kriged thickness and kriging variance are shown in Figure 59. The following bullets provide discussion of the figures:

- In the 18 locations closest to the RH-LLW Disposal Facility site (i.e., USGS-136, USGS-140, USGS-141, USGS-065, TRA-06, TRA-07, and Borings 7 through 18), the average thickness is $2.1 \mathrm{~m}(7.1 \mathrm{ft})$.

- The statistical distribution of top elevation approaches a uniform distribution with three outlying higher elevations northeast of the ATR Complex. The average top elevation is $1,403 \mathrm{~m}(4,603 \mathrm{ft})$, corresponding to a depth of $97 \mathrm{~m}(296 \mathrm{ft})$, with a standard deviation of $7.3 \mathrm{~m}(24 \mathrm{ft})$.

- The mean interbed thickness is $3 \mathrm{~m}(9.8 \mathrm{ft})$, with a standard deviation of $1.3 \mathrm{~m}(0.4 \mathrm{ft})$. Unit 8 sediment thickness ranges up to $6.1 \mathrm{~m}$ (about $20 \mathrm{ft}$ ) with thickest sediment due south of the ATR Complex. The unit is thickest east and south of the ATR Complex. 


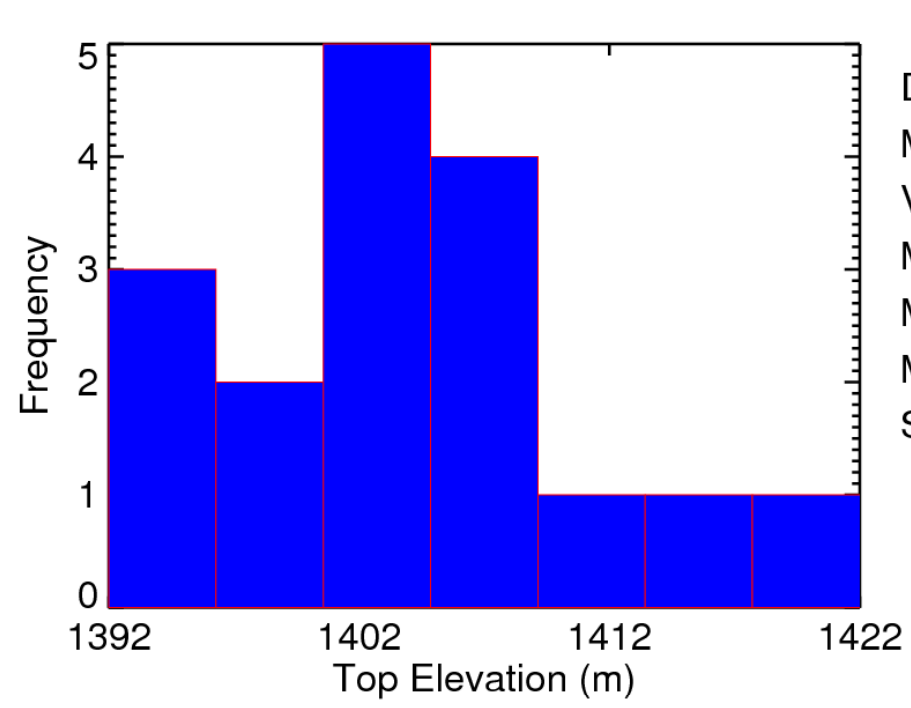

Sediment Unit 8

Data Count: $\quad 15$

Mean: $\quad 1403.11$

Variance: $\quad 49.79$

Maximum: 1421.42

Median: $\quad 1404.21$

Minimum: 1392.94

Shapiro Wilks p: 0.90

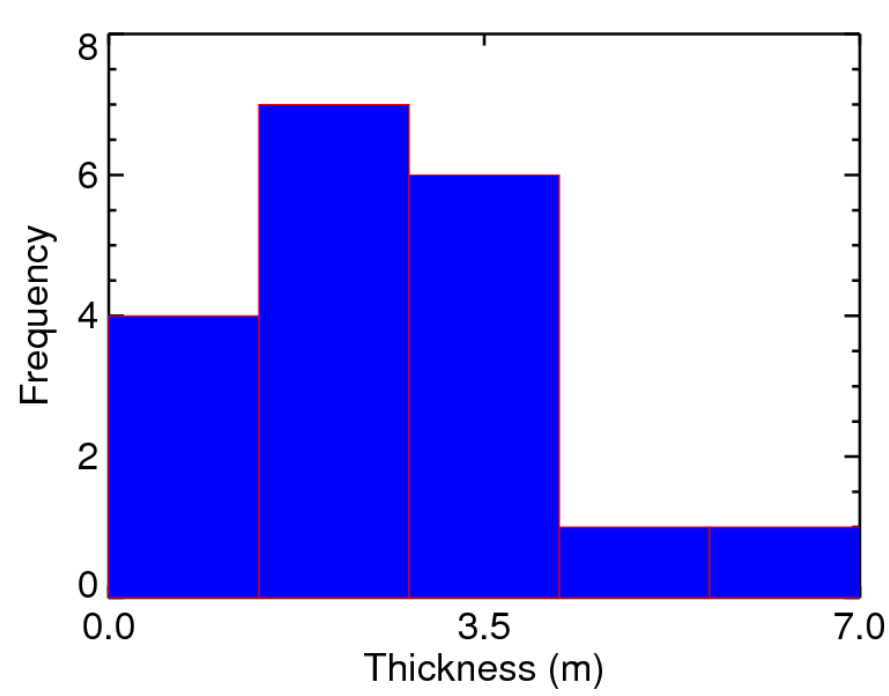

Sediment Unit 8

Data Count: $\quad 19$

Mean: $\quad 3.03$

Variance: $\quad 1.35$

Maximum: $\quad 6.10$

Median: $\quad 3.05$

Minimum: $\quad 1.83$

Shapiro Wilks p: 0.88

Figure 55. Histogram of Sediment Unit 8 elevation (top) and thickness (bottom). Summary statistics for both distributions are shown to the right of each plot.

- The omnidirectional semivariogram for the top elevation of Sediment Unit 8 was fit with an exponential model, with $46.5-\mathrm{m}^{2}$ sill, $457-\mathrm{m}$ range, and zero nugget.

- The semivariogram model for Sediment Unit 8 thickness has a longer range $(1,097 \mathrm{~m})$ and is fit with an exponential model with 3.3-m sill and zero nugget. 

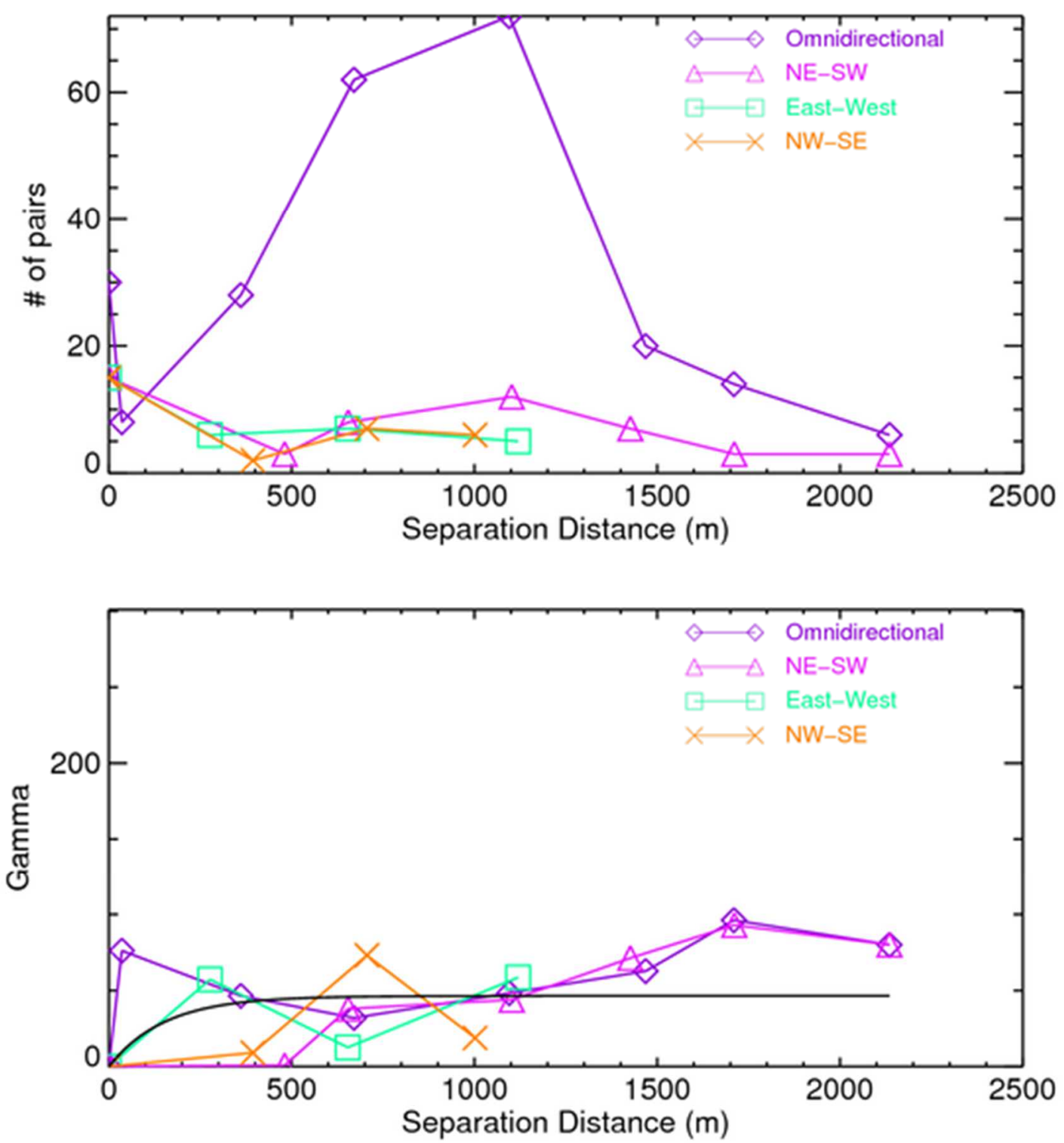

Figure 56. Anisotropic empirical (colored lines and symbols) and modelled (black lines) semivariograms for Sediment Unit 8 top elevation. 

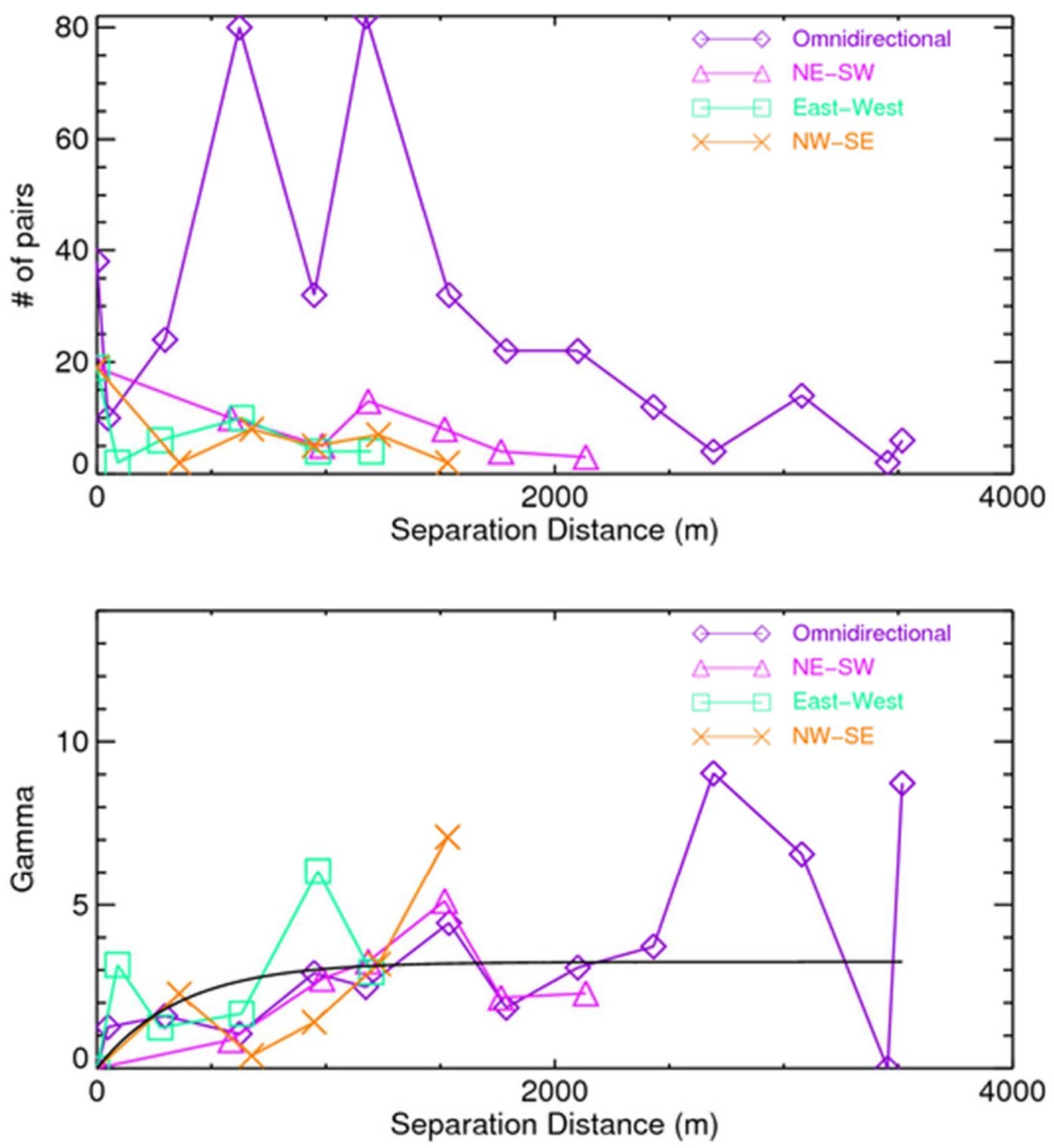

Figure 57. Anisotropic empirical (colored lines and symbols) and modelled (black lines) semivariograms for Sediment Unit 8 thickness.

- Kriging predictions for the sediment top elevation are shown in Figure 58 (left), along with the corresponding kriging variance (right). Sample density throughout the study area is fairly uniform. The relatively long top elevation correlation length is represented by largely connected intermediate-to-low relative values of kriging variance. This unit could actually consist of two different units with wells belonging to the topographic high west of the ATR Complex occurring at shallower depths and wells within the east topographic low occurring in a deeper sediment unit. 
- The kriging predictions for Sediment Unit 8 thickness are shown in Figure 59 (left), with the corresponding kriging variance (right). This sediment unit is relatively uniform in thickness along the western edge of the ATR Complex and also east of the ATR Complex, also suggesting the existence of two separate units. This discontinuity does not run through the RH-LLW Disposal Facility location.
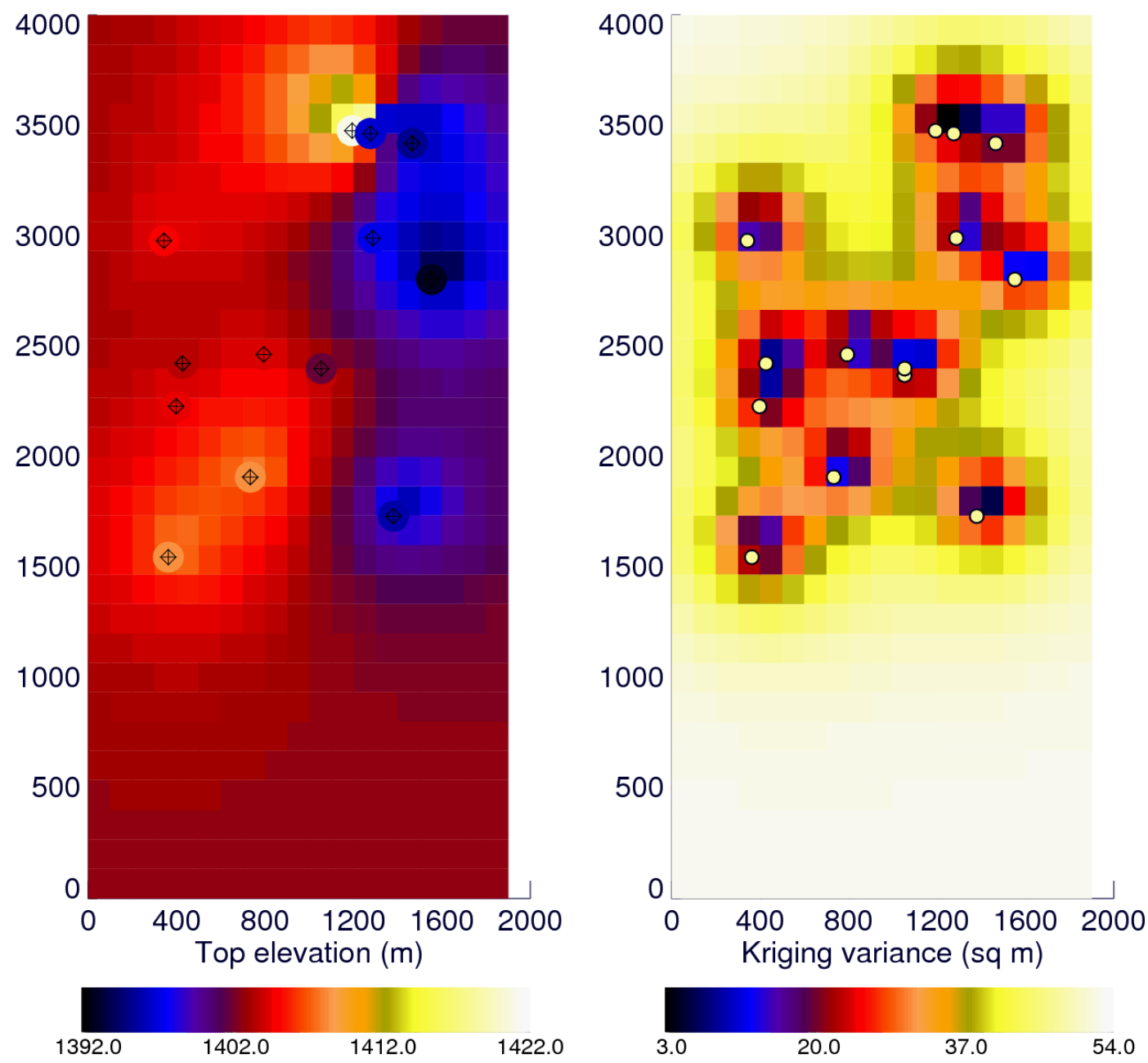

Figure 58. Kriging predictions (left) and kriging variance (right) for Sediment Unit 8 top elevation (m). Points represent sample locations. The gridded area is represented by the box in Figure 1 and the $x-y$ distances (m) are relative to the figure. 

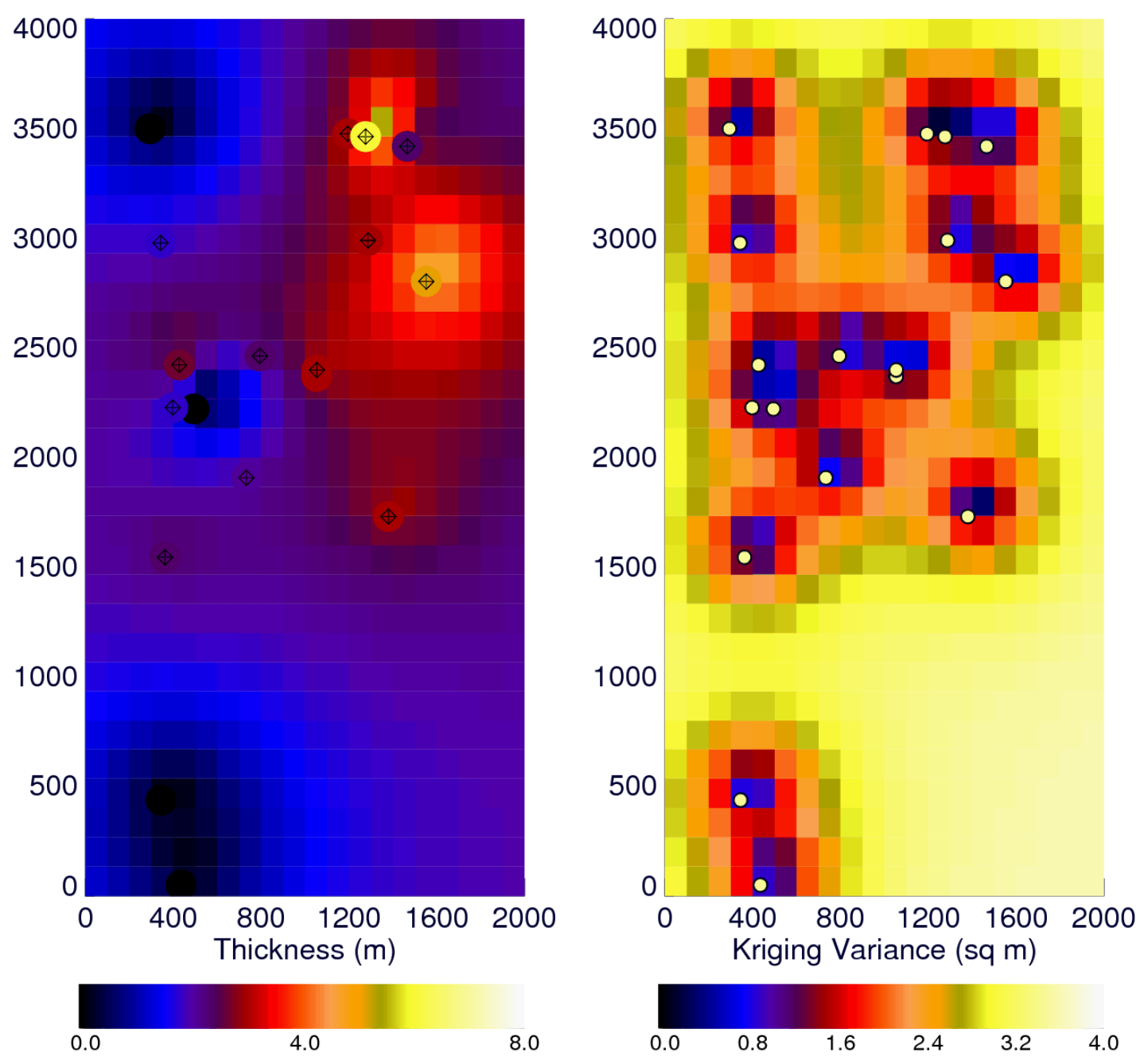

Figure 59. Kriging predictions (left) and kriging variance (right) for Sediment Unit 8 thickness (m). Points represent sample locations. The gridded area is represented by the box in Figure 1 and the $x-y$ distances (m) are relative to the figure.

\section{DISCUSSION}

In the vicinity of the RH-LLW Disposal Facility site, the sedimentary structure has been defined primarily based on the work compiled by Helm-Clark (2005) and augmented by new data collected in well USGS-136, USGS-140, and USGS-141 (Appendix A) and corehole data collected during the summer of 2010 (American Geotechnics 2011). The analysis contained in the Helm-Clark (2005) document focused on identifying continuous basalt flow units in an attempt to locate their origin. However, in doing so, it also provided a basis for delineating sedimentary units important to contaminant transport through the vadose zone south of the ATR Complex. Eight correlatable units have been defined in addition to the surficial alluvium.

Alluvial thickness in the region of the RH-LLW Disposal Facility is in the order of $12.9 \mathrm{~m}$. The 
average thickness for Units 2 through 8 , based on the closest 18 wells, including those with zero thickness, are $0.6,5.8,1.0,5.5,1.3,2.8$, and $2.2 \mathrm{~m}$, respectively (values shown in Table 6 include only non-zero thickness locations). It is unlikely that Unit 1 will be found within the RH-LLW Disposal Facility. Considering only non-zero thickness locations, the sum of the average thicknesses for Sediment Units 2 through 8 is $24.6 \mathrm{~m}(80.8 \mathrm{ft})$.

Table 6. Sedimentary materials near the RH-LLW Disposal Facility.

\begin{tabular}{lccccccccc}
\hline \multicolumn{1}{c}{ Well/Boring Location } & Alluvium & Unit 1 & Unit 2 & Unit 3 & Unit 4 & Unit 5 & Unit 6 & Unit 7 & Unit 8 \\
\hline USGS-136 & 14.8 & 0.0 & 0.5 & 6.6 & 1.0 & 3.0 & 0.2 & 0.0 & 2.7 \\
USGS-140 & 10.4 & 0.0 & 0.0 & 6.5 & 0.0 & 7.5 & 3.0 & 0.6 & 0.0 \\
USGS-141 & 11.9 & 0.0 & 0.0 & 8.2 & 0.0 & 6.4 & 1.8 & 0.0 & 1.8 \\
Boring-7 & 9.0 & & & & & & & & \\
Boring-8 & 7.9 & & & & & & & & \\
Boring-9 & 10.7 & & & & & & & & \\
Boring-10 & 12.0 & & & & & & & & \\
Boring-11 & 15.2 & & & & & & & & \\
Boring-12 & 17.5 & & & & & & & & \\
Boring-13 & 12.3 & & & & & & & & \\
Boring-14 & 13.3 & & & & & & & & \\
Boring-15 & 13.6 & & & & & & & & \\
Boring-16 & 10.8 & & & & & & & & \\
Boring-17 & 14.6 & & & & & & & & \\
Boring-18 & 14.0 & & & & & & & & \\
TRA-07 & 12.8 & 0.0 & 3.0 & 4.6 & 4.6 & 3.7 & 3.0 & 3.7 & 2.4 \\
TRA-06 & 13.7 & 0.0 & 0.0 & 4.6 & 0.0 & 4.9 & 0.0 & 9.1 & 3.0 \\
USGS-065 & 18.3 & 0.0 & 0.0 & 4.6 & 0.0 & 7.3 & 0.0 & 3.0 & 3.0 \\
\hline \# of non-zero thickness wells & 18 & 0 & 2 & 6 & 2 & 6 & 4 & 4 & 5.1 \\
Average thickness (m) & 12.9 & & 1.8 & 5.8 & 2.8 & 5.5 & 2.0 & 4.1 & 2.6 \\
Average thickness (ft) & 42.4 & & 5.9 & 19.1 & 9.1 & 17.9 & 6.6 & 13.5 & 8.6 \\
\hline & & & & & & & & &
\end{tabular}

Taken from the descriptions shown in the stratigraphic columns in Appendices A and B, the sedimentary materials near the RH-LLW Disposal Facility location are shown in Table 6. These wells are shown in cross-section in Figure 60. As shown in the table and fence diagram of wells near the facility location, surficial sediment should be primarily courser sands and gravels. Sediment Unit 2 is a mix of sand, silt, clay, and cinders. Sediment Units 3, 4, and 5 are primarily fine sands and mostly clays. Sediment Units 6 through 8 appear to be silty clays to silty sands.

As is apparent in the fence diagram shown in Figure 60 and those shown in Appendix A, there are many discontinuous occurrences of clays and sands that were not analyzed in this assessment. These less continuous units are likely to exist near the RH-LLW Disposal Facility location at similar depths in which they occur in wells Middle-1823, TRA-07, and TRA-08.

The variograms and kriged results provide an indication of well spacing necessary to capture these larger, more continuous units. In general, this distance should reflect correlation lengths shown in Tables 7 and 8 . Based on the lateral continuity of sediment Units 2 through 8 and the relatively small variance in the region of the RH-LLW Disposal Facility location, a one-dimensional transport model 
should be sufficient to adequately describe vadose zone transport in this region.

Table 7. Summary sediment characteristics for wells shown in Figure 60.

\begin{tabular}{|c|c|c|c|c|c|}
\hline \multirow[b]{2}{*}{ Well } & \multicolumn{5}{|c|}{ Sediment } \\
\hline & $\begin{array}{c}\text { Surficial } \\
\text { Sediment }\end{array}$ & Unit 1 & Unit 2 & Unit 3 & Unit 4 \\
\hline Site-19 & silt and gravel & & cinders and clay & clay and cinders & red sand and gravel \\
\hline USGS-79 & gravel & & cinders and basalt & sand and clay & sand and clay \\
\hline $\begin{array}{l}\text { TRA-5 } \\
\text { (TRA-Disposal) }\end{array}$ & $\begin{array}{l}\text { gravel, sand, } \\
\text { and silt }\end{array}$ & & unknown & sand and cinders & cinders \\
\hline USGS-63 & gravel and silt & & cinders & & \\
\hline TRA-5A/PZ1 & alluvium & & not found & interbed & interbed \\
\hline TRA-7 & gravel and silt & & red silty clay to clay & red silty clay to clay & brown silty sand \\
\hline USGS-136 & $\begin{array}{l}\text { gravel, sand, } \\
\text { silt, and clay }\end{array}$ & sand and silt & $\begin{array}{l}\text { brown/orange silty } \\
\text { clay with sand }\end{array}$ & silty clay with sand & brown silty sand \\
\hline TRA-8 & gravel and silt & & $\begin{array}{l}\text { brown orange sand } \\
\text { and silt }\end{array}$ & $\begin{array}{l}\text { brown/orange clayey } \\
\text { silt }\end{array}$ & $\begin{array}{l}\text { y brown orange clay to } \\
\text { silty clay }\end{array}$ \\
\hline Middle-1823 & $\begin{array}{l}\text { sands and } \\
\text { gravels }\end{array}$ & $\begin{array}{l}\text { dark brown } \\
\text { silt, sand, } \\
\text { and gravel }\end{array}$ & unknown & silty clayey sand & light brown clay \\
\hline ICPP-SCI-V-213 & gravel & & interbed & silty sand & $\begin{array}{l}\text { thinly bedded clays } \\
\text { and sands }\end{array}$ \\
\hline \multirow[t]{2}{*}{ ICPP-SCI-V-214 } & gravel & & $\begin{array}{l}\text { clayey silt and silt } \\
\text { sand }\end{array}$ & $\begin{array}{l}\text { high natural gamma } \\
\text { ray (NGR) silty sand }\end{array}$ & \\
\hline & \multicolumn{5}{|c|}{ Sediment } \\
\hline Well & & nit 5 & Unit 6 & Unit 7 & Unit 8 \\
\hline Site-19 & red sand and $g$ & ravel & & & \\
\hline USGS-79 & sand and clay & & clay and basalt & NGR peak & NGR peak \\
\hline TRA-5 & sand/clay & & & sand & sand and clay? \\
\hline \multicolumn{6}{|l|}{ USGS-163 } \\
\hline TRA-5A/PZ1 & interbed & & & interbed & \\
\hline TRA-7 & brown silty sar & & NGR peak & silty clay & NGR peak \\
\hline USGS-136 & brown silty sar & & fine sand & & red sand \\
\hline TRA-8 & NR & & gravel and sand & & $\begin{array}{l}\text { orange brown clayey } \\
\text { silty }\end{array}$ \\
\hline Middle-1823 & $\begin{array}{l}\text { sandy silty cla } \\
\text { clay and sand }\end{array}$ & y underlain by & $\begin{array}{l}\text { light brown silty } \\
\text { clay }\end{array}$ & $\begin{array}{l}\text { light brown silty } \\
\text { clay }\end{array}$ & $\begin{array}{l}\text { buff clay w/ oxidized } \\
\text { basalt }\end{array}$ \\
\hline ICPP-SCI-V-213 & sand-rubble-cl & & & $\begin{array}{l}\text { brown clayey silty } \\
\text { sand }\end{array}$ & \\
\hline ICPP-SCI-V-214 & & & silty sand & sand & \\
\hline
\end{tabular}




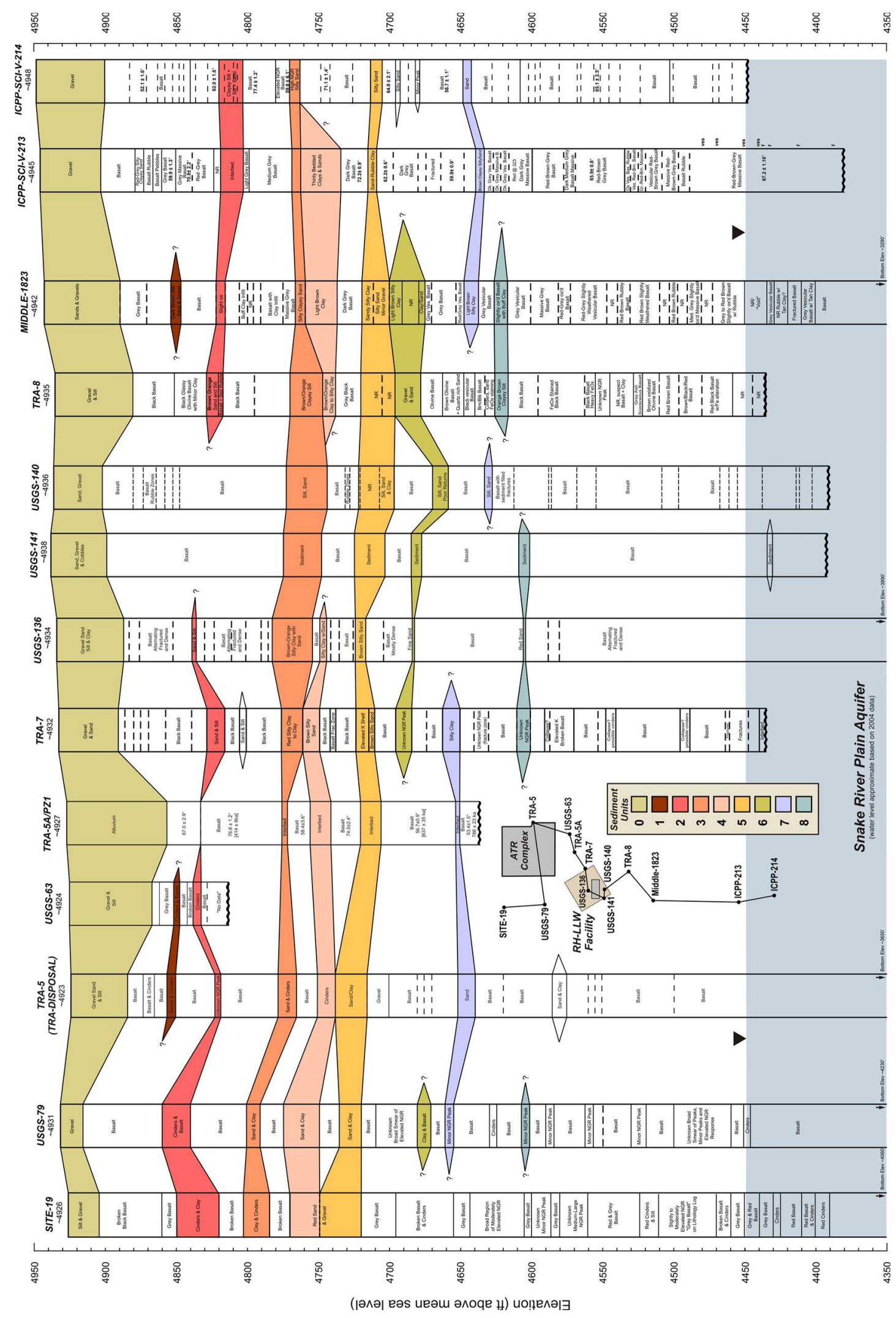

Figure 60. Fence diagram for wells appearing in Table 6. This fence diagram is also reproduced in Appendix A in larger format. 


\section{REFERENCES}

Boucher, A., W. Jianbing, and N. Remy, 2009, Applied Geostatistics with SGeMS, Cambridge University Press.

Deutsch, C. V. and A. G. Journel, 2000, GSLIB: Geostatistical Software Library and User's Guide, New York: Oxford University Press.

DOE-ID, 1997, Comprehensive RI/FS for the Idaho Chemical Processing Plant OU 3-13 at the INEELPart A, RI/BRA Report (Final), DOE/ID-10534, U.S. Department of Energy Idaho Operations Office, November 1997.

DOE-ID, 2005, Waste Area Group 10, Operable Unit 10-08, Remedial Investigation/Feasibility Study Annual Status Report for Fiscal Year 2004, DOE/NE ID 11198, U.S. Department of Energy Idaho Operations Office, March 2005.

DOE-ID, 2006a, Operable Unit 3-14 Tank Farm Soil and Groundwater Remedial Investigation/Baseline Risk Assessment, DOE/ID-11227, U.S. Department of Energy Idaho Operations Office, April 2006.

DOE-ID, 2006b, Remedial Investigation and Baseline Risk Assessment for Operable Unit 7 13/14, DOE/ID-11241, Revision A, U.S. Department of Energy Idaho Operations Office, May 2006.

Goldberger, A., 1962, "Best linear unbiased prediction in the generalized linear regression model," JASA, 57: 369-75.

Goovaerts, P., 1997, Geostatistics for Natural Resources Evaluation, New York: Oxford University Press.

Helm-Clark, C., S. Ansley, T. McLing, and T. Wood, 2005, Borehole and Well Middle-1823 and It's Relationship to the Stratigraphy of the South-Central Idaho National Laboratory, ICP/EXT05-00790, March 2005.

Leecaster, M., 2002, Geostatistical Modeling of Subsurface Characteristics in the Radioactive Waste Management Complex region, Operable Unit 7-13/14: Idaho Falls, Idaho, INEEL/EXT-0200029, Idaho National Engineering and Environmental Laboratory.

Leecaster, M., 2004, Fiscal Year 2004 Geostatistical Modeling of Lithologic Characteristics in the Radioactive Waste Management Complex for OU 7-13/14, ICP/EXT-04-00494, Idaho Completion Project, Idaho National Engineering and Environmental Laboratory, September 2004.

Leecaster, M., 2006, Geostatistical Modeling of Subsurface Characteristics in the Area of the Idaho Nuclear Technology and Engineering Center, Appendix C of DOE-ID, 2006a, Operable Unit 314 Tank Farm Soil and Groundwater Remedial Investigation/Baseline Risk Assessment, DOE/ID-11227, U.S. Department of Energy Idaho Operations Office, April 2006.

Lewis, S. M., P.O. Sinton, M. J. Condran, J. W. Gordon, and Dames and Moore 1992, Remedial Investigation Report for the Test Reactor Area Perched Water System (Operable Unit 2-12), EGG-WM-10002, prepared for the U.S. Department of Energy Idaho Operations Office.

Luenberger, D., 1969, Optimization by Vector Space Methods, John Wiley \& Sons, New York.

Welhan, J. A. and M. F. Reed, 1997, "Geostatistical analysis of regional hydraulic conductivity variations in the Snake River Plain aquifer, eastern Idaho," Geological Society of America Bulletin, 109: 855-868. 
Welhan, J. A., T. M. Clemo, and E. L. Gégo, 2002, "Stochastic simulation of aquifer heterogeneity in a layered basalt aquifer system, eastern Snake River Plain, Idaho," Special Paper 353, Geology, hydrology, and environmental remediation: Idaho National Engineering and Environmental Laboratory, eastern Snake River Plain, Idaho, 353: 225-247.

Welhan, J. A., R. L. Farabough, M. J. Merrick, S. R. Anderson, 2006, Geostatistical Modeling of Sediment Abundance in a Heterogeneous Basalt Aquifer at the Idaho National Laboratory, Idaho, Scientific Investigations Report 2006-5316, USGS, also as DOE/ID-22201, 2006, U.S. Department of Energy Idaho Operations Office. 


\section{Appendix A \\ Lithology Log for Well USGS-136 and Fence Diagrams Near the ATR Complex}

The fence diagrams in this appendix were reproduced from Borehole and Well Middle-1823 and Its Relationship to the Stratigraphy of the South-Central Idaho National Laboratory (Helm-Clark et al. 2005), USGS Scientific Investigations Report 2012-5230, and USGS Scientific Investigations Report 2014-5098. Cross sections from Helm-Clark et al. (2005) were modified to eliminate depths below $550 \mathrm{ft}$ to allow reproduction in this format. One additional figure has been added to illustrate the sediment units identified in the main report. 


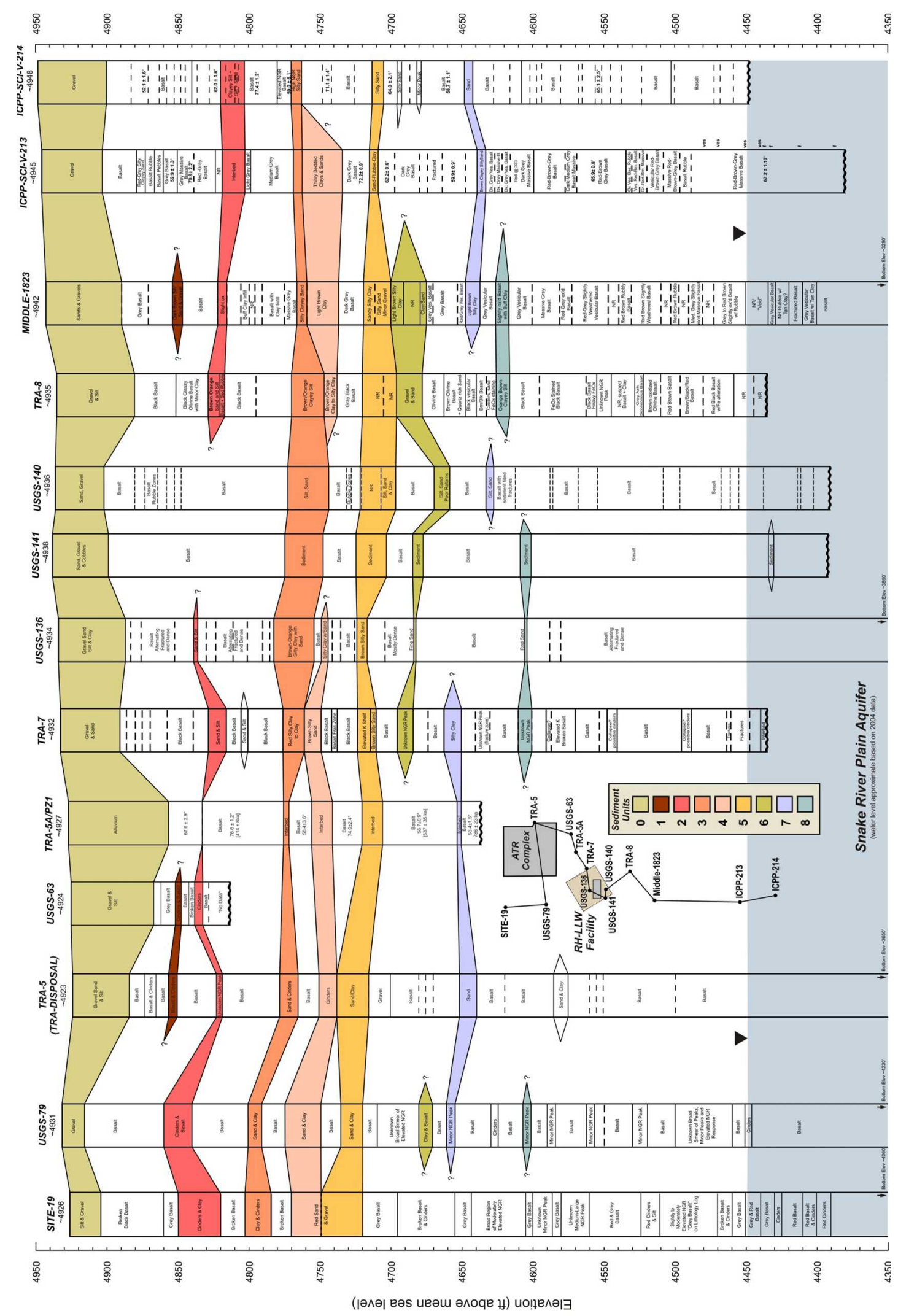

Figure A-1. Fence diagram of wells near the proposed RH-LLW site showing identified sedimentary structures. 


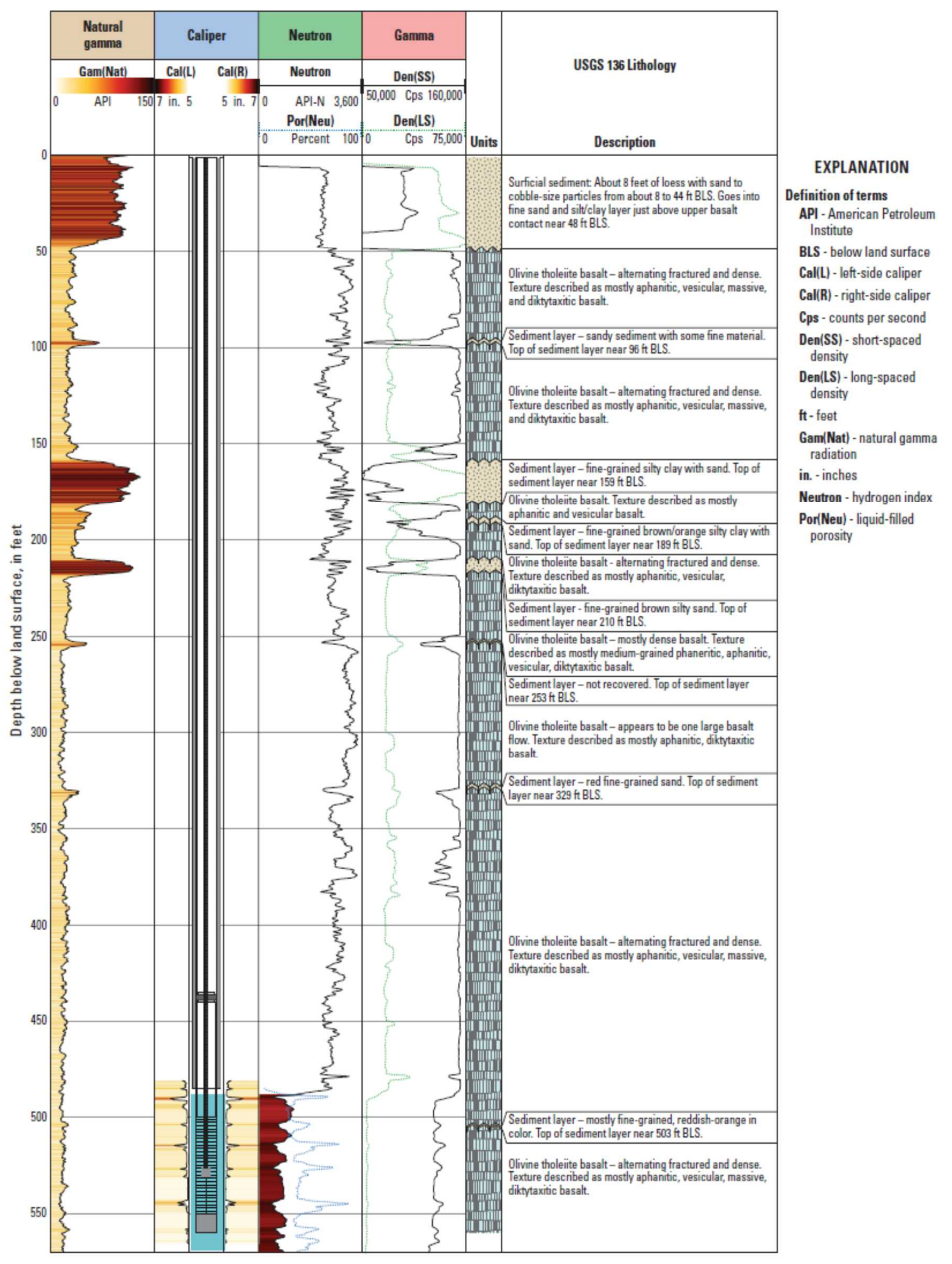

Figure A-2. Lithology in Well USGS-136 down to a 500-ft depth from USGS Scientific Investigations Report 2012-5230. 


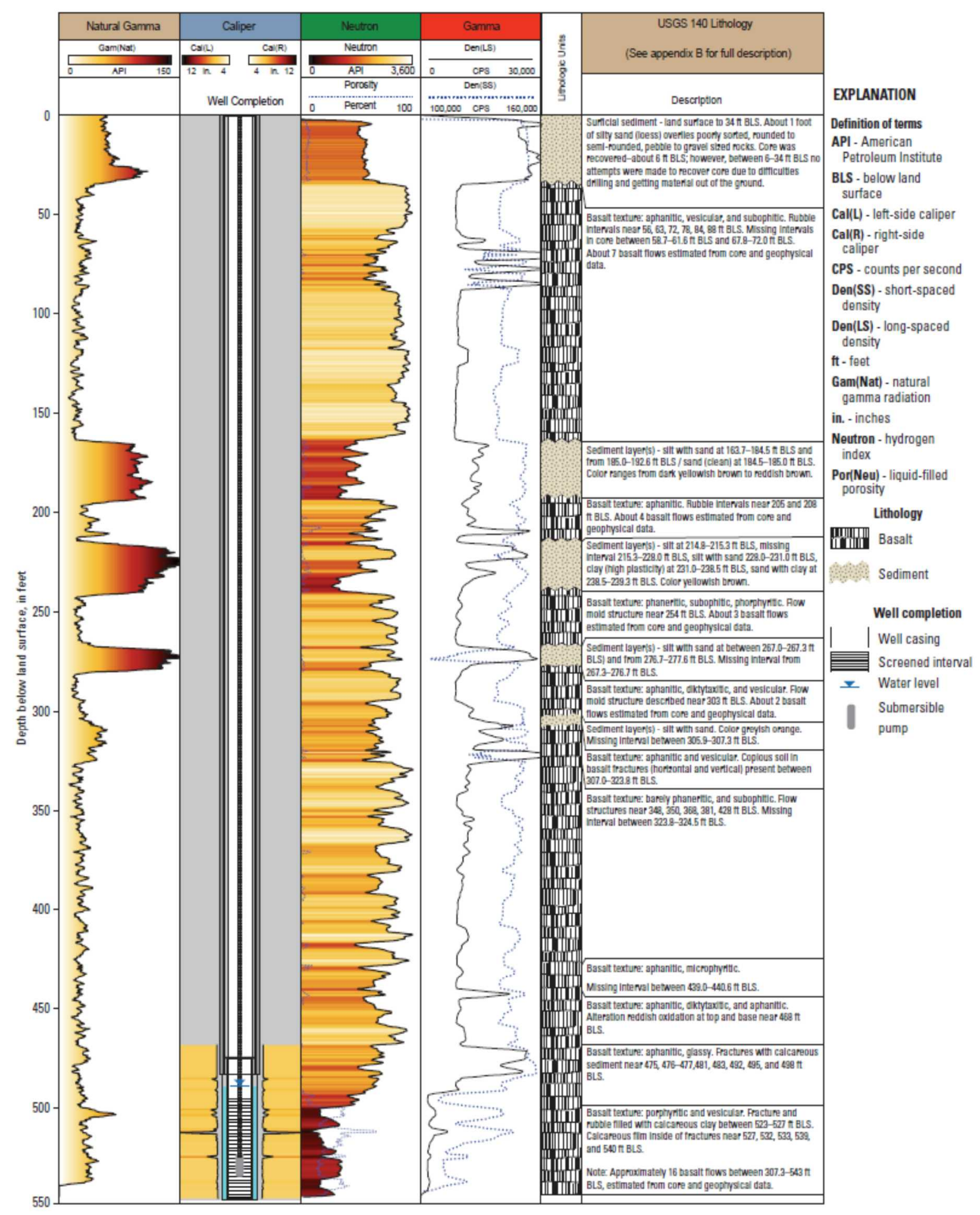

Figure A-3. Lithology in Well USGS-140 down to a 550-ft depth from USGS Scientific Investigations Report 2014-5098. 


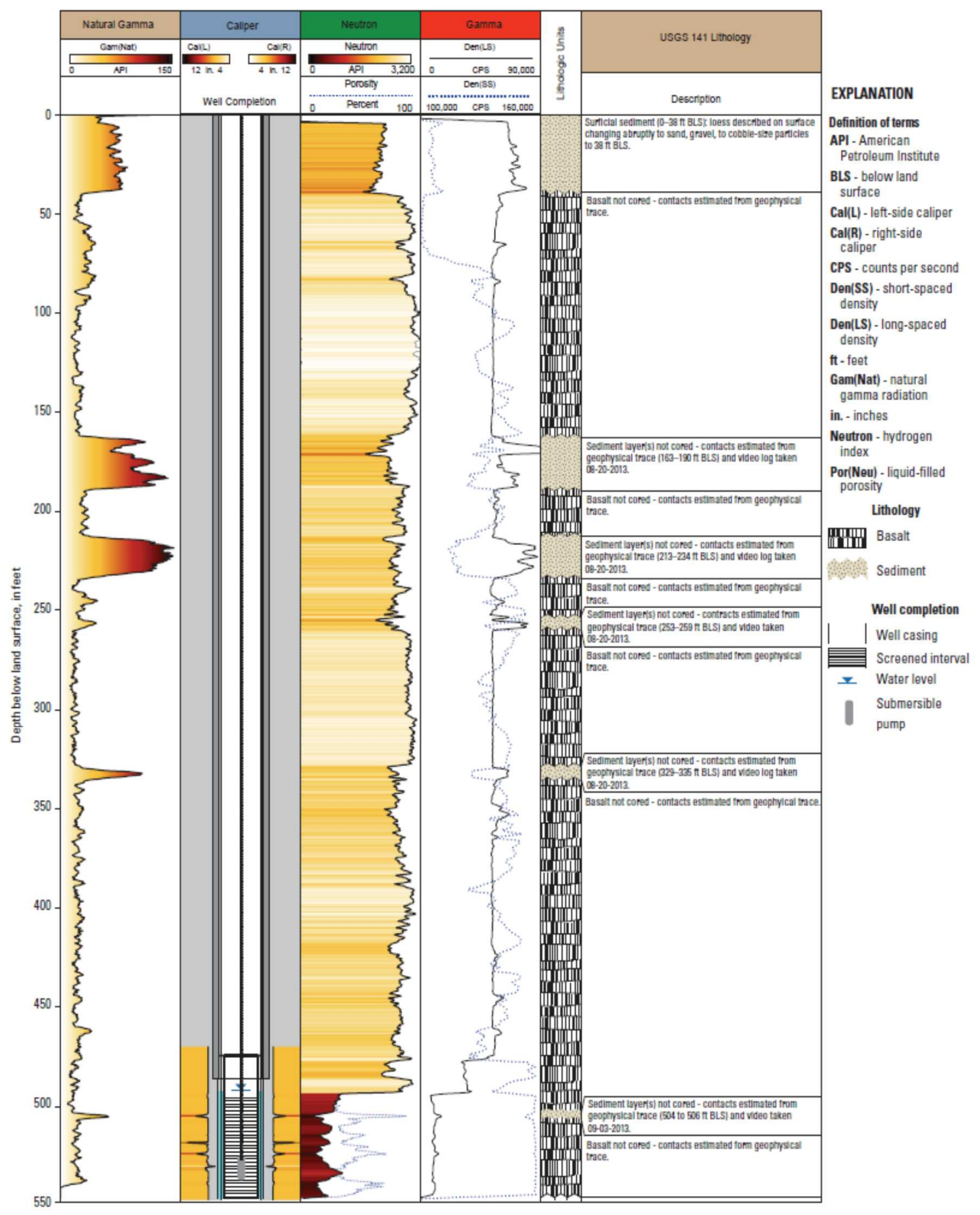

Figure A-4. Lithology in Well USGS-141 down to a 550-ft depth from USGS Scientific Investigations Report 2014-5098. 


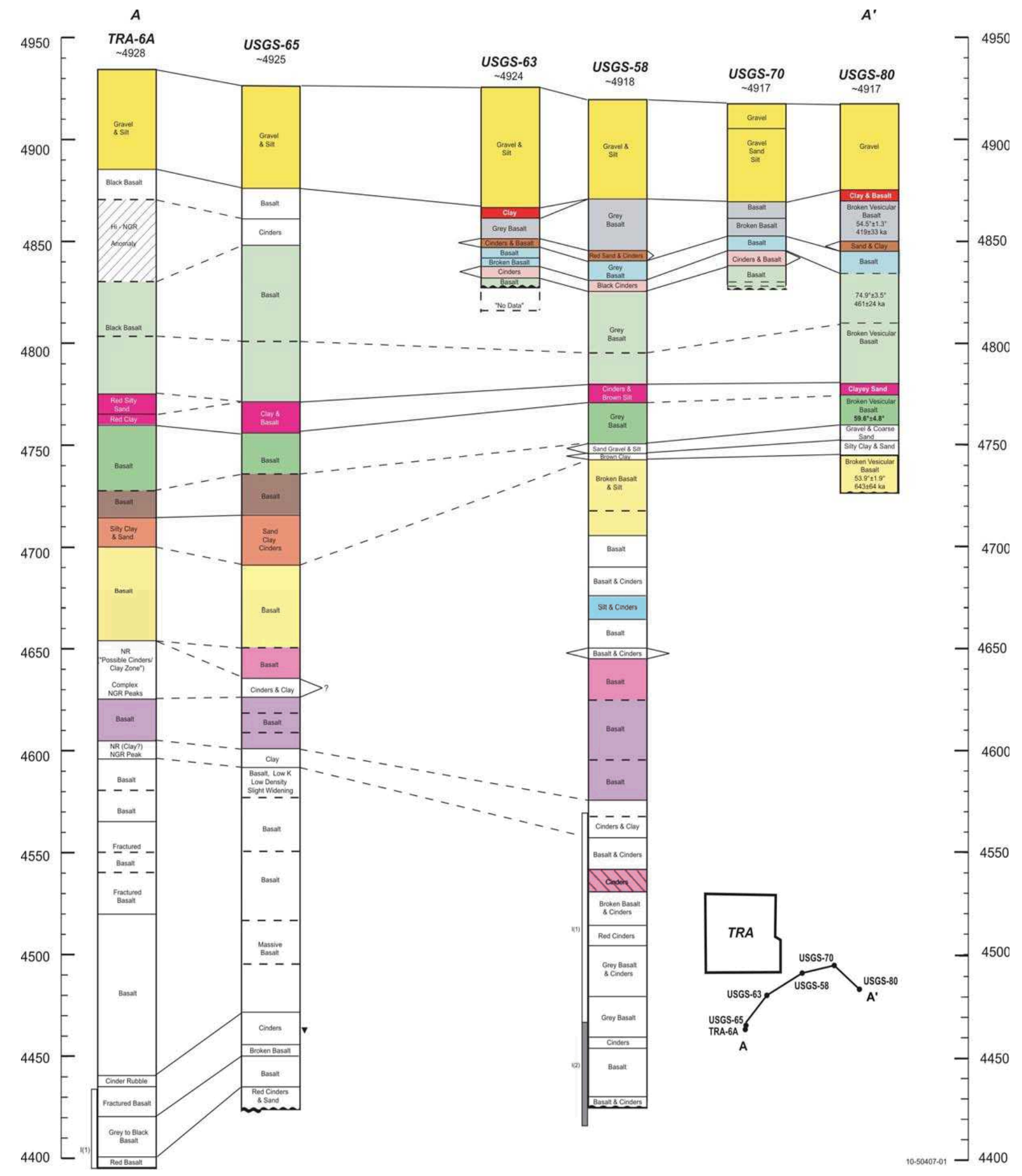

Figure A-5. Fence diagram A-A': TRA-6A to USGS-80. 
B
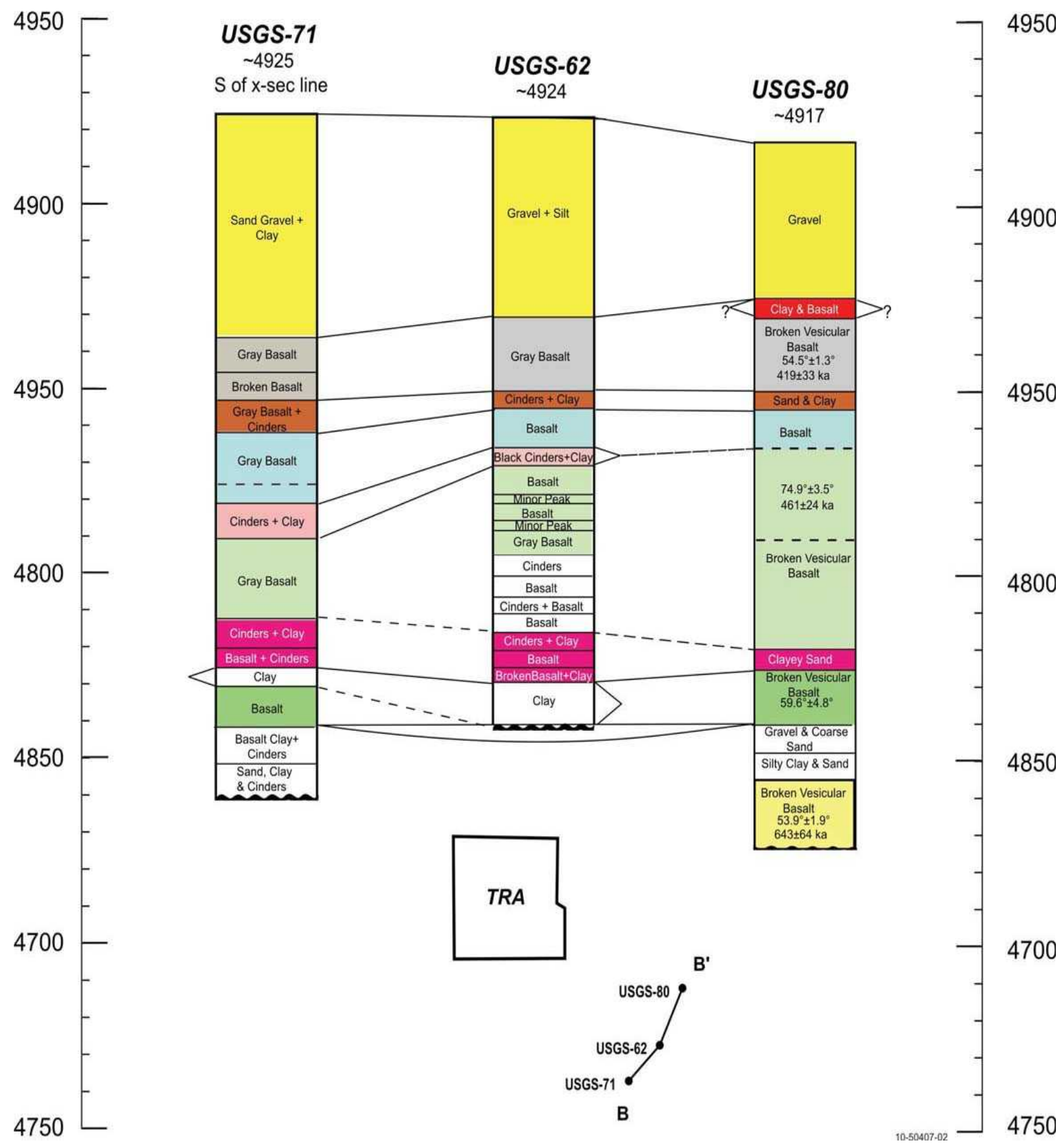

Figure A-6. Fence Diagram B-B': USGS-71 to USGS-80. 


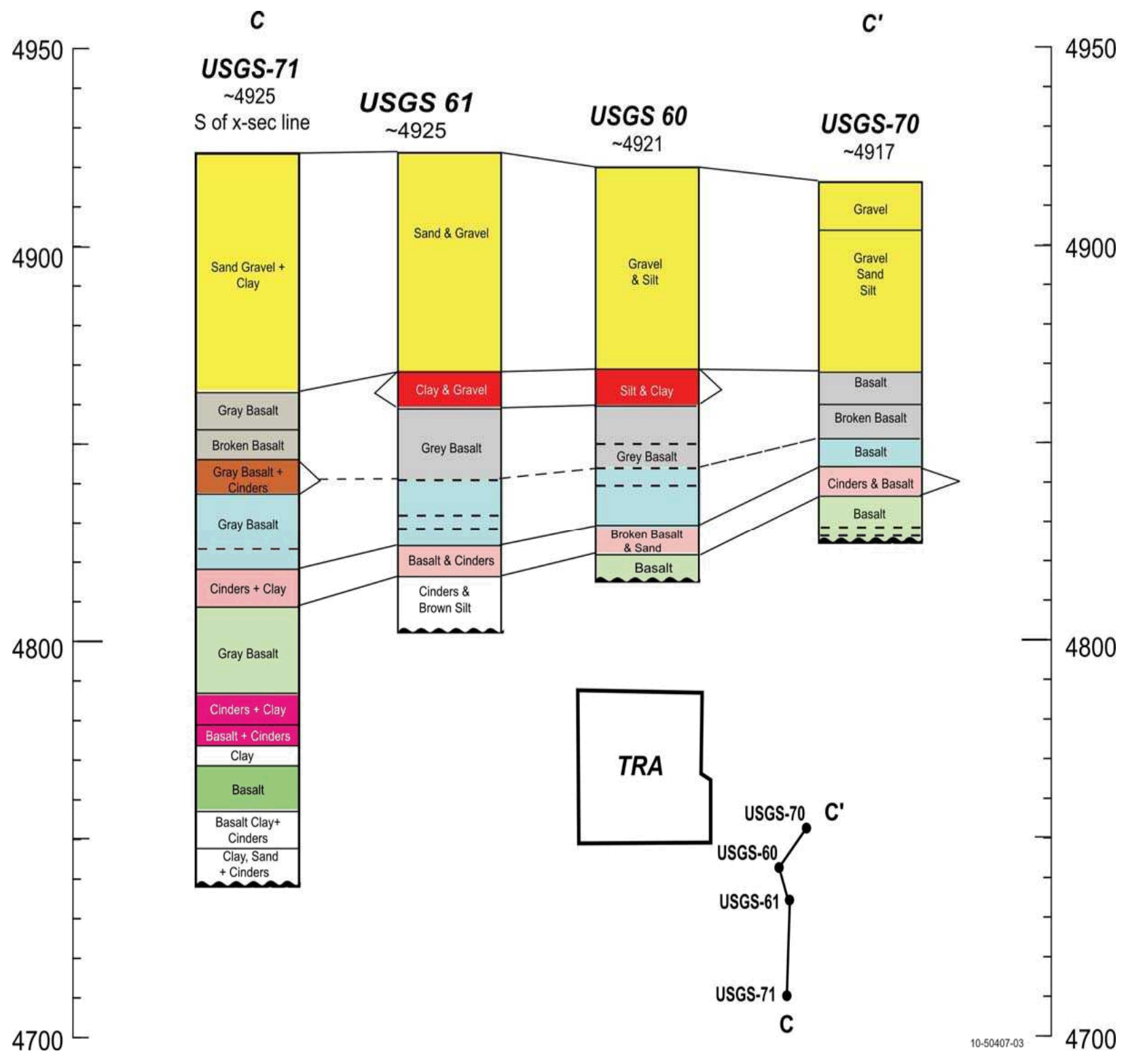

Figure A-7. Fence Diagram C-C': USGS-71 to USGS-70. 


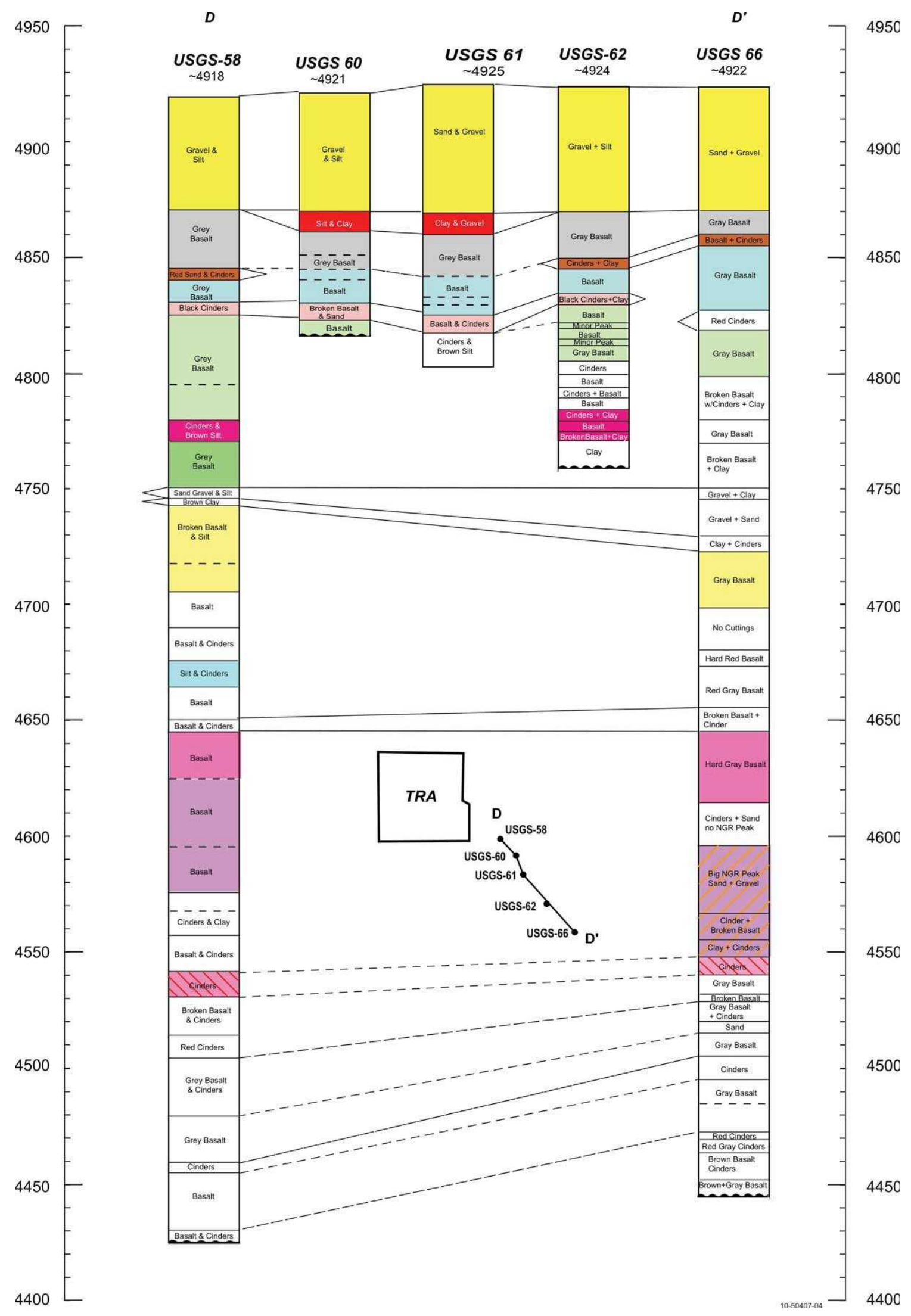

Figure A-8. Fence Diagram D-D': USGS-58 to USGS-66. 


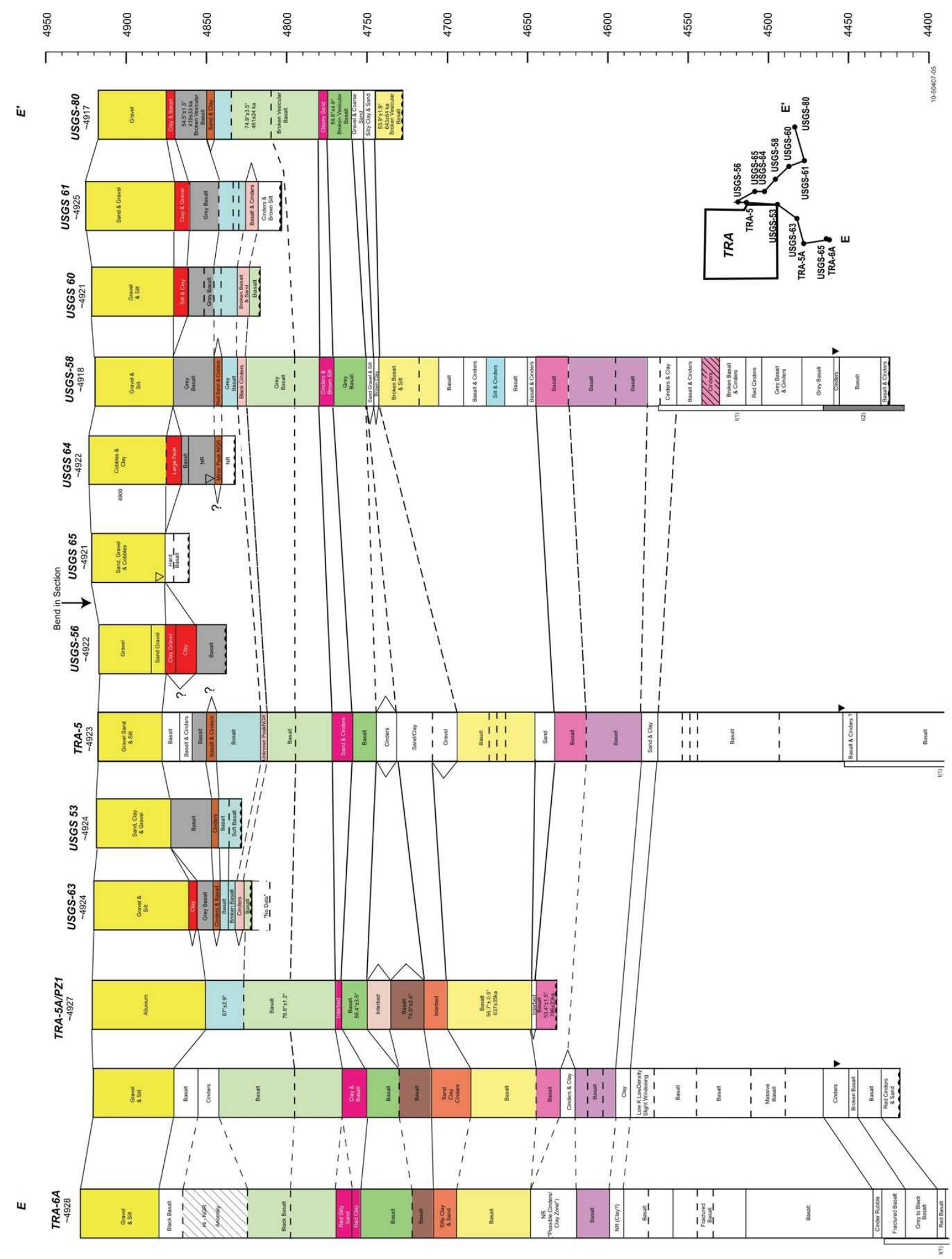

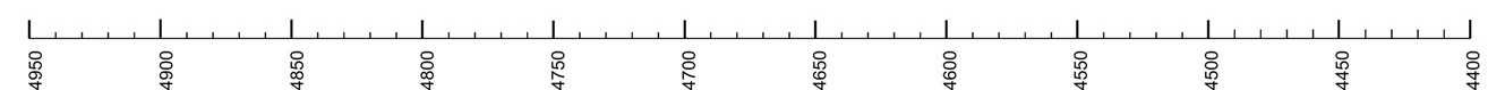

Figure A-9. Fence Diagram E-E': TRA-6A to USGS-80 via TRA-5 (Disposal Well). 


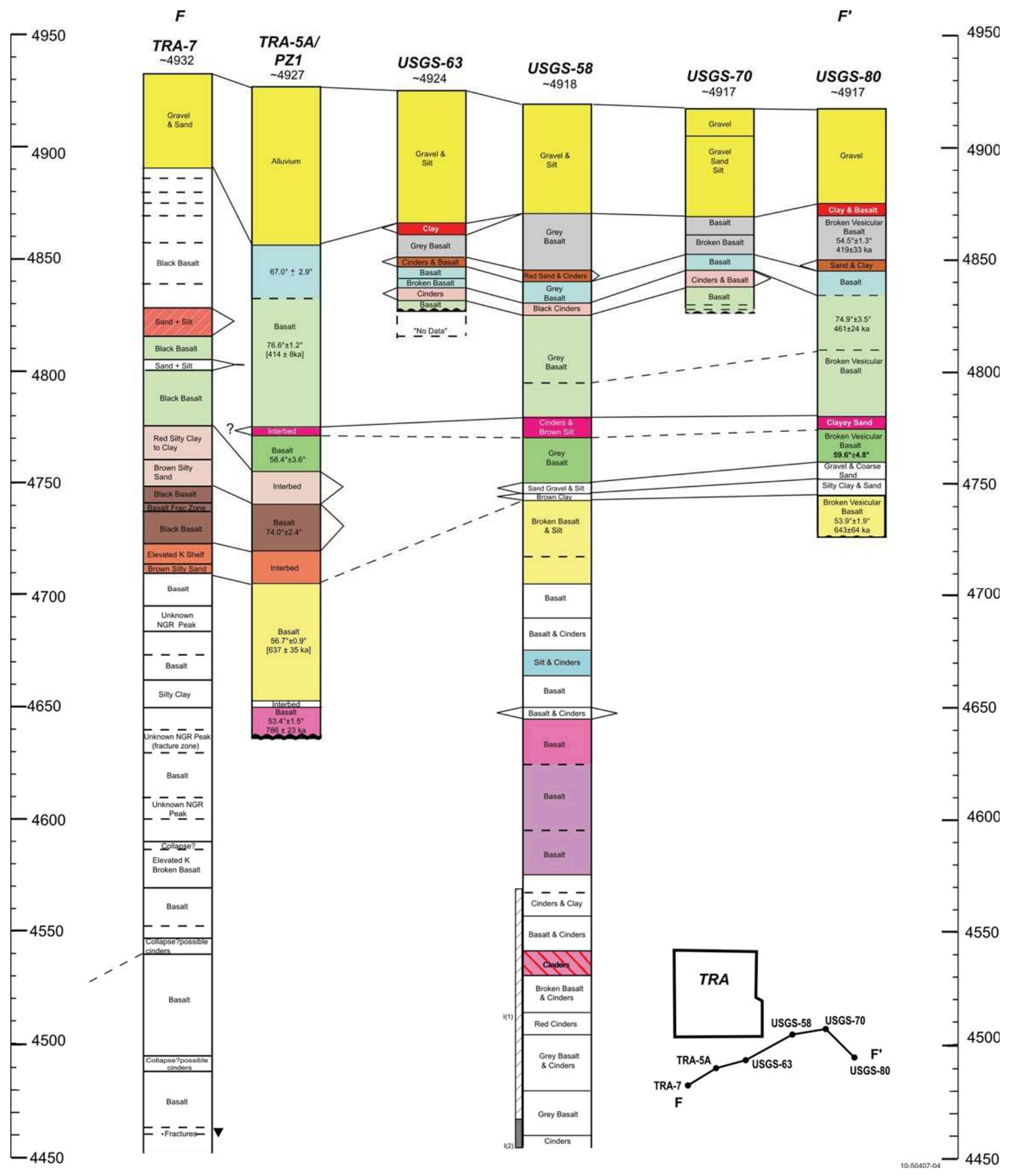

Figure A-10. Fence Diagram F-F': TRA-7 to USGS-80. 


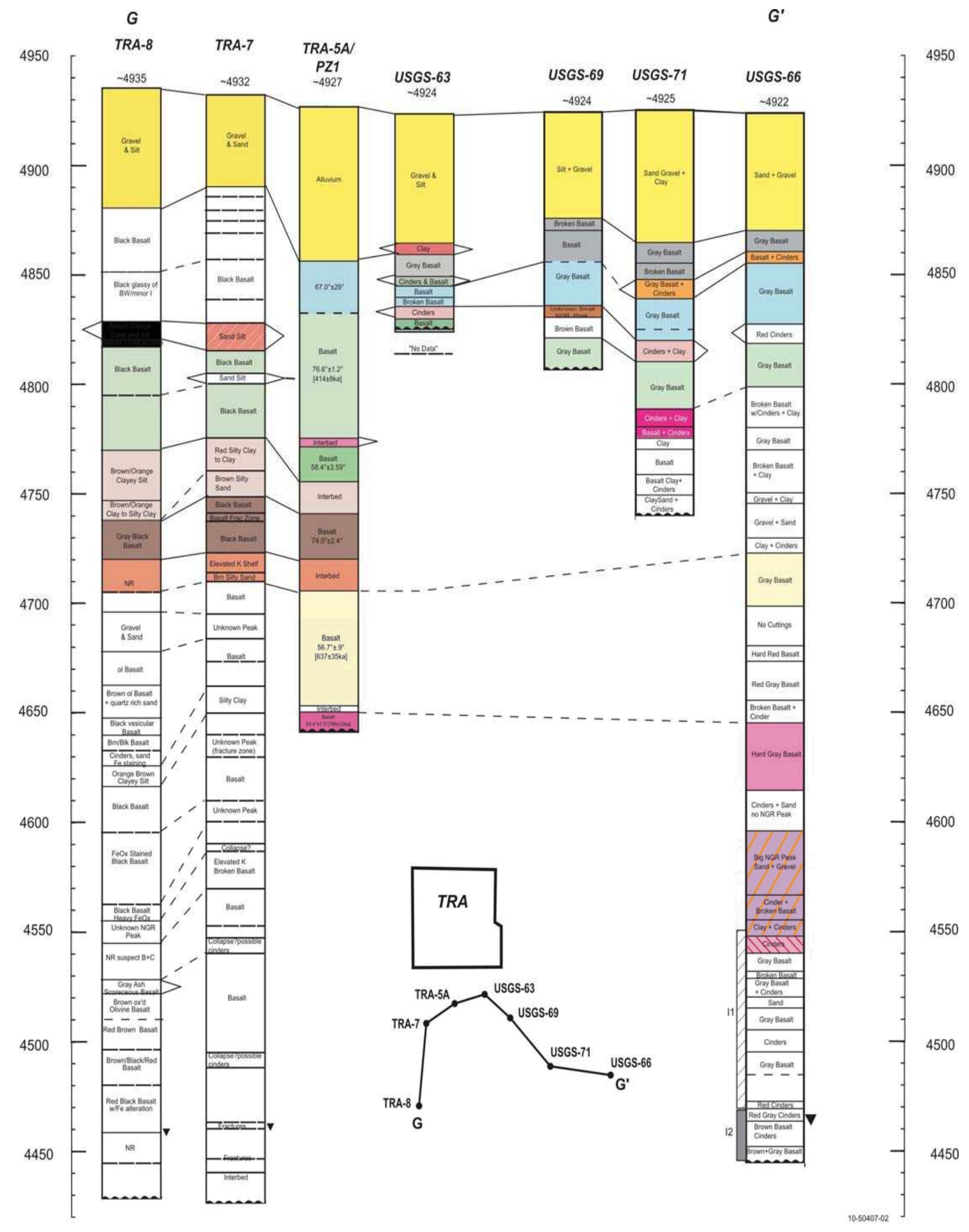

Figure A-11. Fence Diagram G-G': TRA-7 to USGS-66. 

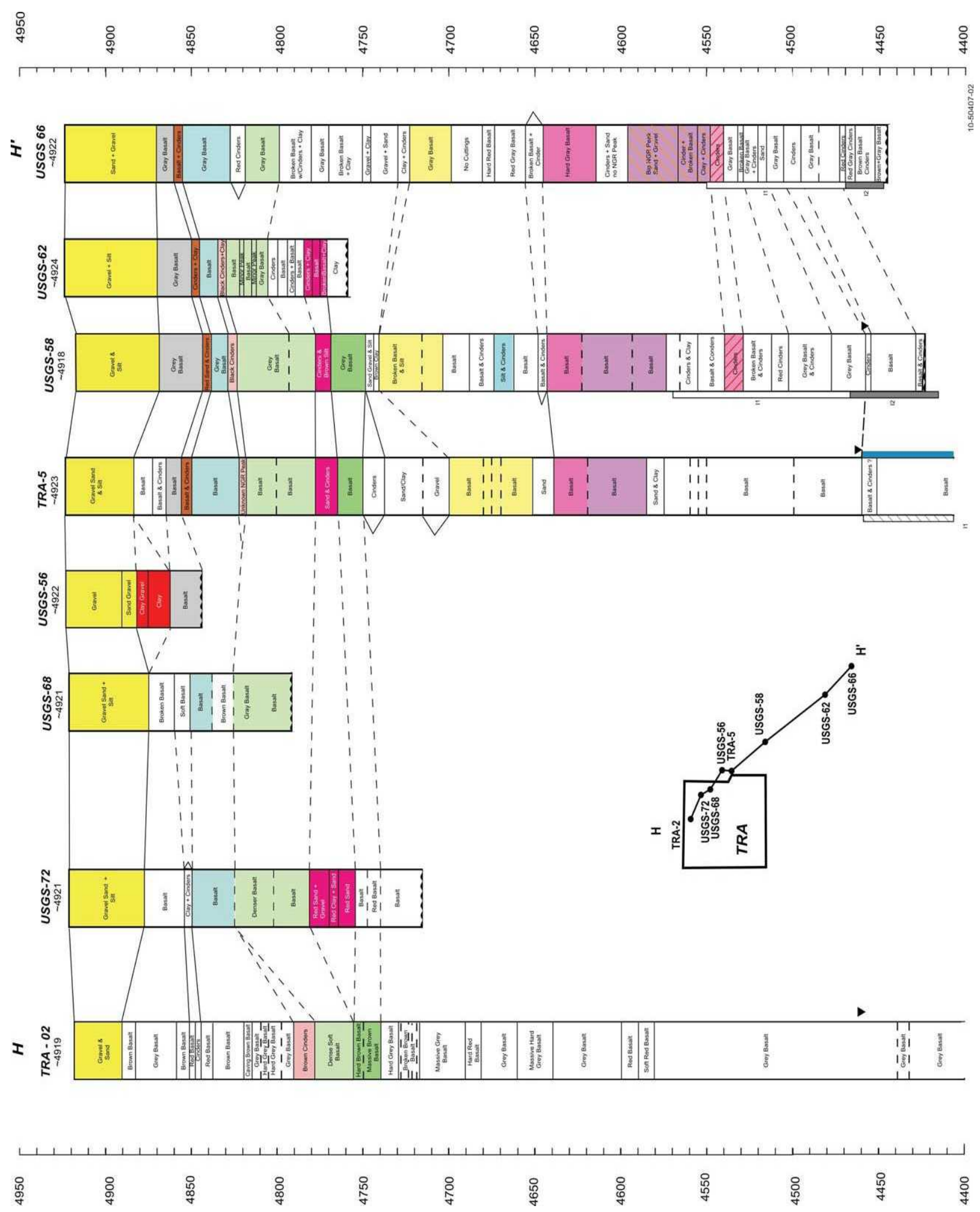

Figure A-12. Fence Diagram H-H': TRA-7 to USGS-80. 

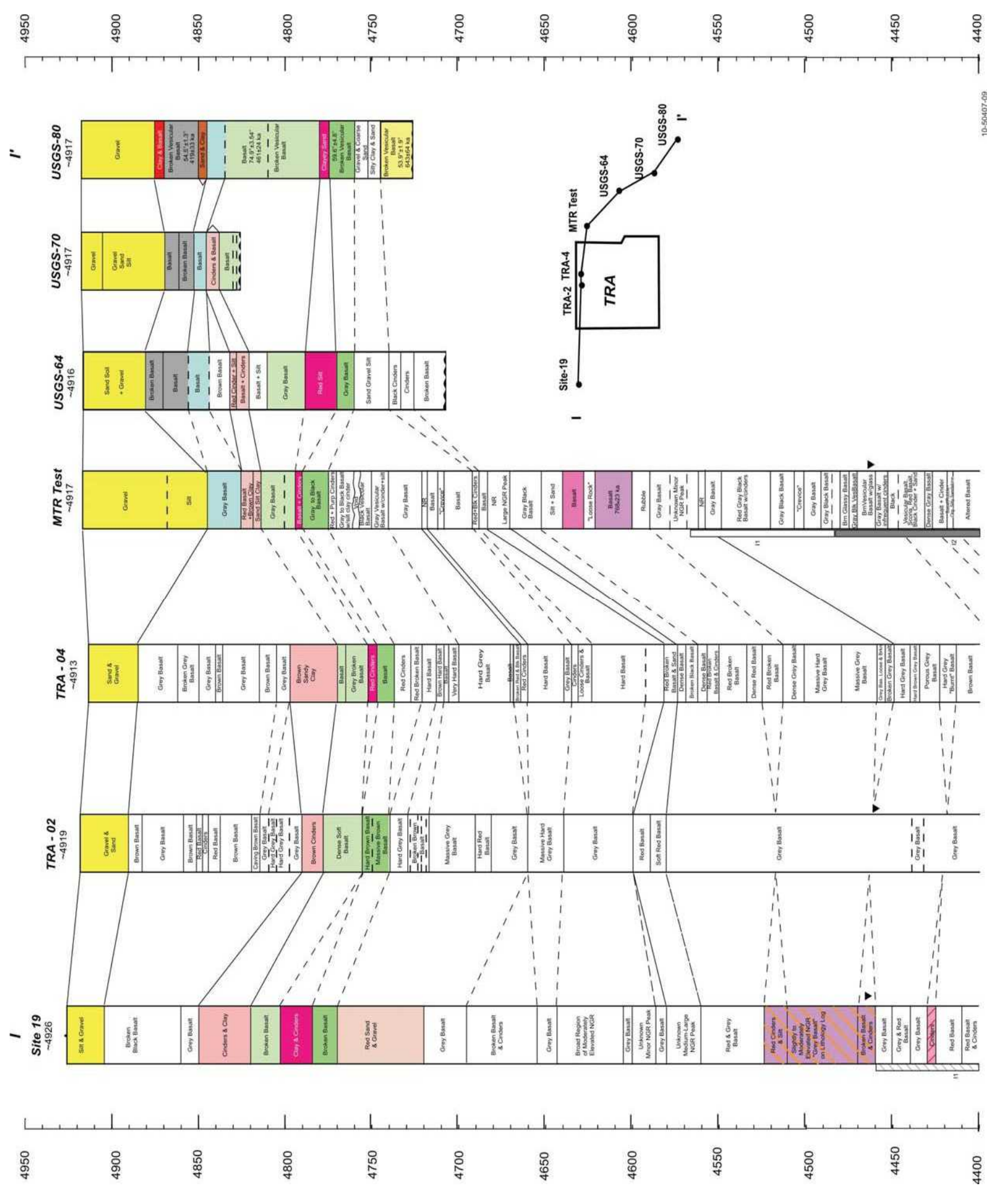

Figure A-13. Fence Diagram I-I: TRA-7 to USGS-80. 


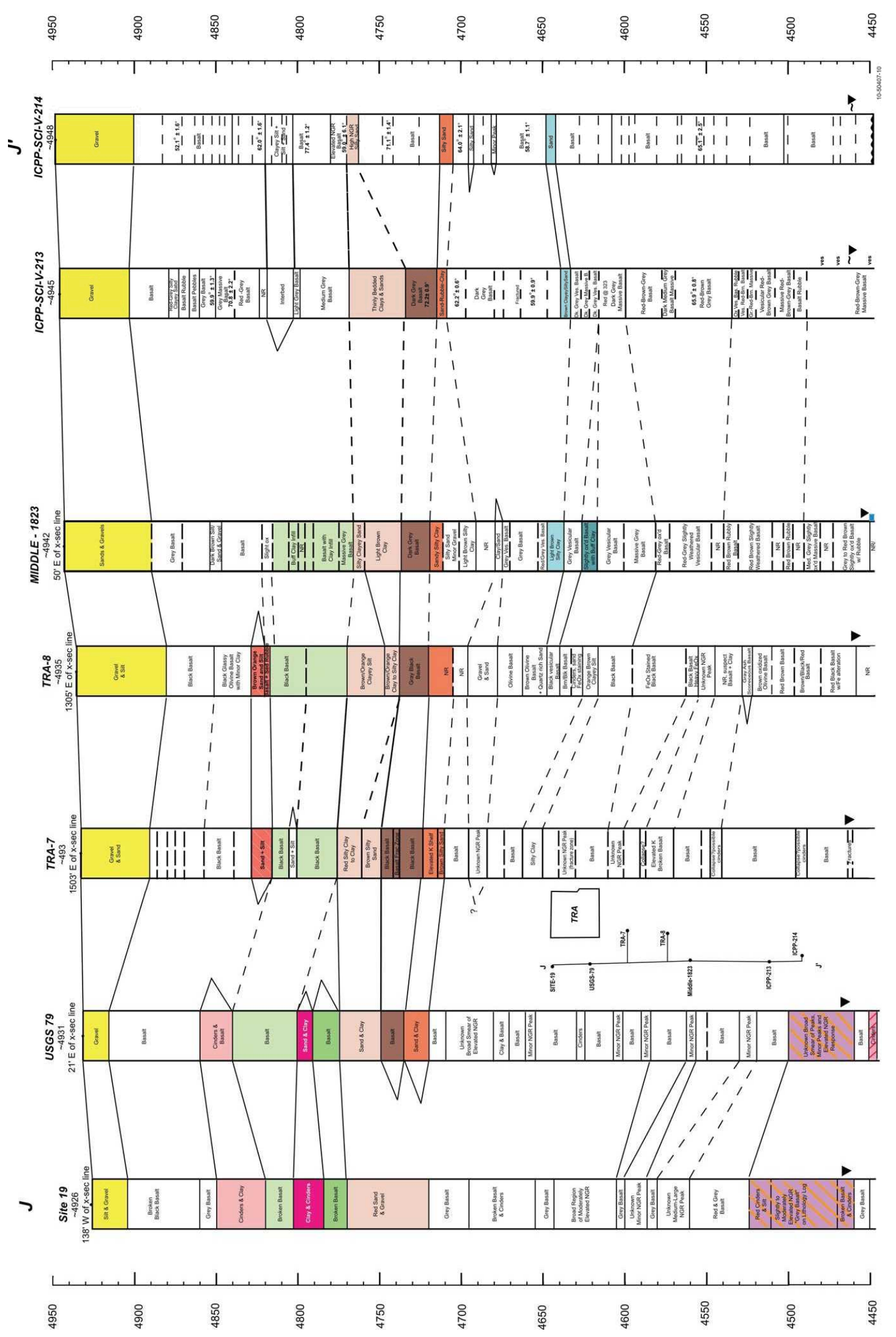

Figure A-14. Fence Diagram J-J': SITE-19 to ICCP-SCI-V-214. 


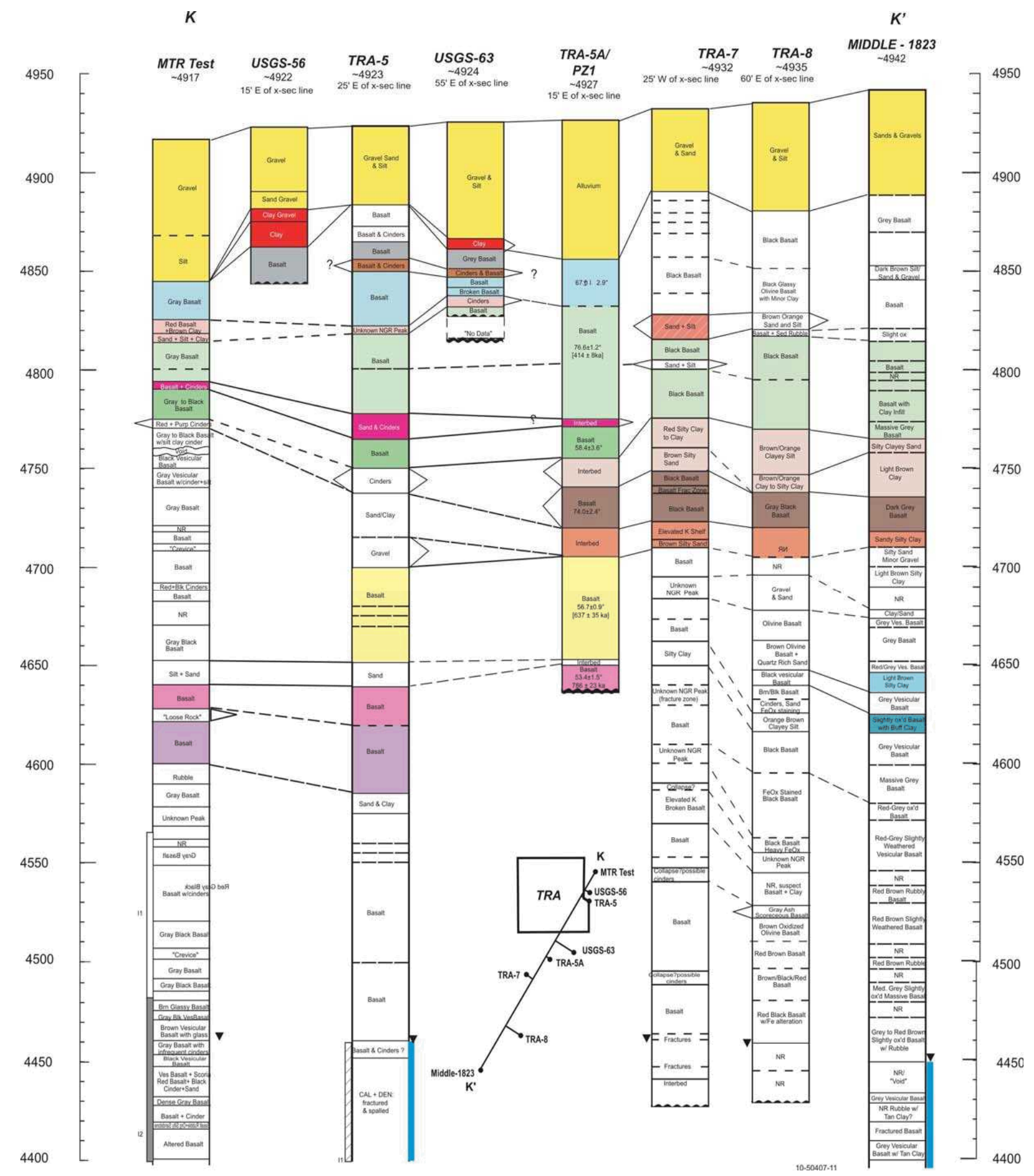

Figure A-15. Fence Diagram K-K': MTR-Test to Middle-1823. 


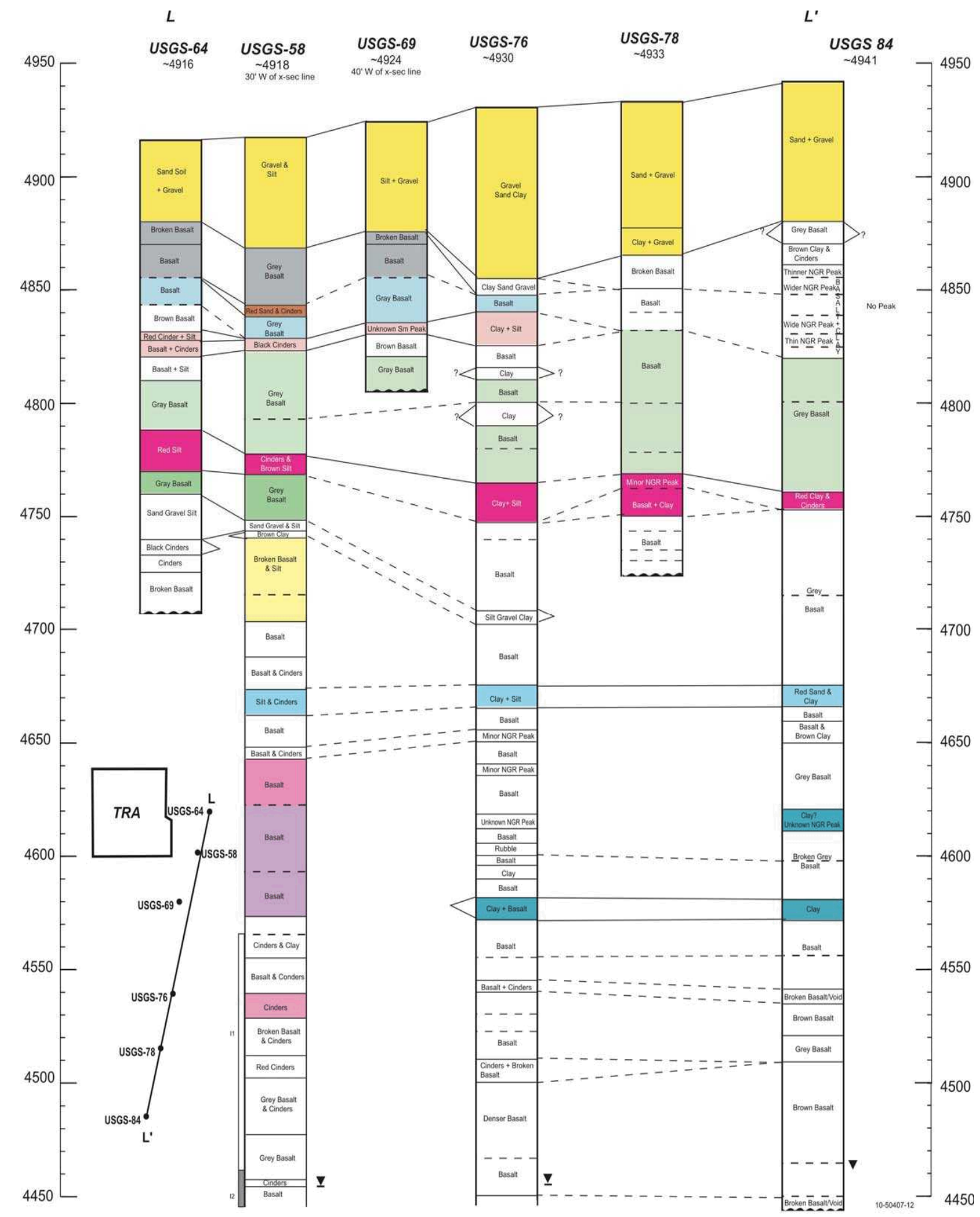

Figure A-16. Fence Diagram L-L’: USGS-64 to USGS-84. 